Andrews University

Digital Commons @ Andrews University

\title{
Adapting To Change in the Swiss German Media Industry: Identifying and Developing Competencies Needed by Journalists and Editors To Cope with Future Market Needs - A Collective Case Study
}

Christiane E. Theiss

Andrews University, theiss@andrews.edu

Follow this and additional works at: https://digitalcommons.andrews.edu/dissertations

Part of the Broadcast and Video Studies Commons, and the Communication Technology and New Media Commons

\section{Recommended Citation}

Theiss, Christiane E., "Adapting To Change in the Swiss German Media Industry: Identifying and Developing Competencies Needed by Journalists and Editors To Cope with Future Market Needs - A Collective Case Study" (2018). Dissertations. 1686.

https://digitalcommons.andrews.edu/dissertations/1686

https://dx.doi.org/10.32597/dissertations/1686

This Dissertation is brought to you for free and open access by the Graduate Research at Digital Commons @ Andrews University. It has been accepted for inclusion in Dissertations by an authorized administrator of Digital Commons@ Andrews University. For more information, please contact repository@andrews.edu. 


\section{ABSTRACT}

\section{ADAPTING TO CHANGE IN THE SWISS GERMAN MEDIA INDUSTRY: IDENTIFYING AND DEVELOPING COMPETENCIES NEEDED BY JOURNALISTS AND EDITORS TO COPE WITH FUTURE MARKET NEEDS - A COLLECTIVE CASE STUDY}

Christiane E. Theiss

\section{Chair: Erich Baumgartner}




\section{ABSTRACT OF GRADUATE STUDENT RESEARCH}

Dissertation

Andrews University

School of Education

\section{Title: ADAPTING TO CHANGE IN THE SWISS GERMAN MEDIA INDUSTRY: IDENTIFYING AND DEVELOPING COMPETENCIES NEEDED BY JOURNALISTS AND EDITORS TO COPE WITH FUTURE MARKET NEEDS - A COLLECTIVE CASE STUDY}

Name of researcher: Christiane E. Theiss

Name and degree of faculty chair: Erich Baumgartner, Ph.D.

Date completed: May 2019

The global media industry has undergone a tremendous change and massive upheaval during the last two decades. On the one side, media consumption has changed immensely and on the other side, media convergence appeared, a phenomenon which describes the merge of different media production genres (print, TV, radio, digital). Using a qualitative collective case study approach, this study was able to explore and depict competencies needed by journalists for coping with media convergence in the Swiss German media industry. The requirements for convergent work are the following seven competency themes: technical skills, social and emotional skills, cognitive skills, writing and linguistic skills, publishing and production skills, innovation and creativity, and leadership and management. This report also gives an overview of the most effective 
strategies to develop these competency themes and provides a competency development model. A competency specific mixture of learning methods, according to the blended learning approach, is suggested to lead to the best results in gaining media convergence excellence. 
Andrews University

School of Education

ADAPTING TO CHANGE IN THE SWISS GERMAN MEDIA INDUSTRY: IDENTIFYING AND DEVELOPING COMPETENCIES NEEDED BY JOURNALISTS AND EDITORS TO COPE WITH FUTURE MARKET NEEDS - A COLLECTIVE CASE STUDY

\author{
A Dissertation \\ Presented in Partial Fulfillment \\ of the Requirements for the Degree \\ Doctor of Philosophy
}

by

Christiane E. Theiss

December 2018 
CCopyright by Christiane E. Theiss 2019 All Rights Reserved 


\title{
ADAPTING TO CHANGE IN THE SWISS GERMAN MEDIA INDUSTRY: IDENTIFYING AND DEVELOPING COMPETENCIES NEEDED BY JOURNALISTS AND EDITORS TO COPE WITH FUTURE MARKET NEEDS - A COLLECTIVE CASE STUDY
}

\author{
A dissertation \\ presented in partial fulfillment \\ of the requirements for the degree \\ Doctor of Philosophy
}

by

Christiane E. Theiss

\section{APPROVAL BY THE COMMITTEE:}

Chair: Erich Baumgartner

Member: Jay Brand

Member: Paul Kim

Member: Gerhard Padderatz

External: Lionel Matthews
Dean, School of Education

Robson Marinho 


\section{TABLE OF CONTENTS}

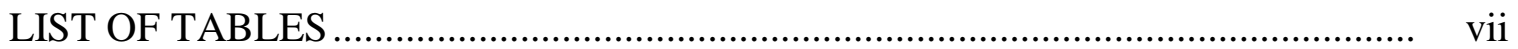

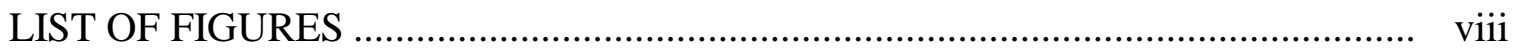

Chapter

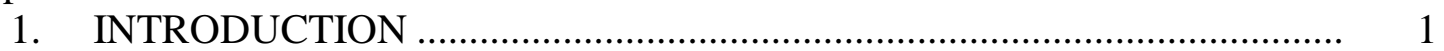

Background of the Problem ................................................................ 1

Statement of the Research Problem ...................................................... 3

Purpose of the Study ........................................................................ 4

Research Questions ....................................................................... 5

Significance of the Study .................................................................. 6

Theoretical and Conceptual Framew ork .............................................. 7

Methodology .............................................................................. 8

Delimitations of the Study ........................................................... 11

Limitations of the Study..................................................................... 11

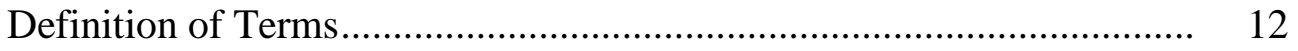

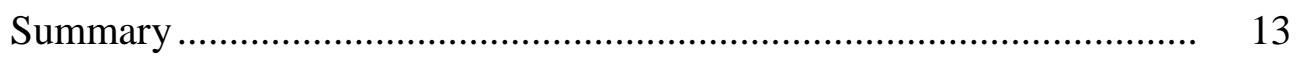

2. LITERATURE REVIEW .................................................................. 15

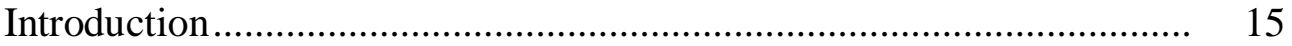

Convergence and Media ..................................................................... 16

Development of Newsroom Convergence ............................................ 17

Competencies from a Human Resources Development

Point of View .............................................................................. 20

Competency-Based Approach for Analysis and Assessment ........... $\quad 20$

Competency-Based Strategies for Selection and

Development ............................................................................ 21

Competency-Based Training Delivery .......................................... 22

Competencies Required in the Media Industry of the Future ................. 25

Competency Required in Broadcasting Journalism ......................... 25

Competency Required in Online and Mobile Journalism ................ 27

Summary ............................................................................... 29

3. RESEARCH METHODOLOGY ............................................................ 31

Introduction and Overview ............................................................... 31

Research Design....................................................................... 32

Research Sample ................................................................... 35 
Data Collection …………............................................................. 36

Data Analysis ........................................................................... 38

Validity, Reliability and Trustworthiness ............................................. 40

Delimitations and Limitations of the Study ............................................ 43

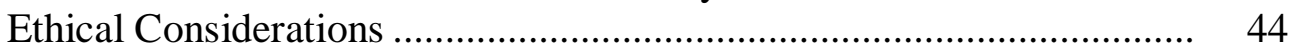

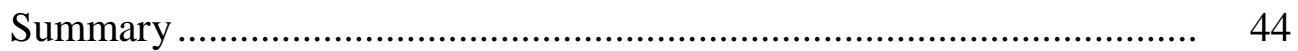

4. FINDINGS: CONVERGENCE IN THE SWISS GERMAN

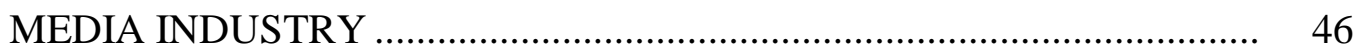

Introduction and Overview ................................................................. 46

Institutional Participation in the Study ………………......................... 48

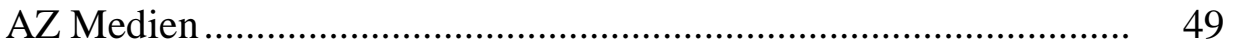

NZZ Mediengruppe ………………...................................... 50

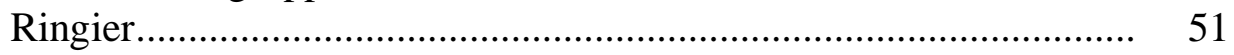

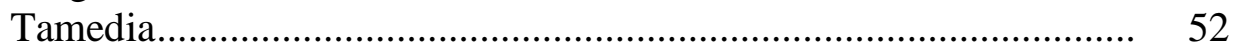

Journalism Education in Switzerland...................................................... 53

MAZ - The Swiss School of Journalism .......................................... 54

Ringier School of Journalism........................................................ 55

Participants of the Study ...................................................................... 55

Demographics and Professional Background of the

Participants................................................................................. 55

Narratives: Personal Experience with Media Convergence............... 57

Media Convergence in Switzerland and Impact on Journalists'

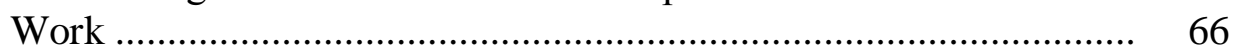

Phases of Emergence of Media Convergence ................................... 66

Media Convergence and AZ Medien ................................................ 68

Media Convergence and NZZ Mediengruppe ……......................... 71

Media Convergence and Ringier ...................................................... 74

Media Convergence and Tamedia ..................................................... 77

Perception of Status of Media Convergence.................................... 80

Impact of Media Convergence on How Journalists Work................ 85

Location of Media Convergence............................................................. $\quad 90$

Appearance of Media Convergence................................................ 90

Newsroom, the Personalized Convergence........................................ 91

Convergence Takes Place Everywhere .............................................. 93

Excursus: Newsrooms in German-Speaking Switzerland ................. 95

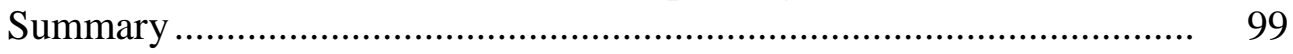

5. FINDINGS: COMPETENCIES NEEDED FOR CONVERGENT

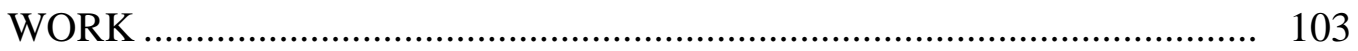

Introduction and Overview ……….................................................... 103

Competency Clusters Needed for Convergent Work.............................. 104

Competency Clusters Needed for Convergent Work Today .............. 114

Competency Clusters Needed for Convergent Work in

the Future 
Competency Clusters Needed for Institutional Participants ............ 120

Excursus: Leadership and Management Competencies........................ 123

Quantitative Content Analysis Job Advertisements .............................. 129

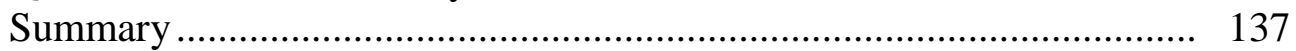

6. A MODEL FOR DEVELOPING COMPETENCIES ................................. 139

Introduction and Overview ............................................................... 139

Convergent Competency Development .............................................. 140

Competency Development Strategies and Didactics ....................... 140

Content of Competency Training and Learning Methods ................. 145

Main Players for Convergent Competency Development ................. 147

Competency Development Model ......................................................... 152

Theories of Learning ...................................................................... 153

Convergent Competency Development Model................................. 167

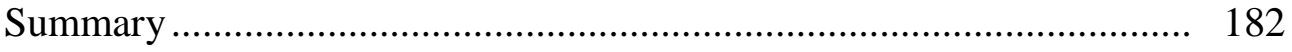

7. SUMMARY, FINDINGS, DISCUSSION, CONCLUSIONS

AND RECOMMENDATIONS …........................................................ 184

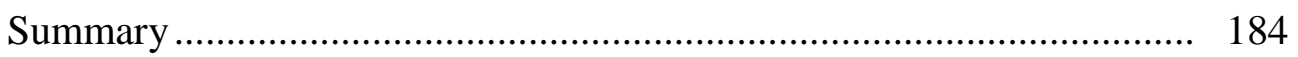

Background of the Problem ......................................................... 184

Purpose of the Study .................................................................. 187

Research Design.......................................................................... 188

Theoretical and Conceptual Framework ………………..................... 190

Media Convergence in the Literature .............................................. 191

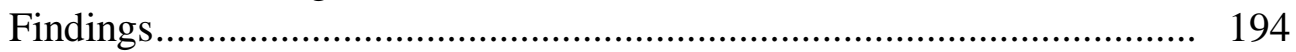

Institutional and Individual Participants …………........................ 195

Main Findings ………............................................................ 196

Research Questions and Key Findings ......................................... 201

Discussion and Unexpected Findings .................................................... 204

Participants Experience with Media Convergence ........................... 206

Convergent Competencies Needed Today and in the Future............. 206

Requirement of Social and Emotional Skills ................................... 207

Development Strategy "Headhunting” ............................................. 208

Leadership and Management Skills .............................................. 209

Conclusions ................................................................................ 211

Recommendations ........................................................................ 214

For Media Professionals ............................................................ 214

For Media Managers …………………………………................ 215

For Policy Makers ........................................................................ 216

Recommendations for Future Research ........................................... 218

Quo Vadis Convergence Competency Development?........................... 219 


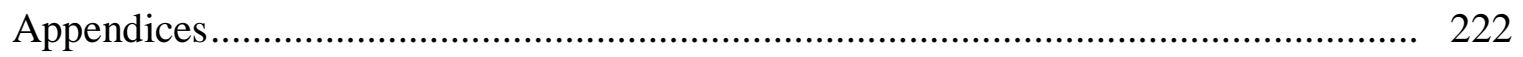

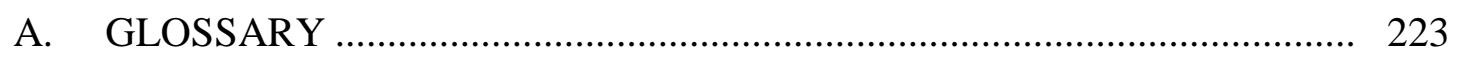

B. INTERVIEW PROTOCOL ........................................................... 224

C. INSTITUTIONAL CONSENT FORMS ............................................. 232

D. PARTICIPANT CONSENT FORM ................................................. 237

E. IRB APPROVAL LETTER FOR RESEARCH ................................... 241

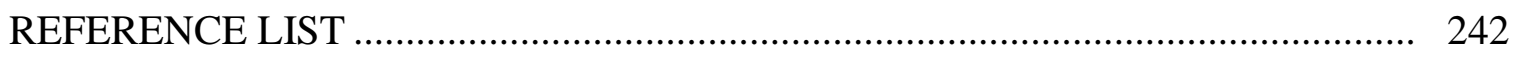

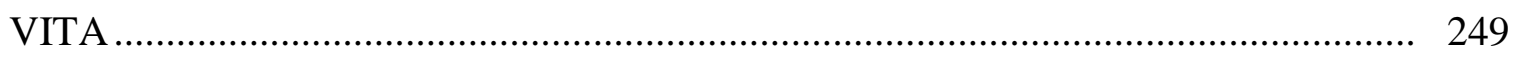




\section{LIST OF TABLES}

1. Interview Questions and Mapping into Categories ............................................ 47

2. Demographics and Professional Background of Participants in the Study............ 56

3. Impact on Media Convergence in the German-speaking part of Switzerland ........ 86

4. Competencies and Skills Needed by Media Professionals ................................. 108

5. Job Advertisements in Swiss German Online Media by Type of Media............... 130

6. Most Frequently Required Skills and Competencies by Position......................... 132

7. Required Skills and Competencies by Skill and Competency Theme.................. 135

8. Convergent Competency Development Strategies .......................................... 142

9. Most Frequent Convergent Competency Development Strategies ...................... 144

10. Important Training Players in Counts ....................................................... 148

11. Competency Cluster 1: Technical Skills .................................................... 174

12. Competency Cluster 2: Social and Emotional Skills ....................................... 175

13. Competency Cluster 3: Cognitive Skills .................................................... 176

14. Competency Cluster 4: Writing and Linguistic Skills .................................. 177

15. Competency Cluster 5: Publishing and Production Skills ................................. 179

16. Competency Cluster 6: Innovation and Creativity ...................................... 179

17. Competency Cluster 7: Leadership and Management .................................. 181 


\section{LIST OF FIGURES}

1. Blended Learning .............................................................................................. 23

2. The Experiential Learning Cycle ……………….......................................... 160

3. Competency Development Model for the Swiss German Media Industry ............. 172

4. Convergent Competency Development Model.................................................... 202 


\section{CHAPTER 1}

\section{INTRODUCTION}

\section{Background of the Problem}

In 2006 Henri Jenkins, the American media scholar, published a book on Convergence culture with the insightful subtitle "Where old and new media collide." This subtitle on the convergence of the print, online, radio and TV news media paraphrases very well the current state of the media industry worldwide. The entire industry globally has undergone a tremendous change and massive upheaval during the last two decades. Until about 20 years ago media were clustered neatly into print media (daily newspapers, weekly journals or magazines), radio and television. The emerging digital age and broadband communications opened new channels such as the World Wide Web (www), social media and social network services (e.g. Facebook, Instagram, Twitter), and video sharing services (e.g. YouTube). Mobile devices and respective applications (apps) facilitate ways of communication and exchange of news, that our grandfathers could not even have dreamed of. The final results of these changes and developments cannot yet be foreseen.

Today everyone can receive news, not only via various channels and through on-

demand services and streaming, but the customers themselves can now self-produce news items. The challenge for media professionals therefore is "to move with the times" not 
only in terms of news production but also in terms of the needs of news media consumers which are currently highly heterogeneous and multi-faceted.

Journalistic research through traditional sources such as people, letters, books, files, films, tapes etc., according to my observation, collides with online newsgathering and the usage of search engines (e.g. Google). In this sense modern electronic media literacy seems to have become an indispensable and essential requirement for journalists. At the same time journalism students and young professionals have to establish a certain kind of sensitivity for the credibility of online sources and acquire verification

procedures. Tyler (2015) links this important issue to the fact that

there is a widespread lack of gatekeepers on the Web, content can be uploaded unchecked; advertising is often blended with information, blurring the line between sponsored and objective content; source reputation is often unclear, which begets a lack of accountability for information posted on the Web; and the nature of the Web makes content susceptible to alternation, either on purpose or by accident. (p. 1291)

In addition, the ways in which journalists and editorial staff have to submit their work have changed immensely over the past years. The so-called newsroom as well as a new news production area combines the classical newspaper with online journalism. This integration demands strong writing and communication skills, web and multimedia publishing skills, and stress resistance as the Editor-in-Chief of AZ Medien explained to me. Decision-makers in the media industry today often stress that journalists are expected to have multitasking skills. It can be assumed that this postulate is associated with the reality that journalists often have to handle different assignments in different media genres simultaneously. This coexistence and merging process of different types of mass media is commonly called media convergence. 
In connection with this recent change in the newsroom, which integrates print news, online content, TV and radio production, hiring media managers now need journalists who are able to integrate writing skills for news production aimed at the web with skills in image and video news production. Media professionals, who until recently had been working only for one type of media, can feel the heat generated by the new convergent media environment. Still it is unclear which skills are needed in this convergent environment, which is still very dynamic. What are possible new skills needed in the future within this more complex, integrated news environment and how can these competencies be acquired and developed?

\section{Statement of the Research Problem}

Even though the appearance of media convergence has been explored in various case studies in the U.S. and in some European countries showing the current state of convergence in the field of news production, there is no neutral and objective information available on media convergence in the German-speaking part of Switzerland. Currently very little evidence exists for helping to decipher to what extent findings from previous studies in the U.S. are applicable to the Swiss media environment.

Since I started my role as Head of Human Resources of one of the major media players in the German-speaking part of Switzerland in 2012, I have had various informal talks with players in the Swiss German media industry. They all insisted that news consumption in German-speaking Switzerland is different from consumer behavior in Germany and in the U.S. These discussions supported my impression that there is very little empirical guidance for the question which kinds of competencies will be required for future journalists. This situation leaves both media managers and editorial staff with a 
great deal of uncertainty. In addition, there seems to be little understanding as to how these future convergent competencies can be gained and developed. For strategic planners this fact creates an almost unbearable tension between coping with contemporary challenges and preparing for the future. A competency model is therefore needed to guide the preparation of future media professionals in the German-speaking Swiss media environment.

Hence, I set out to further explore the impact of media convergence in Switzerland with a qualitative approach and interview editors-in-chief and human resources managers/talent managers. I was particularly interested in the question whether or not media convergence already plays a role in large Swiss media companies and how far this already may have changed the way journalists work today. Furthermore, I wanted to understand how editors-in-chief and human resources managers/talent managers at major players in the Swiss German media industry describe skills and competencies needed for media professionals in the future, in order to bring together their suggestions as to how convergent competencies can be acquired and developed.

The study therefore focuses on the current status of media convergence in major media players in the German-speaking part of Switzerland, the convergent competencies needed by media professionals in order to cope with the ongoing media convergence and constant development of new forms of media in the media industry in Switzerland.

\section{Purpose of the Study}

The purpose of this study is to create a competency development model for media professionals in the convergent media environment in the German-speaking part of Switzerland that can serve as a guide for the professional development of media 
professionals. To this end, I first portray the current status of media convergence in the main media companies in the German-speaking part of Switzerland and describe experiences, perceptions and expectations that media managers have of the media professionals they hire to cope with today's market needs in the context of a convergent media environment in German-speaking Switzerland. Media managers are print, TV, radio and digital editors-in-chief, heads of media profit centers, presidents of media associations, and human resources managers or talent development managers whom media companies employ to lead media industry firms. Media professionals are the editorial staff who work on the production of the actual news items to be dispersed in online, TV and the newspaper media.

The study identifies the perceptions of media managers of the necessary competencies in the convergent media environment today as well as their expectations of the competencies needed in the future. I also explore how the media industry develops this new cluster of competencies in their existing media professionals and how media training institutions and professional media schools approach the development of these new convergent skills.

Future competencies needed in the Swiss German media industry will be defined generally as "convergent media competencies." The data gathered through the selected cases in the Swiss German media industry served as foundation to create a competency development model.

\section{Research Questions}

The core questions of this study are: 
1. What are the current and future competencies needed by media professionals (journalists and editors) in the convergent media environment in the Germanspeaking part of Switzerland?

2. What are the most effective strategies for developing these competencies?

The two sub-questions of the study are:

How are the new competency clusters needed for convergent media production currently being developed? More specifically, what does such training need to include in order to develop convergent competencies?

\section{Significance of the Study}

The study aims at identifying the competency clusters needed for convergent media production in the Swiss German media industry, to answer the question of media managers as to how these competencies can be developed and what training may be needed to help media professionals acquire the competencies needed to thrive in an increasingly convergent media environment.

The raison d'être of a human resources leader is to select, develop and retain employees whose talents and skills align with the larger objective of an organization. I therefore sought to understand and describe experiences, perceptions and expectations that media managers in the Swiss German media industry have in regard to the convergent competencies needed by media professionals for coping with future needs. The views of media managers and the most successful training methods I merged in the study report into a Competency Development Model for convergent competencies.

The results of the study also have the potential to contribute to competency development plans and programs and will support media managers in order to select 
talents and anticipate skills required of future journalists. For this reason, the study report is divided into different parts: first, an overview of required competencies from the point of view of selected media managers in the Swiss German media industry and professional journalism training institutions; second, analysis, assessment, selection and development strategies for convergent competencies in order to update media companies in the light of recent technology dynamics; and third, a recommendation for the delivery of appropriate training. Furthermore, this research study, also provides an overview of recent international findings regarding journalistic skills needed in the media production of TV, online and mobile content.

\section{Theoretical and Conceptual Framework}

How can I find reality as a researcher? Grajales \& Gonzales (2008) answer this question by exploring the difference between truth and reality. "Truth is the understanding of reality through a process of a self-correcting search made by the intellectual community throughout the ages." They further explain that "reality exists independent of human searching" and that "there is more than one way to approach knowledge but only one reality" (p. 162). I support their position that "reality is the what 'is' and the truth is what the subject considers that reality to be" (p. 162). James (1908) goes one step further by following "the epistemological dualism of common sense" approach (p. 455) and explains that an absolute 'truth' is not as important as what we perceive as truth.

In order to understand which "reality" underlies a postulate for media convergence and competencies needed in the future, I conducted a qualitative research project. Charmaz (2010) compares a qualitative research approach with the use of 
different lenses of a camera through which one can observe an object with different foci and granularity.

In this sense the first section of the research, the literature review, works like the 'wide angle lens of a camera.' This review of relevant research will explore most recent research on competencies, which are required currently and in the future for broadcast journalism, online and mobile journalism and print journalism.

In the second section the 'research camera lens,' is focused on experiences, perceptions and expectations which newspaper, online and TV editors-in-chief and educators have of convergent competencies needed by journalists and editors in order to cope with future needs in the Swiss German media industry. In this research step, I analyze training methods and their effectiveness with regards to the gaining of convergent competencies. The choice of analyzing main media players in Switzerland works in this sense like the use of a 'camera flash.'

In the third part of this research I work on my understanding of the 'histogram of the research camera.' This means I am integrating all observations and findings into a competency development model for journalists in the Swiss German media industry. This model includes suggestions as to what kind of trainings might be needed and how appropriate training might be delivered.

\section{Methodology}

In order to explore and understand the competencies needed by journalists in the future to cope with media convergence I conducted a qualitative case study evaluating the Swiss German media industry. Thus, I tried to produce a composite view from the perspective of the four leading media companies in the German-speaking part of 
Switzerland. A case study is a qualitative research method "that facilitates exploration of a phenomenon within its context using a variety of data sources" (Baxter \& Jack, 2008, p. 544). Complex phenomena under exploration can be programs, events, activities, processes, or individuals. Thomas (2011) suggests that a case study should comprise of two elements: the subject of the case study (practical, historical unity) and the object of the study (analytical or theoretical frame). Thus, he provides the following definition for case studies:

Case studies are analyses of persons, events, decisions, periods, projects, policies, institutions, or other systems that are studied holistically by one or more methods. The case that is the subject of the inquiry will be an instance of a class of phenomena that provides an analytical frame - an object - within which the study is conducted and which the case illuminates and explicates. (p. 513)

Case studies were already applied centuries ago to explore scientific phenomena. Galileo Galilei's rejection of Ptolemy's geocentric theory of the solar system, and Aristotle's law of gravity and his preference for the Copernican system of heliocentrism were based on experiments (case studies), just as were the studies of the Swiss developmental psychologist and philosopher Jean Piaget which he conducted with mostly his own children. Today, case studies enjoy popularity in the scientific world as well as in teaching and professional development. In the last decades the Harvard Business School gained a great reputation in regard to case studies in business science.

According to Yin (2003), a case study design might be appropriate when (a) the focus of the study is on answering "how" and "why" questions, (b) the behavior of those involved in the study cannot be manipulated, (c) contextual conditions should be covered because they are perceived as being relevant to the phenomenon under study, or (d) the boundaries between the phenomenon and its context are not clear. All those conditions 
applied to my intended research subject about competencies needed in an environment of media convergence.

Creswell (2013, p. 98f) suggests that case study research start with the identification of a specific case (single case or multiple cases) and have the intention to illustrate a case which gains interest because of its specific nature (intrinsic case) or for understanding a specific issue, problem or concern (instrumental case). A good qualitative case study provides an in-depth understanding of a case. The data analysis in a case study will change according to a respective approach, e.g., some researchers will pick multiple cases and compare them with each other while in another study only one single case might be analyzed. Case studies often provide "conclusions formed by the researcher about the overall meaning derived from the case(s). These are called 'assertions' by Stake (1995) or building 'patterns' or 'explanations' by Yin (2009).”

I was aware of the fact that data collection in a case study is "typically extensive, drawing on multiple sources of information, such as observations, interviews, documents, and audiovisual material" (Creswell, 2013, p. 100). I collected data from different types of sources, documents, archival records, interviews, direct observations, participant observation, and physical artifacts.

Creswell (2013) further explains that the analysis of data can be holistic (entire case) or embedded (specific aspect of the case) and should conclude with the final interpretive phase where "the researcher reports the meaning of the case, whether that meaning comes from learning about the issue of the case (an instrumental case) or learning about an unusual situation (an intrinsic case)” (p. 101). 


\section{Delimitations of the Study}

This research is delimitated to the editors-in-chief and media managers of the main players in the Swiss German media industry. There is one Swiss public broadcasting organization, the SRG SSR, which is a non-profit organization funded mainly through mandatory radio and television license fees collected from the public. This company has more than 6,000 employees. Additional major privately owned media companies are Tamedia AG with a workforce of 3,300, Ringier AG with about 3,100 employees in Switzerland alone, the NZZ (Neue Zürcher Zeitung) Mediengruppe with 1,900 employees, the AZ Medien group with 1,200 employees and Somedia AG with 950 employees. The study focuses only on convergent competencies and respective training and development.

\section{Limitations of the Study}

The biggest issue and limitation of the study is the fact that all media companies are competitors in the market. Therefore, I was depending on the willingness of individuals for participating in the study.

Even though I was the Head of Human Resources Management of one of the key Swiss media players, I did not anticipate the ethical issues in regard to competition and confidentiality issues that arose because my work contract was terminated in September 2015.

Considering Creswell (2013) on avoiding ethical issues I - prior to conducting the study - contacted my previous employer's CEO and that company's Editor-in-Chief as well as the Director of the Swiss Media Association and received verbal confirmation from the three of them that they would support my research project. Hence, I used them 
as "messengers" and door openers towards the Swiss media companies. I expected them to explain clearly the purpose and scope of the study and secure their agreement to confidentiality; based on that I negotiated necessary publishing rights. Likewise, I used members of a Swiss Media Human Resources network, a project developed and implemented by my professional HR colleagues and myself during the last few years. This network is characterized by mutual trust. Its members served as gatekeepers for approaching editors-in-chief and for recruiting them to participate in the project.

\section{Definition of Terms}

The following definitions apply to the terms to be used:

Media convergence: How journalists work most recently has changed tremendously. Different kinds of news production, like traditional newspaper editing, online and web content production and TV production, have merged into the so-called newsroom. In the media industry, this merging process of different types of mass media is called "media convergence."

Competencies: They are described in the light of Human Resources and Organizational Development. Organizational performance and characteristics of core competencies are commonly linked to the competitive advantage of a company. According to Clardy (2008a) I support the expansion of a limited definition of competency as 'knowledge,' 'skills' and 'abilities' towards the resource-based model where competencies include a variety of additional factors such as personality, behavior, added value to customers, etc. The resource-based model endorses the assumption that core competencies of organizations determine their competitiveness. At the same time a resource-based approach widens the definition of core competencies by competency 
characteristics that (a) are typical for the organization and which are the basis for a sustained competitive advantage, (b) indicate long-term organizational performance, (c) are properties of an organization or system and are linked to individuals, (d) are difficult to acquire or obtain by players outside of the organization, and (e) are creating an asymmetrical and differentiating position versus the organization's competitors. Clardy (2008a) argues that "core competencies cannot, by definition, be common, generic, or universal, because if they are shared, then any firm can use them to achieve competitive advantage" (p. 391). Therefore, I underline the significance of an established proper core competency assessment, evaluation and measurement method in organizations, particularly in media companies.

Convergent competencies: Competencies that are necessary to compete in an increasingly convergent media environment are called in the study "convergent competencies." These competencies may not be located in a single individual, but in a team or organization.

\section{Summary}

The study is structured into seven chapters. Chapter 1 discusses the background of the problem of an emerging media convergence and the related change in the constellation of competencies required of journalists in order to cope with future market needs. It articulates the statement of the research problem, the purpose of the study, the research questions, the rationale of the study, its theoretical and conceptual framework, the significance and importance of the study, the delimitations and limitations of the study, the definitions of terms, and the methodology of the research. 
Chapter 2 is a literature review. It is divided into different parts: first, a summary on media convergence, second, an overview of required competencies from a generic Human Resources development point of view; third, an analysis, assessment, selection and development of strategies; and fourth, an appropriate training delivery. Furthermore, this paper provides an overview of recent findings regarding journalistic skills needed in the media production of TV, online and mobile content.

Chapter 3 discusses the research methodology used in this qualitative case study. It shows how this approach fits with the study. The chapter describes the data sources like interviews, observations, artifacts and methods of data analysis.

Results of the data analysis are presented in Chapters 4, 5 and 6. Chapter 4 describes the status of media convergence in the Swiss German media industry. In Chapter 5 an emphasis is put on competencies which are required currently and in the future. Chapter 6 presents a model for developing competencies. Chapter 7 concludes the research study with a discussion of the findings of lessons learned and gives recommendations for practice and for further investigation. 


\section{CHAPTER 2}

\section{LITERATURE REVIEW}

\section{Introduction}

The media industry worldwide in recent years has undergone a massive transformation. This substantial change impacted the way in which journalists and editorial staff work today and the set of competencies needed in order to be successful as a media professional. Emerging new media and communication channels require new research skills and a multimedia literacy. Due to the fact that journalists often handle different assignments simultaneously, the main focus is currently given to multitasking skills. In connection with a most recent change in the newsroom towards convergence, where different media genres are merged, new skills like writing and producing for the web and production of image and video news seem to be required of all journalists.

Mainly U.S. American studies provide skill-sets for different media disciplines. A comprehensive overview of competencies in the light of convergence, however, is still missing.

My personal research therefore, focuses on future competencies required of editorial staff in the Swiss media industry. In order to identify relevant literature in connection with my planned study project I have screened most recent research projects, with an emphasis on "new media," "convergence," "skills" and "competencies." 
The following chapter is divided into the following parts: first, a summary on media convergence, second, an overview of required competencies from a generic Human Resources development point of view; third, an analysis, assessment, selection and development of strategies; and fourth, an appropriate training delivery. Furthermore, this paper will provide an overview of recent findings regarding journalistic skills needed in the media production of TV, online and mobile content.

\section{Convergence and Media}

During the last 20 years the media industry in Europe and the USA underwent a tremendous change in regard to the dissolution of traditional borders between the production of content for print, online, radio and television. Avilés \& Carvajal (2008) explain this phenomenon with the emergence of digital systems, which "allow journalists to share data files (audio, video and text) with increased versatility, in order to elaborate content for the various platforms" (p. 221). Traditionally, content is produced separately for each media platform. A so-called media convergence is taking place, in which a combination of technologies, products and staff appears, according to Avilés \& Carvajal (2008), seems to be "related to industry convergence" and "is reshaping the landscape of journalism in a variety of ways" (p. 222). Quinn (2005) explains the popularity of media convergence with a quality improvement of journalism and reduction of product costs.

On the other hand, convergence is brought into a context with job dissatisfaction and loss of quality. Huang, Rademakers, Fayemiwo, \& Dunlap (2004) elaborate in this sense:

“Opponents of converged journalism worry that, with less profound professional knowledge in a non-primary platform and with limited time for filing a story for multiple media platforms, reporters might not be able to produce quality journalism” (p. 73). 


\section{Development of Newsroom Convergence}

Many newspapers and television stations launched their first web services at the end of the 1990s. According to Avilés \& Carvajal (2008), "they generally chose to set up a small newsroom, whose journalists were devoted for the most part to repackaging news content from the traditional media in the new platform" (p. 223). Stone \& Bierhoff in a 2002 study estimated that around 100 media companies in Europe had implemented some kind of convergence. Pioneers in Europe were the Nordic countries (mainly Sweden and Denmark), U.K. and Spain. Media companies in Switzerland indulge in this development. Ringier implemented the first convergent newsroom in the German-speaking part of Switzerland in 2010, AZ Medien followed this development in 2011, the NZZ Mediengruppe in 2012 and Tamedia, which in 2010 still spoke out against a convergent newsroom, introduced one in 2013.

Avilés \& Carvajal (2008) present three essential activities that "take place within the value chain of any [media] business: information gathering, news production and content aggregation, and distribution" (p. 225). Convergence can be found on the information gathering stage in that manner that journalists produce content for different platforms and share it with their peers. On the level of news production and aggregation content from various sources is repackaged for different media platforms. Media distribution appears when a single company uses different platforms for content distribution.

Gordon (2003) developed a model, which is based on five different appearances of media convergence:

1. ownership convergence,

2. tactical convergence, 
3. structural convergence,

4. information gathering convergence, and

5. presentation convergence.

Ownership convergence is linked to multiple content and distribution channels by media corporations "while tactical convergence involves cooperation and collaboration in areas such as content, marketing, and revenue enhancement” (Mishra, 2014, p. 2). Media companies introducing convergence often change ways of working, assignments and roles. The forth characteristic of Gordon's model has to do with a new convergent way of gathering news and the fifths with new ways of presenting content and story-telling using new multimedia tools.

Contrary to Gordon, Kolodzy (2009) describes a model of media convergence which consists of three aspects:

1. technological, which focuses on media technological change and media digitalization;

2. economic, which covers the influence of convergence on a structural level, including cross-promotion; and

3. journalistic, which includes the merging of traditional print journalism with online, television and radio journalism.

A third model of newsroom convergence, called 'the convergence continuum' is presented by Dailey, Demo, \& Spillman (2005a). This hierarchical model includes (a) cross-promotion, (b) cloning, (c) coopetition, (d) content sharing, and (e) full convergence. It assumes an interaction and cooperation among cross-media partners. The lowest level of convergence is found on cross-promotion where only promotion of each 
other's content is found but no interaction. Cloning covers a way of collaboration where the material of others is republished with minor adjustments. Coopetition "is the level where cooperation in content production is coupled with competition based on cultural differences" (Yin \& Liu, 2014, p. 563). Content sharing contains sharing of gathered information, repackaging of content and common planning, reporting and producing of content.

Avilés \& Carvajal (2008), based on a case study about two Spanish multimedia companies, developed another model of newsroom convergence, which contents of two facets:

1. the integrated model, and

2. the cross-media model.

The integrated model follows the objective to create "a single journalistic culture transgressing traditional media boundaries" (p. 235). In contrast, the cross-media model is a resource and organizational strategy, "where multimedia production based on synergies is the desired ideal" (p. 235). According to the above-mentioned researchers, "cross-media work is not regarded as a goal itself, rather as a tool" where "managers express a desire to strengthen the company as a news provider on the whole, regardless of media platform" (p. 235).

All major media companies in the German-speaking part of Switzerland currently range between the cross-media model and the fully integrated model. None of the bigger players practices yet a fully integrated model. Hence Dailey et al. (2005a) 'convergence continuum' will function as an underlying convergence model. 


\section{Competencies from a Human Resources Development Point of View}

Since the intention of my research project is to scrutinize competencies needed in the media industry of the future, it will evaluate 'competencies' in the light of Human Resources and Organizational Development. The first part of this section will describe a competency-based approach for analysis and assessment, the second part of this section will describe competency-based strategies for selection and development and the third part of this section will describe competency-based training delivery.

Competency-Based Approach for Analysis and Assessment

Organizational performance and characteristics of core competencies are commonly linked to the competitive advantage of a company. Clardy (2008a) supports the expansion of a limited definition of competency as 'knowledge,' 'skills' and 'abilities' towards the resource-based model where competencies include a variety of additional factors such as personality, behavior, added value to customers etc. The resource-based model supports the assumption that core competencies of organizations determine their competitiveness. At the same time a resource-based approach widens the definition of core competencies by competency characteristics which are (a) typical for the organization and which are the basis for a sustained competitive advantage, (b) indicating a long-term performance, (c) properties of an organization or system and are linked to individuals, (d) difficult to acquire or obtain by players outside of the organization, and (e) creating an asymmetrical position versus the organization's competitors.

Clardy 2008a argues that "core competencies cannot, by definition, be common, generic, or universal, because if they are shared, then any firm can use them to achieve competitive advantage" (p. 391). Therefore, he underlines the significance of an 
established proper core competency assessment, evaluation and measurement method in organizations. Any incomplete or misinterpreted assessment process can limit or even harm the organization's excellence: "In short, looking for core competencies among individual performers can actually limit the opportunity to produce superior and differential organizational performance" (p. 389). That is the reason why I intend to create a competency development model, which can be applied to an entire organization.

\section{Competency-Based Strategies for Selection and Development}

As soon as core competencies of organizations are identified and assessed they can be implemented for selection and development purposes. In this sense the proper implementation of competencies, which can be industry-specific knowledge, skills and abilities, is a key performance factor in organizations. This presupposes a creation and implementation process of competencies, which depict the strategy of a respective company. Hence, respective core competencies of an organization should underpin the recruitment of new potential employees and, of course, any employee development. Carroll and McCrackin (1998), consultants in the area of creating and implementing competency-based development strategies, identified a mixed picture in companies: Some organizations invested time and money in carefully assessed competencies, but did not integrate them into the daily business. Other companies collectively selected, developed and implemented them. As soon as competency-based development tools were rolled-out and respective annual performance reviews were based on this set of competencies, a significant business outcome improvement could be detected. In order to decide on people development strategies in the media industry "well defined competencies provide the basis for identifying development needs, targeting curriculum 
and other development activities" and according to Carroll \& McCrackin (1998) help to build "effective partnerships with external sources of education and development" (p. 49). They also support a four-step strategy process, including business alignment, project planning, competency model-building, roll-out and ongoing performance management.

\section{Competency-Based Training Delivery}

Since the publications under discussion, as far as they are related to Human Resource and Organizational Development, do not address the question of relevant training methodologies, which support the development of competencies into organizations, additional literature sources were explored. Particularly revealing in this regard is Westera (2001) who states that competencies are not fixed structures but rather individual abilities, which can be improved upon. They "are gained in multiple ways, such as life experience, on-the-job training, and training and development programs" (Holton, Coco, Lowe, \& Dutsch, 2006, p. 211). Therefore, an appropriate competencysupporting training method is suggested. It combines traditional learning with new learning methods like e-learning or distance learning. Holton, Coco, Lowe, and Dutsch (2006) postulate in this sense the use of a blended learning strategy (cf. Figure 1) where needs and cultural differences of the respective target group are taken into consideration.

A competency-based model can be a descriptive tool for identifying the knowledge, skills, and behaviors needed to effectively perform a role in an organization in order to assist this organization in achieving strategic goals. By linking individual competency modeling, the development of successful training and development programs becomes an effort that will meet the needs of all stakeholders. (p. 211) 


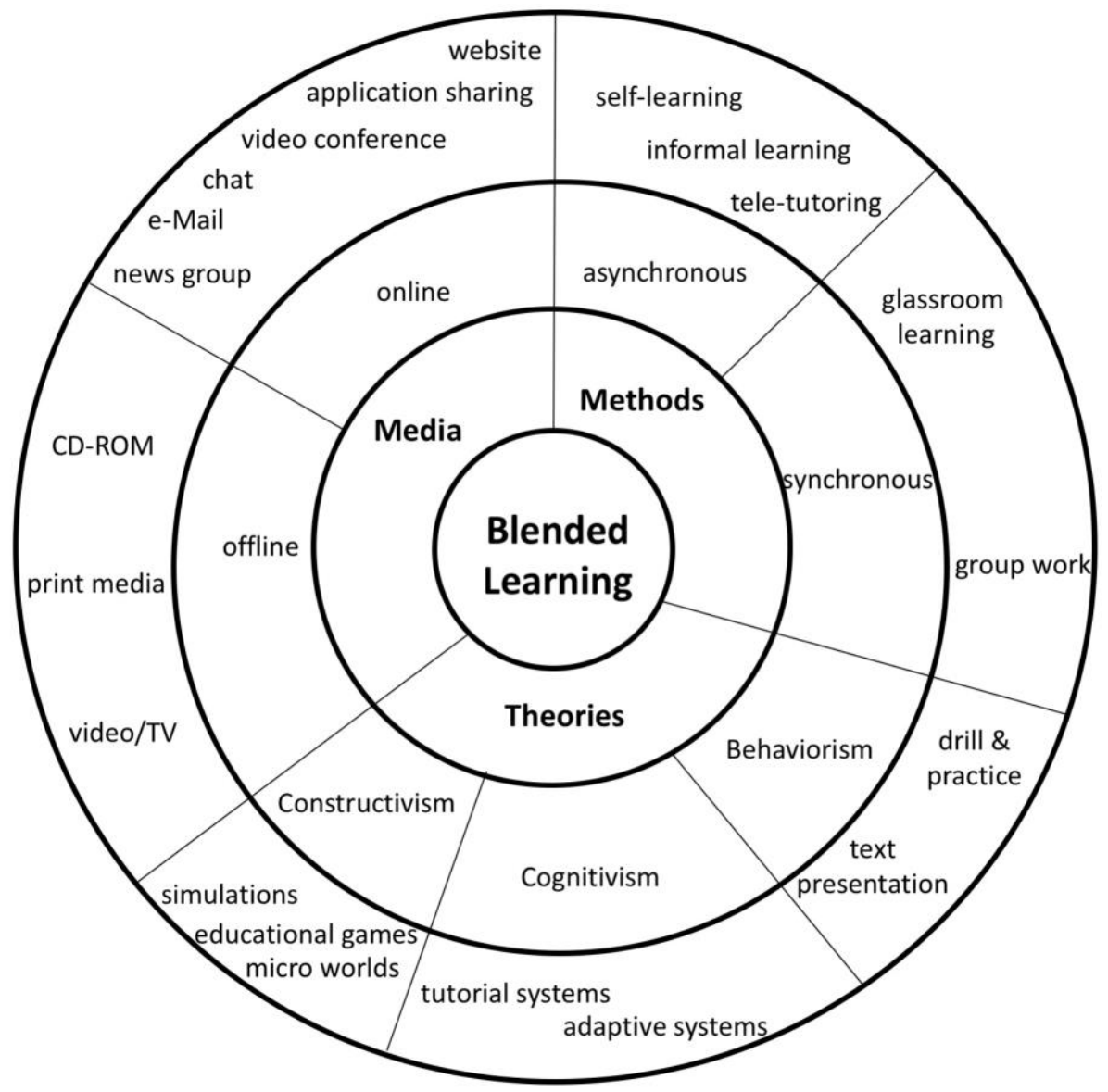

Figure 1. Blended Learning (Wiepcke, 2006, p. 60) [original in German]

In connection with the development of a blended training strategy, Holton et al. (2006) provide the following three principles:

1. Distance learning designs consider specific content, needs, learning goals, and other characteristics of the learner, the nature of the content, appropriate instructional technologies, desired learning outcomes and the local learning environment.

2. Distance learning opportunities support the needs of learning and include site and tutorial support, student advising and counseling, partnering and collaboration. 
3. The provider of distance learning opportunities has both a technology plan and a human infrastructure to ensure that compatibility needs are met and learners as well as facilitators are supported in their use of these technologies (p. 221).

Additionally, the question was investigated as to which effect an organization can be expected to have from the implementation of a competency-based training and development program. Naquin and Holton (2006) provide the following insight from a study on leadership and managerial competency models: "by linking individual competencies with the desired organizational competencies through competency modeling, the development of successful training and development programs becomes an effort with great potential for meeting needs of all parties involved" (p. 145). This means when individual competencies are linked to required organizational competencies and when individual performance skills are embedded into the organization's performance objectives, a positive result can be predicted with high probability. Even though the assessment, development and implementation of competency-based training programs are very time-consuming, it "is the only viable solution to training problems within the context of today's working environment" (p. 163).

Over a period of two years Naquin and Holton (2006), for a public sector customer with more than 10,000 employees, developed a competency model with 24 competencies. Even though the development process of the competency model could be a model for similar development projects, their research does not provide a competency model, which could be applied to the media industry. Since the general research basis for competency models still is narrow future research is needed. 


\section{Competencies Required in the Media Industry of the Future}

The question as to what the behavior of newspaper readers and their affinity to online services and paid content will look like has been on the forefront of media professionals and academia for the past two decades. In order to define competencies required in the media industry of the future Beyers (2004) attempted to provide some insight into the future usage of online interaction and interactivity. He also tried to make more predictable the demand for expected content. A survey conducted by him showed that the majority of online news visitors were only reading messages (63.9 per cent). Other services offered by newspapers, like portable digital assistance, texting services, WAP/i-mode, were hardly ever used. In contrast, however, online archives, search features and electronic newsletters were demanded quite often. The premise that "news sites must offer relevant information that is not readily available elsewhere, particularly not via other websites or media" (p. 16) provides the basis for further exploration on competencies required of journalists in the future so they will be equipped for coping with future challenges.

\section{Competency Required in Broadcasting Journalism}

In the past, journalism students were either trained in print or broadcast communication. This clear separation may soon be a thing of the past. Various studies on mass media suggest that news content on television websites could increase viewer loyalty and that the trend for increased online consumption has not yet reached its peak (Cahn-Olmstead \& Kim, 2001). Therefore, it is appropriate to ask, what kind of mass media elements and competencies should be covered by a training, which prepares journalist for the future. Tanner, Forde, Besley, \& Weir (2012) maintain that 
much discussion has focused on whether a skills-oriented or a liberal arts-based curriculum is the "best" approach to educating young journalists. In recent years, however, dramatic shifts in the production and consumption of news content have reenergized this debate as educators attempt to find ways to prepare students for an increasingly complex media environment. (p. 219)

Cremedas and Lysak's (2011) study among employees of network-affiliated ( $A B C, C B S, N B S$, and $F o x$ ) television stations in the U.S. unveiled that the greater part of TV stations do not pay particular attention to web producing. A reporter, the show producer or news director him- or herself is in charge of web producing, parallel to his or her other responsibilities. With regard to web production Cremedas and Lysak (2011) conclude "indeed, for most small and medium-sized local TV markets, the question of what types of news formats are produced and who produces them for the web is very much a work in progress. But it is clear stations are assigning more and more of their staff to web-related duties" (p. 44). In this sense, the study supported the idea that news directors see as a requirement of newly hired staff a proficiency in new media skills for news producers (38\%) and for reporters (40\%). The integration of the web into the daily news production is common for the majority of local U.S. American television stations. Since viewers are expecting the integration of local news into the TV program, web content became a priority for all partners interviewed. Newscasts posted on interviewed TV stations and reporter packages, like extended raw video, natural sound pieces or full interviews, are new forms of news content that stations place on their web sites. Additional video, print-style web stories, breaking news, specialized in-depth information/links in web stories and resizing/reformatting still images or video for the web are new media duties, which have to be performed by show producers and reporters. 
HTML knowledge is the most required skill for prospective news producers and reporters.

An educational trend towards training in convergent media is confirmed as the following statement shows:

The increasing emphasis on web site content has prompted many broadcast journalism educators to reevaluate the training students receive, changing curricula and program focus to ensure students acquire the necessary web skills. But there's debate as to how much journalism students should be trained in new media skills, as compared with more traditional newsgathering skills. (Cremedas \& Lysak, 2011, p. 44)

One of the key findings of a study conducted by Tanner et al. (2012) also confirms the new emphasis on television newscast production for all kinds of journalism students and a new orientation on multi-platform and convergent journalism.

\section{Competency Required in Online and Mobile Journalism}

The use of mobile devices by news consumers during the past years has increased tremendously. Today $50 \%$ of U.S. American adults own a mobile device, either a tablet or smartphone. A study conducted by the Pew Research Center in 2012 (Mitchell, Rosenstiel, Santhanam, \& Christian, 2012) revealed that two thirds of mobile device owners in the U.S. are getting news on their device on a regular basis and are reading news that way even more now than before the arrival of mobile devices. There also is a movement away from the usage of applications towards the usage of a browser when consuming news (60 percent of tablet users prefer to use the browser to get news on their device). The study suggests that a post-PC era was entered at least in the sense of callingup news. In this sense Mitchell, Rosenstiel, Santhanam, and Christian (2012) explain:

News remains an important part of what people do on their mobile devices - $64 \%$ of tablet owners and $62 \%$ of smartphone owners say that they use the devices for news at least weekly, tying news statistically with other popular activities such as email and 
playing games on tablets and behind only email on smartphones (not including talking on the phone). This means fully a third of all U.S. adults now get news on a mobile device at least once a week. (p. 2)

Cremedas and Lysak (2011) mention that previous studies show that "the web is not a place to produce new content but rather ... a medium that's merely an extension of what they already provide" (p. 43). This means that news producers today are publishing exactly the same content online as they publish in print media.

But can this practice be sustained in the future?

A research conducted by Fahmy (2008) concluded, that the traditional training of journalists still is appropriate even though the technology in the news industry has changed tremendously over the last few years. On one hand journalism educators are putting an emphasis on traditional journalism skills when providing trainings to students. On the other hand, the media industry underwent a tremendous change in technology during the past ten years. A cross-media newsroom where the same personnel produce at the same time print, online and video news is the standard working environment in today's media industry. Fahmy (2008) provides proof of the need for persisting "traditional journalism skills" like research and writing but shows as well that a requirement for teamwork and photography skills will emerge. In particular, digital journalism and web-coding skills will be demanded vis-à-vis an increase in media convergence during the next five years.

Consequently, an ongoing trend for media convergence can be assumed. However, future customer behavior regarding the acceptance of paying for online content, the demanded quality of online services and the news reading behavior of younger generations are all still research imponderables. Furthermore, the influence on 
news consumption through new technologies has been explored sufficiently on a very limited range only. Therefore, there still is plenty of room for future studies regarding the skills required of journalists in the future. It concerns print, online, mobile, broadcasting. This, no doubt, will require an appropriate competency development.

\section{Summary}

The emerging digital era resulted in major changes in the communication and media world. These cataclysmic changes led to new methods as to how journalists and editorial staff do research work and how they have to submit their work. The presented literature review revealed that the newsroom, a characteristic for a convergent media environment, mingles classical newspaper with online journalism where strong writing and communication skills, web and multimedia publishing skills and stress resistance are required. Wenger and Owen (2012) further explain in which direction future training should be aimed: "For journalism educators in general, these findings should reinforce the notion that cross-platform skills are and will continue to be important in helping students find employment" (p. 22). Therefore, a clear picture on the status of media convergence in Switzerland and a respective training and competency development concept might be crucial for the future success of the media industry in the Germanspeaking part of Switzerland.

Since it is not evident to what extent the findings of the literature discussed above are applicable to the Swiss media environment I intend to further explore the impact of media convergence in Switzerland. I am particularly interested in the question whether or not media convergence already is playing a role in large Swiss media companies and how far this already may have changed the way journalists work today. 
Another question, which I would like to answer, aims at bringing light into demanded skills for future editorial staff in Switzerland. Following the conclusion of Carroll and McCrackin (1998) that special attention should be paid to the exact analysis and sustained development and implementation of competencies into organizations, my first planned research step is to determine competencies for editorial staff in the Swiss media industry required in the future. Carroll and McCrackin (1998) note that

Significant lessons have been learned by enthusiasts in many organizations who have not had patience for the process of developing their own competencies and models. Accepting a laundry list of competencies without analyzing culture, business outcomes, and specific factors of excellent performance in the organization's unique environment leads to considerable difficulty in the implementation and application phase. For example, fast trackers will quickly see a disconnection between the skills and behaviors that are rewarded by top management and a generic "motherhood and apple pie" list compiled by a human resources group working in isolation. (p. 51)

Therefore, in a consecutive step of this research project, I develop a competency development model that includes a catalogue of measures for implementing competencies, which reflects in particular the need of the media industry in the Germanspeaking part of Switzerland. 


\section{CHAPTER 3}

\section{RESEARCH METHODOLOGY}

\section{Introduction and Overview}

During the last two decades a new phenomenon, called media convergence, involving the collapse of boundaries between the production of content for print, online, radio and television, has been chronicled by many observers of mass media production. This tendency of media convergence has clearly emerged in newsrooms where journalists from different genres work together closely, or where individual journalists use different media production methods. These new ways of working require the acquisition of new skills. Because the pertinent research literature lacks clarity as to which new skills and competencies are needed in a field increasingly characterized by media convergence, I explored how newspaper, online and TV editors-in-chief and media managers of the main four private Swiss German media corporations experience and describe competencies relevant for journalists and editors in the context of emerging media convergence. After confirming a set of future competencies to address the unique challenges of media convergence, I address how these integrated competencies can be developed and what kind(s) or form(s) of training might best help journalists develop such convergent competencies.

The methodology chapter features the following structure: introduction and overview, research design, research sample, data collection method, data analysis and 
synthesis, issues regarding validity, reliability and trustworthiness, ethical

consideration(s), and closes with a chapter summary.

\section{Research Design}

In order to explore and understand the competencies needed by journalists for coping with media convergence in the future, I employed the research design of a collective case study. I explored these Swiss German media companies (four cases) which already have introduced a newsroom in order to try to produce a composite look from different perspectives of the leading media companies in the German-speaking part of Switzerland. A case study is a qualitative research method "that facilitates exploration of a phenomenon within its context using a variety of data sources" (Baxter \& Jack, 2008, p. 544). The exploration of related complex phenomena in this study included (a) experiences, perceptions and expectations that media managers in the Swiss German media industry have in regard to convergent competencies needed by media professionals in order to cope with future needs, and their experiences, perceptions and expectations on effective strategies for developing these competencies; (b) experiences, perceptions and expectations that media professionals in the Swiss German media industry have about convergent competencies needed in the future and their experiences, perceptions and expectations on effective strategies for developing these competencies; (c) the planning and implementing of newsrooms in three of the big media companies in the Germanspeaking part of Switzerland; (d) visitation of operating newsrooms and observation of working processes; (e) evaluation of requirements in published job ads in Switzerland during a certain time period; (f) analysis of job descriptions and job requirements for different kinds for journalists of different Swiss German media companies, and (g) 
biographical and autobiographical testimonies ("life stories") of editors-in-chief and individual journalists, who are working in convergent environments. Thomas (2011) suggests that a case study should comprise two elements: the subject of the case study (practical, historical unity) and the object of the study (analytical or theoretical frame). Thus, he provides following definition for case studies:

Case studies are analyses of persons, events, decisions, periods, projects, policies, institutions, or other systems that are studied holistically by one or more methods. The case that is the subject of the inquiry will be an instance of a class of phenomena that provides an analytical frame - an object - within which the study is conducted and which the case illuminates and explicates. (p. 513)

I am aware of the fact that data collection in a case study is, according to Creswell (2013), "typically extensive, drawing on multiple sources of information, such as observations, interviews, documents, and audiovisual material" (p. 100). I collected additional information, including documents about the implementation of newsrooms in major Swiss media companies; archival records such as media reports; interviews with editors-in-chief and media managers; direct observations of different newsrooms; observation of newsroom culture, behaviors, attitudes, communication patterns, processes, workflow tasks and activities of participants; as well as physical artifacts such as 'online first' guidelines for convergent production (Yin, 2009). Because I cannot adequately anticipate the appropriate analyses for these data, I refer to Creswell (2013). He explains that the analysis of data can be holistic (entire case) or embedded (specific aspect of the case) and should conclude with the final interpretive phase where "the researcher reports the meaning of the case, whether that meaning comes from learning about the issue of the case (an instrumental case) or learning about an unusual situation (an intrinsic case)" (p. 101). 
Case studies today enjoy popularity in the scientific world as well as in teaching and professional development. In the last decades, the Harvard Business School gained a great reputation in regard to case studies in business science. Various recent studies in the media environment use a case study approach, such as Avilés \& Carvajal (2008), Dupagne \& Garrison (2006), Huang \& Heider (2007), Perryman (2008), Verweij (2009).

The main question I answered with this study is: How do newspaper, online and TV editors-in-chief and media managers of the main four private Swiss German media companies experience and describe necessary competencies for journalists and editors in the context of emerging media convergence and therefore consider relevant for the future? Even though I assume that the future will include additional trends that may substantially or significantly add to the necessary competencies, the focus of the study is on competencies in the context of media convergence. I further intend to answer the following two sub-questions: How can competencies necessary for coping with media convergence and its corollary challenges be developed? And which training didactics, methodology and content have to be applied that can help to develop these convergent competencies?

According to Yin (2003) a case study design for this prospective research project is appropriate since (a) the focus of the study is to answer "how" and "why" questions, (b) the behavior of those involved in the study cannot be manipulated, (c) contextual conditions should be covered because they are perceived as being relevant to the phenomenon under study, or (d) since the boundaries between the phenomenon and context are not clear. Following Creswell's (2013) suggestion, I started the case study research with the identification, comparison and analysis of four cases in the privately 
owned Swiss media industry where convergent newsrooms are already in place and operating. I strive to provide with my case study an in-depth understanding of the status of convergence in the Swiss German media industry. Furthermore, I provide conclusions about the overall meaning of media convergence derived from the chosen cases. These conclusions are called "assertions" by Stake (1995) or building "patterns" or "explanations" by Yin (2009). I ran a collective case study. Yin (2003) explains that a collective case study or multiple-case studies enable the exploration of differences within and between cases. Their goal is the replication of findings across cases. For the sake of comparison, carefully chosen cases are imperative in order to enable the researcher to predict similar results across cases, or predict contrasting results based on a theory (Yin, 2003).

\section{Research Sample}

Creswell (2012) clarifies that the intention in qualitative research "is not to generalize to a population, but to develop an in-depth exploration of a central phenomenon" (p. 206). In this sense, a qualitative inquiry requires a purposeful sample, while quantitative research generally uses random sampling. Creswell distinguishes between sampling 'before' data collection and sampling 'after' data collection. Although a 'before' data collection sampling develops many perspectives and describes a case that “dramatically” illustrates the situation (p. 207), 'after' data collection sampling takes advantage of whatever a case unfolded or explores confirming or disconfirming cases. My research design is based on a case study approach, therefore I chose a "critical" anticipating sampling approach, where I studied two to three "exceptional cases" so as to "learn much about the phenomenon" (p. 208), which in the context of this study will 
focus on emergent media convergence and expected new skills and competencies for editorial personnel. The respective exceptional cases for the study I found in these Swiss media companies, which already have introduced a newsroom.

In the German-speaking part of Switzerland there are six leading media companies: SRG SSR, Tamedia, Ringier, NZZ, Somedia, and AZ Medien. The companies chosen for this study were selected by the following criteria: they must have implemented a newsroom in the last decade and accompanied the implementation with some actions. Therefore, the research samples of the study are the NZZ (Neue Zürcher Zeitung) Mediengruppe, Zürich; AZ Medien, Aarau (my previous employer); Ringier, Zürich; and Tamedia, Zürich. The media companies SRG SSR (publicly owned) and Somedia have convergent working departments but did not have a newsroom in a pure form during the period of the study.

\section{Data Collection}

The use of different data is critical for the understanding and interpretation of the cases under examination. Therefore, I collected data from the following seven different types of sources:

1. Experiences, perceptions and expectations that media managers in the Swiss German media industry have concerning convergent competencies needed by media professionals in order to cope with future needs and their experiences, perceptions and expectations on effective strategies for develop these competencies.

2. Experiences, perceptions and expectations that media professionals in the Swiss German media industry have about convergent competencies needed in the future and 
their experiences, perceptions, and expectations on effective strategies for developing these competencies.

3. Details on the planning and implementation of existing newsrooms in the Swiss media industry (such as processes, workflow, layout, and technical equipment of newsrooms).

4. Visitation of operating newsrooms and observation of working processes (methods of journalistic research, production of news, and collaboration between different news production genres)

5. Evaluation of requirements in published job ads in Switzerland.

6. Analysis of job descriptions and job requirements for different kinds of media professionals.

7. Biographical and autobiographical testimonies ("life stories") of editors-inchief and individual journalists.

Data was acquired from the following sources: one and two I acquired in semistructured interviews conducted with media managers and media professionals; three and four I gained from media managers and media staff of the respective sample companies; five were collected from online jobs ads published during a certain period of time; six were be provided by media Human Resources managers; and source seven was obtained through semi-structured interviews with selected media managers and professionals.

All data were stored electronically and double safeguarded through Dropbox and a NAS server, which is a network-attached storage.

Twenty face-to-face semi-structured interviews with media managers and media professionals were executed between August 2016 and March 2017. Each interview took 
between 45 minutes and two hours, and the number of interviews held in various locations is indicated. Interviews were held in the natural office environment of the interviewee (10 times), in a conference room ( 7 times), in the lobby of the respective company (once) or in a restaurant (twice). The interviews primarily consisted of closedended questions but also contained open-ended questions concerning the life story of the respective interviewee. All interviews were audio recorded on two Apple iPhones, using the app Voice Memos and afterwards transcribed with the use of the online service transcribe from Wreally Studios Inc. After transcription, they were analyzed under the usage of Dedoose, a web-based qualitative data analysis software developed by academics of UCLA, for common themes in order to answer the questions about their perceptions of the currently and in the future needed competencies of media professionals that work in a convergent media environment in German-speaking Switzerland.

\section{Data Analysis}

The focus of my study lies on exploring cases of successful implementation of convergent ways of working in the Swiss media industry through the eyes of participants. I collected data from seven different types of sources, which are documents about the implementation of newsrooms in the four major Swiss media companies, archival records like media reports, interviews with editors-in-chief and media managers, direct observations in different newsrooms, participant observation, and physical artifacts as 'online first' guidelines for convergent production. The main data base came from interviews which I ran with editors-in-chief of media companies where media convergence appears. 
The analysis of the data gained follows a coding approach. Saldana (2012) suggests that coding is just one way of analyzing qualitative data and encourages researchers to "determine whether coding is appropriate for your particular research project" (p. 2). I used the method of coding in order to better structure and understand the data gathered. Through coding I hoped to explore data in depth and to experience that "coding is a heuristic (from the Greek, meaning 'to discover')" (Saldana, 2012, p. 8). I planned to comply with Saldana's following suggestion of a 'pre-coding' process: "in addition to coding with words and short phrases, never overlook the opportunity to 'precode' by circling, highlighting, bolding, underlining or coloring rich or significant participant quotes or passages that strike you" (p. 19). Even though Saldana (2012) dissuades from line-by-line coding I examined first findings - in particular when they are complex and intense - in-depth and by a kind of 'line-by-line coding.' I also applied this coding method since its advantage, as introduced by Charmaz (2010), lies in its encouraging ongoing study of the data and remaining attuned to the subjects' views of their realities (p. 187). During the coding I considered the following questions: How do participants talk, characterize, and describe their experiences in a convergent media environment? What assumptions are they making? What do I see going on here? What do I learn from these narratives? What surprises me? What intrigues me? What disturbs me? Furthermore, I plan to follow mainly a "descriptive coding," "which summarizes the primary topic of the excerpt" (Saldana 2012, p. 4) and in relevant cases 'in vivo code' in order to cite participants in my study.

In a further step, I identified and described themes with regards to media convergence and competencies needed for producing news in a convergent environment. 
Saldana (2012) explains "coding is thus a method that enables you to organize and group similar coded data into categories or 'families' because they share some characteristic" (p. 9). I realized during the coding that various codes are linked to each other and are even belonging to the same group or same theme. According to Creswell (2013) "themes in qualitative research (also called categories) are broad units of information that consist of several codes aggregated to form a common idea" (p. 186). I therefore bundled sets of codes to themes.

\section{Validity, Reliability and Trustworthiness}

In qualitative research scholarly literature provides a variety of perspectives on validation. Some of the respective authors, according to Creswell (2013), “view qualitative validation in terms of quantitative equivalents, use qualitative terms that are distinct from quantitative terms" (p. 244). Concerning the importance of validation there is a wide range of notions. Some postmodern approaches perceive validation as being not important for qualitative studies at all. Other approaches favor a combination of different perspectives and see validation as a crystal. I personally perceive the validity of my prospective qualitative research as vital. Therefore, I validated my study in compliance with the method of triangulation, which, according to Lather (1993), is one dimension of validation. The method of triangulation is indicated to suggest a relationship between multiple data sources, methods, and theoretical schemes, which will be the situation in my case study approach where I collected data from seven different sources.

In this sense, I follow Creswell's (2013) eight validation strategies and consideration that 'validation' in qualitative research is "an attempt to assess the 'accuracy' of the findings, as best described by the researcher and the participants." He 
also views "validation as distinct strength of qualitative research in that the account made through extensive time spent in the field, the detailed thick description, and the closeness of the researcher to participants in the study all add to the value of accuracy of a study" (p. 250).

I also follow Howe \& Eisenhardt's (1990) methodological perspectives. They recommend, that "only broad, abstract standards are possible for qualitative (and quantitative) research" (Creswell, 2013, p. 255). In order to check my future research towards validity and reliability I answered the following questions: Does my research questions drive the data collection and analysis? Are my data collection and analysis techniques applied completely in a technical sense? Have my assumptions been made clear? Is my study warranted overall in regard to theoretical explanations and discussions? Does my study have a "value" with regards to informing and improving practice?

Concerning quality issues, I rely on Lincoln (1995) who tracked "her own thinking ... from early approaches of developing parallel methodological criteria to establish the criteria of 'fairness' (a balance of stakeholder views), sharing knowledge, and fostering social action" (Creswell, 2013, p. 256). In this sense she provided eight standards, which I intended to follow and consider in my research: The standard set in the inquiry community like guidelines for publication (APA style at Andrews). The standard of positionality guides interpretive or qualitative research, which for my study means to prove honesty and authenticity. And the standard "rubric of community" will be considered, which acknowledges that all research should serve the purpose of the community in which it is executed. I will also take care of giving voice to participants 
and consider critical subjectivity in sense of heightening my self-awareness. Further on, I put a particular emphasis on intensive sharing and building of mutual trust between participants and me as researcher. Respect towards the sacredness of relationships in the research-to-action continuum seems to be essential for my being self-evident as well as the sharing of rewards with people portrayed in my study.

Another insightful advice for my research report I gained from Richardson \& St. Pierre (2005) who explain their underlying criteria when reviewing papers or monographs submitted for publication. I planned to follow the advice of providing with my study a substantive contribution to the understanding of social life. In particular, I put an eye on aesthetic merit and tried to shape my report artistically, satisfying, complex, and not boring (p. 964). Reflexibility is among the criteria I wanted to put special attention on. Questions will be dealt with like, "How has my subjectivity been both a producer and a product of my report?", "Is there self-awareness and self-exposure?" and "Do I hold myself accountable to the standards of knowing and telling of the people I studied?" I intended to ask myself these and similar questions during the development of my study report. Which kind of impact has my research and analysis on me emotionally and intellectually? That was another question I tried to answering before submitting my research work. In addition, I tried to elaborate, if my research raised new questions, which move the discipline forward to new research approaches and practices.

Because I consider as essential the validity of my prospective qualitative research, I applied the method of triangulation in order to build a relationship between the different elements of my qualitative research approach and plan to establish convergent validity where similar concepts correspond which each other. I put my utmost attention on the 
chosen data collection methods and if my analysis corresponds with my research questions. In a further step, I assessed the accuracy of the findings, whether my data collection and analysis techniques are applied completely in a technical sense and if my study has a value about informing and improving practice. I wanted to prove honesty and authenticity and contribute with a substantial extent to the understanding of social life. Reflexibility and accountability to the standards of knowing and telling of the people I studied are additional underlying standards for my research work.

\section{Delimitations and Limitations of the Study}

This research is delimitated to the editors-in-chief and media managers of main players in the Swiss German media industry. In the German-speaking part of Switzerland there are the following major six media players. SRG SSR, which is a non-profit organization funded mainly through radio and television viewer fees, a company with more than 6,000 employees; the privately-owned media companies Tamedia AG with a workforce of 3,300; Ringier AG with 3,100 employees in Switzerland alone; NZZ (Neue Zürcher Zeitung) Mediengruppe with 1,900 employees; Somedia AG with 950 employees and AZ Medien group with 1,200 employees. The study focusses only on convergent competencies and respective training and development.

The biggest issue and limitation of the study was the fact that all media companies are in competition with each other. Therefore, I was depending on the willingness of individuals for participating in the study. In order to avoid ethical issues, - prior to

conducting the study - I had already contacted my previous employer's CEO and Editorin-Chief as well as the Director of the Swiss Media Association for the purpose of receiving verbal confirmations for the support of my research project. Consecutively I 
used them as "messengers" and door openers towards the Swiss media companies. I also approached members of a Swiss Media Human Resources network, which consisted of my professional colleagues and which was characterized by mutual trust that we had developed over the years. The members of this network served as gatekeepers for approaching editors-in-chief and for winning them for a participation in the project.

\section{Ethical Considerations}

Prior to beginning my research, I applied for the approval of the Andrews University Institutional Review Board (IRB); this was given on July 15, 2016. I did not start until I had obtained the approval. I described to prospective interviewees my project and role as researcher and promised to all interviewees that I would comply with agreed levels of confidentiality in reporting and publishing. Prior to each interview I provided each interviewee with a protocol, which described the purpose of the study, data collection, research questions and an overview of my research methodology. The protocol contained a consent form, which had to be read and signed by individual interviewees. I also invited interviewees to review my report prior to its publication. Even though the interviewees are public individuals, their names were not used in the report.

\section{Summary}

In order to explore and describe cases of successful implementation of convergent media production in the Swiss media industry a qualitative study approach was chosen. Editors-in-chief and media managers of the four major Swiss media companies were interviewed and various artifacts collected and analyzed. These four media companies, NZZ, Ringier, Tamedia and AZ Medien, which have already implemented a convergent 
newsroom, were examined in depth with a collective case study approach where differences and replication across cases were elaborated. 


\section{CHAPTER 4}

\section{FINDINGS: CONVERGENCE IN THE SWISS GERMAN MEDIA INDUSTRY}

\section{Introduction and Overview}

This chapter describes the results of the data analysis with a focus on major themes related to media convergence in the German-speaking part of Switzerland.

Twenty media managers/editors-in-chief of four major Swiss media companies in the German-speaking part of Switzerland were interviewed with the purpose of understanding their view of the status of media convergence. Altogether, 17 interview questions were asked which I divided into eight categories as displayed in Table 1. The

first was a single question about the length of the stay in the current role of the interviewee. The second set of four questions tried to elicit the status of media convergence and the impact media convergence has on the way journalists work today. The third category, consisting of two questions, was to find an answer as to where media convergence is happening and if the newsroom is the physical location where media convergence takes place. The following questions, assigned to categories four through eight, are the core questions for this study and are linked to competencies needed of media professionals. A respective data analysis is presented in Chapter 5. 


\section{Table 1}

\section{Interview Questions and Mapping into Categories}

\begin{tabular}{l} 
Interview Question \\
\hline 1. How long have you served in your current role as
\end{tabular}

Current Function?

2. How much did the emergence of media convergence change since you started your current role?

3. Which role does media convergence play in large Swiss German / German media companies today?

4. Which role does media convergence play in Name of Media Company today?

5. How far has media convergence already changed the way journalists work in the German-speaking part of Switzerland today?

6. Where, primarily, does 'media convergence' take place, in terms of its functional and/or physical location? 7. Is the newsroom the place where convergence takes place?

8. Which competencies and skills are needed by media professionals in a convergent environment?

9. Please describe your experiences, perceptions and expectations with regards to competencies and skills needed for media professionals in a convergent environment today?

10. Please describe your experiences, perceptions and expectations with regards to possible competencies and skills needed for media professionals in a convergent environment in the future?

11. Please describe possible competencies and skills needed for Name of Media Company.

12. Please describe your experiences, perceptions and expectations with regards to the most effective and successful strategies and didactics to develop convergent competencies and skills.

13. How are the competency clusters needed for convergent media production currently being developed in Name of Media Company?

\section{Category}

1

C

Current Role and Media

Convergence

2

2

$4 \quad$ Competency Skill-set for Convergent Work

4 Competency Skill-set for

5 Training Methods and Content

\section{Company Specific} Training 
Table 1 - Continued

14. What do such training/learning methods need to include in order to develop convergent competencies? 15. Who are important players in facilitating and supplying training/learning offers which help to develop convergent competencies?

16. Do you have any other comments/insights/thoughts you want to share with me with regards to media convergence and convergent competencies in the media industry in the near future? Longer term?

17. What is your personal professional experience with media convergence?

$\begin{array}{cc}5 & \text { Training Methods and } \\ \text { Content } \\ 7 & \text { Training Players } \\ & \\ 8 & \text { Personal Experience with } \\ \text { Media Convergence / } \\ \text { Personal View-Points }\end{array}$

The presentation of the findings and the data analysis about convergence in the Swiss German media industry is structured in the following five parts:

1. Institutional participation in the study (AZ Medien, NZZ Mediengruppe, Ringier, Tamedia)

2. journalism education in Switzerland

3. participants of the study

4. media convergence in Switzerland and the impact on how journalists work 5. location of media convergence.

\section{Institutional Participation in the Study}

In connection with my research project I approached four privately-owned major media companies in the German-speaking part of Switzerland, including my previous employer AZ Medien. All four companies were willing to participate in the study and prior to the interviews signed institutional consent forms. AZ Medien issued two institutional consent forms, one on July 5, 2016 for their newspaper department, 'AZ Aargauer Zeitung, ' and another one on October 24, 2016 for the entire media corporation. In the following section of the report, all four companies, AZ Medien, NZZ, 
Ringier and Tamedia, which provided the samples for the case study, are presented. Information was gathered from annual business reports, company websites, and Wikipedia.

\section{AZ Medien}

The AZ Medien group is a privately-owned media corporation headquartered in Aarau, Switzerland, with 1,200 employees and a yearly revenue of approx. CHF 236 mio. (\$251 million, 2016). Other locations are spread throughout Northwestern Switzerland. AZ media publishes 11 newspapers and regional editions and operates a multimedia network with regional online news portals, e-papers, iPad and mobile applications. Television stations, various high-circulation weekly newspapers, special interest magazines, a book publishing house as well as customer printing complement the product and service range. Axel Wüstmann has been CEO of AZ Medien since 2013.

The history of the company dates back to 1836, when Josef Zehnder, great-greatgrandfather of today's publisher and majority owner Peter Wanner, published for the first time the 'Aargauer Volkszeitung.' In 1848, Zehnder founded the first daily newspaper in Baden, from which later on the 'Badener Tagblatt' emerged. Almost parallel to this, publisher Samuel Landolt in 1847 founded the 'Aarauer Tagblatt,' which in 1880 took the name of 'Aargauer Tagblatt.' AZ Medien in 1996 emerged from a merger between the two media companies 'Aargauer Tagblatt AG' and 'Badener Tagblatt AG.' The 'Mittelland Zeitung' was founded in 2001. It was a cooperation of the 'Aargauer Zeitung,' the 'Solothurner Zeitung,' the 'Oltner Tagblatt,' the 'Zofinger Tagblatt' as well as the 'Limmattaler Zeitung' and the 'Basellandschaftliche Zeitung.' This cooperation in 2007 resulted in the Sunday newspaper 'Der Sonntag.' At the end of 2011, the AZ 
Medien group took over the regional TV stations 'TeleZüri' and 'TeleBärn,' which today, together with 'Tele M1,' 'TV24' and 'TV25,' belongs to the AZ Medien TV sector. In 2014, the digital business was consolidated into a separate division, AZ Medien Digital. Thus all digital know-how was bundled in order to operate all online products of the AZ Medien group.

In December 2017, AZ Medien and the NZZ Mediengruppe announced plans to merge into a joint venture their regional newspapers and associated online portals, as well as their radio and TV stations, to equally share ownership of both groups.

\section{NZZ Mediengruppe}

NZZ (Neue Zürcher Zeitung) Mediengruppe is a media company with business activities in the field of newspaper publishing, magazine and book publishing, regional radio and television broadcasting all for the German-speaking regions of Switzerland. The company also operates online editions of its publications. The NZZ Mediengruppe with 1,900 employees and annual revenue of CHF 423 mio. (\$451 million, 2016) has its headquarters in Zürich, Switzerland. Veit Dengler, the group's CEO, left the company in June of 2017. His successor, Felix Graf, joined the company in June of 2018.

On January 12, 1780, Salomon Gessner published the first Swiss newspaper. The name: 'Zürcher Zeitung. ' It thus is the oldest newspaper still published in Switzerland today. Since 1821 the newspaper is known as 'Neue Zürcher Zeitung.' In 1868, a joint stock company was founded which publishes the NZZ until today. Remarkable is the fact that none of the 1,400 shareholders owns more than 1 percent of the newspaper's equity capital. The newspaper publishing division of the group consists of two companies: NZZ and Free Press Holding AG. In addition to 'Neue Zürcher Zeitung,' the company also 
owns regional daily newspapers, i.e. the 'St. Galler Tagblatt' and 'Neue Luzerner Zeitung.' Through its subsidiary, Free Press Holding AG, the group also owns $74.93 \%$ of the St. Galler Tagblatt AG which publishes St. Galler Tagblatt. In May 2014 Free Press Holding AG acquired from PubliGroupe the remaining stake of the company. NZZ Mediengruppe was the owner of the Bund Verlag AG, publisher of the daily newspaper 'Der Bund' at least until 2003 when it was sold to the Espace Media Groupe.

\section{Ringier}

Ringier AG is a privately owned internationally operating media group with its headquarters in Zurich, Switzerland. In Switzerland Ringier has a yearly income of approx. CHF 840 mio. (\$895 million, 2016) and a workforce of more than 3,100. Since 2012, Marc Walder is the company's CEO.

In 1833, Johann Rudolf Ringier, the son of a pastor, bought a print shop in Zofingen. For the next 40 years, he primarily printed local gazettes, school syllabuses and speeches for public executions. Early publications included the 'Zofinger Wochenblatt,' which was declared the city's official gazette. In 1911, 'Schweizer Illustrierte, ' a richlyillustrated magazine with high production value, was published for the first time. It provided a mix of current event reporting, Swiss folklore and history, a mix which turned out to be very popular. Ten years after the first issue of Schweizer Illustrierte, Ringier also published a French-language version 'L'illustré.' A year later, in 1922, 'Ringiers Unterhaltungsblätter' (RUB) made its first appearance. Also referred to as the 'yellow booklet' due to its color, the publication offered the public short, strictly apolitical current events spiced with short stories and novellas. For decades, RUB remained one of the largest and most stable publications. For Ringier it was a great financial success. It 
marked Ringier's shift to mass entertainment. The arrival of an entertaining provocateur in 1959 was the publication of 'Blick.' As the first tabloid in Switzerland, it told stories in a way completely different from any other Swiss newspaper at the time. It brought in numerous innovations, including a telephone advice hotline called 'der heisse Draht' and an American-style editorial concept which at the time was new to Switzerland. The first appearing of Blick caused a stir. A mix of attention, approval and aggression swept the country and Ringier's transition into an internationally operating cross-media entertainment company had begun. Ringier today is a diversified media group with publishing, e-commerce and entertainment activities.

\section{Tamedia}

Tamedia AG is a media company headquartered in Zürich, Switzerland. Through a portfolio of daily and weekly newspapers, magazines and digital platforms, as well as their own printing facilities, it is the largest media group in the country. The company has been listed on the Swiss Stock Exchange since 2000. Tamedia has about 3,300 employees and generates a yearly revenue of CHF 1,005 bill. (\$1,07 billion, 2016). Christoph Tonini has been Tamedia's CEO since 2013.

Wilhelm Girardet and Fritz Walz had founded the newspaper 'Tages-Anzeiger' in 1893. In the following years, through various acquisitions, Tamedia grew and launched additional products. In 1933, the magazine 'Schweizer Familie' was bought and in 1981 'Annabelle,' a magazine for women. In 1983 the company acquired a majority stake in the 'Tagblatt der Stadt Zürich,' a Zurich city gazette, which was founded in 1730. Today Tamedia owns a wide range of daily and weekly newspapers in different languages, among them the weekly 'SonntagsZeitung, ' the free national newspaper '20 minutes,' 
'Finanz und Wirtschaft,' the television supplement 'TV täglich,' and the daily newspapers 'Thurgauer Zeitung' und 'Zürichsee-Zeitung.' The media company also holds digital platforms and marketplaces 'autoricardo.ch, 'car4you,' 'homegate.ch,' 'hommages.ch,' 'ricardo.ch, ' 'tutti.ch' and scheduling and ticket services 'Doodle' and 'Starticket.' Tamedia is the majority partner of Newsnet, a joint venture of the 'Basler Zeitung' as well as the Tamedia-owned newspapers 'BZ Berner Zeitung,' 'TagesAnzeiger, ' 'Der Bund, ' 'Le Matin, ' Tribune de Genève' and '24 heures.' Newsnet's editorial staff also produces news content for these newspapers' web portals. In 2015, the media group introduced the 12-App (\#12) which presents the day's top stories from 21 editorial teams within Tamedia. And with '20minuten.ch,' Tamedia owns the biggest online news site with the most unique clients in Switzerland.

The professional training and development of journalists/editors in Switzerland is closely connected to the work of the media companies. Therefore, the 'Ringier School of Journalism' which is owned by the Ringier corporation and the 'MAZ - The Swiss School of Journalism,' which in turn is run and financed by the Swiss media industry, was included in the investigation for this thesis. In the following section a brief outline will be given of the training of journalists and corresponding offers in the Germanspeaking part of Switzerland.

\section{Journalism Education in Switzerland}

In Switzerland, journalist is not a protected professional title. Therefore, there are various ways for obtaining a journalism education. Today an aspiring journalist typically participates in a basic course of journalism training in a professional school, college or

university. Before or during the training/studies he or she acquires practical experience as 
an intern or volunteer (journalistic German term: Volontär), a practical time of learning on the job which usually is not compensated.

The two most renowned professional journalism training centers in the Germanspeaking part of Switzerland are the 'MAZ - Die Schweizer Journalistenschule' and the 'Ringier Journalistenschule.'

The publicly-owned Swiss Radio and Television Corporation (SRG SSR) offers short-term internships and a two-year trimedia journalism training course in a dual system, combining school and practical work.

In addition to these, the following four universities and some so-called universities for applied sciences (in German: Fachhochschule) offer academic journalism education: IAM Institut für Angewandte Medienwissenschaft der ZHAW Zürcher Hochschule für Angewandte Wissenschaften, Institut für Publizistikwissenschaft und Medienforschung (IPMZ) der Universität Zürich, Institut für Medien- und Kommunikationswissenschaft (IKMB) der Universität Bern, Institut für Kommunikation und Marketing (IKM) der Hochschule Luzern.

MAZ - The Swiss School of Journalism

The MAZ, the Swiss School of Journalism, based in Lucerne, Switzerland, was founded under the name 'Medien-Ausbildungs-Zentrum' in 1984. Today the MAZ is operated as a foundation and financed by the Swiss media industry. Foundation members are: Association of Swiss Media, the Swiss Conference of Editors-in-Chief, the Swiss Radio and Television Corporation (SRG SSR), the two trade unions for journalists, 'impressum' and 'syndicom,' and the city and canton of Lucerne. Furthermore, the MAZ is supported by the Swiss Federal Office of Communications. Director of the MAZ is 
Diego Yanez (since 2014). The educational offer of the MAZ ranges from a two-year journalism course to numerous training programs and training courses.

\section{Ringier School of Journalism}

In 1974 the Ringier School of Journalism ('Ringier Journalistenschule') was founded as the first school of journalism in Switzerland. Founder was Hans Ringier, CEO, owner and publisher of Ringier AG from 1960 to 1985. Today, the school is operated by the Hans Ringier Foundation. Head of the school is Hannes Britschgi. It offers a two-year journalism course in a dual system with school and practical work alternating. During the course students are assigned to different departments of the Ringier media corporation.

\section{Participants of the Study}

After the institutional approval of the four major media companies in Switzerland, interviews with 20 media executives and media managers, all employees of these four media corporations were conducted between August 16, 2016 and March 22, 2017. Prior to each interview, the participant, with appropriate explanation, was handed the participant consent form which was signed by all participants.

\section{Demographics and Professional Background of the Participants}

Among the participants were, as shown in Table 2, six female and 14 male media managers. $80 \%$ of the interviewees had gained their experience as journalists/editors either in their past careers or the use of their editorial skills in their current position. $30 \%$ of the participants of the study had served in the current position less than two years, 
Table 2

Demographics and Professional Background of Participants in the Study

\begin{tabular}{|c|c|c|}
\hline $\begin{array}{l}\text { Demographics and Professional } \\
\text { Background }\end{array}$ & Number & $\%$ of all \\
\hline \multicolumn{3}{|l|}{ Gender of Participants } \\
\hline Female & 6 & 30 \\
\hline Male & 14 & 70 \\
\hline \multicolumn{3}{|l|}{ Editorial Experience } \\
\hline Yes & 15 & 80 \\
\hline No & 5 & 20 \\
\hline \multicolumn{3}{|l|}{ Job Role } \\
\hline Commercial Media Executive & 3 & 15 \\
\hline Digital Media Executive & 1 & 5 \\
\hline PR Media Executive & 1 & 5 \\
\hline (Deputy) Editor-in-Chief & 10 & 50 \\
\hline PM / Project Director Digital & 3 & 15 \\
\hline Educator & 2 & 10 \\
\hline \multicolumn{3}{|l|}{ Time in Job } \\
\hline 3 months to $<1$ year & 3 & 15 \\
\hline 1 year to $<2$ years & 3 & 15 \\
\hline 2 years to $<3$ years & 4 & 20 \\
\hline 3 years to $<5$ years & 3 & 15 \\
\hline 5 years to $<10$ years & 5 & 25 \\
\hline$>10$ years & 2 & 10 \\
\hline \multicolumn{3}{|l|}{ Media Company / Organization } \\
\hline AZ Medien & 5 & 25 \\
\hline NZZ Mediengruppe & 4 & 20 \\
\hline Ringier & 4 & 20 \\
\hline Tamedia & 5 & 25 \\
\hline MAZ & 1 & 5 \\
\hline Ringier Journalistenschule & 1 & 5 \\
\hline
\end{tabular}

$35 \%$ between two and five years, $25 \%$ for more than five years and two participants or $10 \%$ had stayed in the same position for more than ten years. Among the individuals interviewed there were three commercial media executives, one digital media executive, one PR media executive, 10 editors-in-chief and deputy editors-in-chief, three project managers/project directors digital and two educators. 
Position titles of participants of the study were at the time of the interview as follows: CEO, AZ Medien; Editor-in-Chief, AZ Zeitungen; Deputy Editor-in-Chief, AZ Zeitungen; Editor-in-Chief, Schweiz am Sonntag; Editor-in-Chief, Limmattaler Zeitung; Freelance journalist, Consultant for the media industry, Training Manager Journalism Education; Chief Product Officer; Head of Digital Products; Project Director Convergence; Head of Magazines and Member of the Editorial Office, NZZ am Sonntag; COO Ringier AG; Head of Public Affairs; Co-Editor-in-Chief, Schweizer Illustrierte; Editor-in-Chief, Blick Sport; Head of Ringier School of Journalism; Member of the Group Management Board, Head of Paid Media; Member of the Editorial Office, TagesAnzeiger and Head of Digital and Newsnet; Editor-in-Chief, 20 Minuten; Deputy Editorin-Chief, SonntagsZeitung; Head Digital Sales Development.

\section{Narratives: Personal Experience with Media Convergence}

This section of the data analysis provides stories of interviewed media managers' personal professional experience with media convergence during their career in the media industry. During the interviews, I found that media managers and executives were quite at ease when it came to sharing their personal media convergence stories. Some of the narratives collected were more anecdotal and others more procedural descriptions.

In order to protect the privacy of the participants, even though they are public persons, each participant will be numbered consecutively. Exemplary personal stories of participants with same subjects were put together into categories and headlined with most prominent characteristics of these categories: 'Personal Journalistic Journeys,' 'Usage of New Media Technologies,' 'New Ways of Media Consumption' and 'New Opportunities for Journalism.' 


\section{Personal Journalistic Journeys}

Various personal stories contained parts of life journeys and how the craft of journalism changed during the last decades towards a convergent way of working.

Participant 8 , a journalist and media executive, described how her self-conception as a journalist changed with job assignments in different media areas and that nowadays, journalists have to use different ways of storytelling, depending on the news channel they are producing for.

I started in journalism in the mid-eighties when I was a [high school] student. I was in this channel, I first worked in radio. Therefore, I understood myself as a radio journalist. I then joined a TV network and understood myself as a TV journalist. I then joined a newspaper and understood myself as a newspaper journalist. During my time as a newspaper journalist the digital area became more and more important, and it was there that I already felt, Okay, we have a story. We realized that online we had to tell that story in a different way. And now, in a sense, all these channels have merged completely.

Participant 1, an editor-in-chief of a regional newspaper, continued with the journey aspect of the development of journalists today: "I think in general it is an exciting journey which I like to take part in." She further explains that journalism-wise she grew up as a print journalist: "I am still a bit old school," therefore, she still likes to produce for print newspapers and hence understands readers who prefer print journalism. At the same time, she is a consumer of online media and sees the opportunity of using different types of media for producing a story in an exciting way.

Participant 17's move towards a more convergent media production had a slightly different character; it was linked to a career offer:

I was a print Editor-in-Chief, once responsible for a classified ads platform as managing director. I have pushed internet right there. I'm a curious person, but I was a classic print journalist who realized, I was missing out on something if I was not getting myself somehow fit. Realizing that, I then got the opportunity, when jobs were newly arranged between the online editor-in-chief and myself, that I was lucky 
enough to get the convergent position. By the way, that is quite interesting, because I really felt like getting into online, while the online editor-in-chief did not feel like taking the responsibility for print because he declared print as old and old-fashioned.

He continued to explain that at his current department where print and online news are produced, $60 \%$ of the sales revenue is still generated by print newspaper products. While his company's strategy is not to invest any additional resources into print products, they still require great content and needs "be done well" in order not to lose even more revenue. Therefore, he concludes that his curiosity and interest in online, combined with his print experience, is currently the right mixture to survive in a convergent environment.

\section{Usage of New Media Technologies}

Some participants shared their experience as to how the adaption of their media usage linked to the emergence of new technologies was more 'born out of necessity' rather than to their interest in new media.

Participant 7 started as a journalist for a TV network in 1986 and proposed a story about a peasant painter in the Swiss Appenzell region. His boss liked the concept, therefore he started the production. But what did the production look like? He ordered a van and took along with him a cameraman, a sound technician and a lighting technician. They were four people to record the raw material for a story which had to be cut and reworked in the studio later on. In 2016, he was in the field on his own with his iPhone functioning as a TV station. On his own, he even was able to produce a live transmission. "My little smartphone is the TV station and I'm live on air and I'm all alone. And I do not have to go back to the editing room. And that's it, that's unbelievable." He further reports that neither people whom he interviewed and recorded with his iPhone camera, nor his 
colleagues could believe he was able to produce live TV on his own by using only a phone and without any further support by additional media professionals. Proudly he said, "Yes, that's live streaming, that's live reporting." He compares the effort that TV production required in the past to how easy it is today by using new technology. But new technology does not only make possible a one-man production, it also enables interactivity with viewers. New technology makes it possible to receive comments from viewers and, at the same time, answer their questions. This participant rated the usage of new media technology as follows: "That's easy, it kills you when you look at this development." Then he continues: "Of course, it cheers my heart, that I can do all of this as an oldie of over $60 . "$

"I entered convergence involuntarily," says participant 20 . "I had to do it. It really was all about money. It was clearly the wallet, and that is insane. Looking back, I understand it now. And that's why I can understand resistance. I can understand fears, too." Technically, she had to teach herself how to use new technical devices and methods. Because at that time online tutorials were non-existent and her frustration tolerance when it comes to new programs was quite high but on the other hand she applied a lot of time-consuming detours where her younger colleagues tell her today that she could use new technology in a much easier way than she does.

Another participant, no. 13, shared his personal experience that for many journalists the world of new media opportunities and a convergent media production would not be accessible, if they did not master new technology. "Yes, you just have to be able to handle these smart phones and tablets and laptops in your sleep." He ran a media training course and was quite surprised that people of all ages brought their laptops along, 
according to the requirement of the training, but were not able to set-up a wireless connection. 'Somehow the people looked at me in horror: 'How does that work?' And then I said, 'okay, stop.' Then, for the second course I tightened the requirements and said, 'Okay, everyone who comes to the course, bring a laptop and be online and have this and that installed.'" He received a few complaints about his pushy approach but also explained why today he perceives it as important to have a bit of a 'digital natives' access to technology in order to be able to cope with future challenges linked to convergent media production. It is "as if I buy an electric toothbrush, okay? And then I might just have to look into the manual if I do not know what each button is for," he concludes and emphasizes the importance of using new media technology.

\section{New Ways of Media Consumption}

Another area of personal experiences with media convergence of the study's participants was linked to new ways of media consumption.

Participant 13 realized new ways of media consumption and how space and time dissipated for the first time when his employer equipped him with a cell phone in 1992. "You sit somewhere in a beer garden, you receive a call on a technical question, answer it, and then you become aware of the fact, that the one who has received the answer, does not know from where that has come."

Reflecting on his personal experience with media convergence participant 6 , an editor-in-chief himself, states that he never thought that the industry he is working for could change so rapidly. "Well, for a long time I considered the weight this change has been attributed to by many people as to too hysterical." And then he further explains that wherever he travels in the world, "Yes, I was in the Caribbean now or I was in Africa 
recently" and then, somewhere, saw a phone lying around, he looks at the phone and is

frightened because he thinks that this phone is his.

Everybody has the same thing; down to the last corner of the world everybody has the same apps. Everyone has somehow Instagram, Facebook and two, three news apps in addition or some kind of Spotify. Then I startle. You see a 13-year-old in the Dominican Republic and you look at his cell phone- Oh, that could be mine. And then you become aware of what kind of crazy movement this really is, which has captured everyone in a few years down to the farthest corners of the world. That's gigantic. It also makes me feel a little scared. I think that's Silicon Valley. What has accumulated over there, like Google, Facebook and so on, Snapchat, Instagram. These companies now virtually control this world, down to the last corner. That's it. It actually is a strange idea how fast that went. I had not thought that this could be possible.

The opening of his own Twitter account in 2011 and its active use changed his perception of new ways of media consumption for participant 4 , an editor-in-chief of a print newspaper. Through self-experience as an active Twitter user, he understood communication paths, ways of approaching and reaching out to people and target groups and respective reactions: "This is another audience compared to what has been reached so far. That is what actually opened my eyes, at least to a certain extent. I think I had already understood in theory what Twitter was all about, but if you drop a few tweets yourself and you get into hot water, then you learn the most."

The access of free information and news is another new way of personal media consumption. Personally, as a reader, Deputy Editor-in-Chief, participant 15, perceives free available information as a huge enrichment. She states: "Frankly, I understand everyone who pays nothing, because I do not pay for anything." Her friends are sharing with her on Facebook interesting news from all over the world. Since she is interested in a lot of different subjects, it is a very comfortable way of accessing interesting information, which 'can then come from 'The New Yorker' or the 'Süddeutsche Zeitung' magazine, information which can come from anywhere from a magazine that I even do 
not know." But she also experienced that free access to information can be a limitation and, to a certain extent, a danger since people consume what they like and lose out of needed basic information like reports from the local municipal council meeting, which regional print newspapers provide. She continues: "I have to read the whole boring nonsense as well, otherwise, if I read only on a whim, [...] I think sometimes people lack the basics to form their own opinion."

New Opportunities for Journalism

New opportunities for journalism in connection with media convergence were described by participant 20. She was a freelance journalist in Moscow from 2000 to 2007. After the burst of the internet bubble in 2001, the media industry in Russia struggled to survive. Fees for journalists began to dwindle. At that time she worked as a print journalist and since research in Russia was very time and cost intensive, she had to find new sources of income. Therefore, she began to reuse her research for different media projects. She figured out that 'Focus, ' a richly illustrated German news magazine, was still paying good fees. But print journalists were not allowed to contribute pictures to the magazine on their own. "Hence, I created a pen name," she explains, "and I enjoyed it a lot since I got the impression that the print article got better, because images and text were cast in one piece." She also started producing sound but stayed away from videos because they were technically still too complex to produce. After a while, she also started speaking on the radio; she developed her skills in such a way that she even produced entire programs. "And that's how I got into it," she summarizes. "I realized that journalism-wise it was a tremendous asset and that there are a lot of things you do not have to write about." She explains that very often a picture says more than a long text. 
"One picture is enough. Of course, I can describe it, but if I have a picture of it, why should I describe it in writing what it looks like over there, if you can see it yourself. And I think journalistically it is much more exciting." Thinking about an attention span of 90 seconds maximum, she also confirms here positive personal experience with convergent media production where text, picture and video are combined in order to keep media consumers' attention.

Participant 16 was a magazine journalist, producing articles with a length of up to thirty thousand characters each, before he started as a digital journalist nine years ago. $\mathrm{He}$ always enjoyed debugging new technologies and perceived digital news production as a new journalistic 'playground' where he could elaborate on "what works, what does not work, which pictures are attractive and which are not." He continues: "Yes, and then I actually became convergent myself, out of interest and passion." But at the same time he could not understand why many of his colleagues did not feel the same. "I thought," he said, "that they also perceive it as fun and as job enrichment. Of course, it was not like that." And even at his convergent production editorial office it is difficult to take people along on to this journey, to inspire and motivate them.

Another participant (number 3), an editor-in-chief of one of the renowned print newspapers, experienced media convergence, in principle, as "something great," because "you have completely new opportunities. You can reach new readers, users also." He further elaborates on his observation that today, news users "probably spend more time with our media as in the pre-digital age and that's actually great." Hence, he confirms, that journalism today "has many, many more opportunities, than risks. Commercially, it 
has far more risks than opportunities, because of the loss of print revenue which so far cannot be compensated by online publishing."

Interesting insights were given by participant 13 about the work and convergent impact of so-called storytellers in the media company where he works as a Project Director Convergence. He emphasized the voluntary character of the acknowledgment by media professionals of new media opportunities in journalism. When they recruited storytellers and the editor-in-chief recommended journalists to use their service, nobody made full use of them. Thus, he changed his approach and reduced the accessibility of the storyteller's service for editors and journalists by explaining that the storytellers' resources were very limited because of another important assignment. Within a short time, everybody was demanding their service. Today the storytellers produce up to 402 D graphics for each edition of their daily newspapers. They practice 'Data Journalism,' which means they evaluate and visualize large amounts of data and produce interactive graphics made for online publications where users can modify the screen display with a cursor. A very successful example for digital storytelling is the presentation of data published by the Swiss Federal Statistics office on a yearly basis about the geographical distribution of baby names given in the cantons of Switzerland. 'It's the same every year," participant 13 explains, “and people yawn.” But the storytellers saw the potential and noticed that these data are "fun; we can make something of," and thus created an interactive map with the geographical distribution of most frequently given first names in Switzerland by canton and year for the past several years. By using a virtual time control, users can now follow how the given name 'Kevin' first appeared in Basel, moved to Berne and, strange enough, finally, with a detour through the canton Valais, reached the 
eastern part of Switzerland. "Yes, you can see exactly when the Kevins were traveling. These are such little things" he comments, but they inspire editors to tell stories in various convergent ways. He explains "there are really thousands of topics that can be told graphically, visually much faster than telling the Kevin story only by text. Such a text would be completely boring, no one would read such a text, but with such a toy, everyone plays and even learns something."

\section{Media Convergence in Switzerland and Impact on Journalists' Work}

The following part of the study report portrays the status of media convergence in four main media companies in the German-speaking part of Switzerland and describes perceptions media managers have of how far media convergence has already changed the way journalists work in the German-speaking part of Switzerland.

\section{Phases of Emergence of Media Convergence}

When I asked how much the emergence of media convergence has changed since they started their current roles, some of the media managers and executives interviewed were brooding about the change of the media landscape during the past few decades and shared their personal observations about media convergence. They all shared the perception that the emergence of media convergence appeared in phases. Participant 14 indicated that at the time when she started in online journalism, online media products of major media companies defined themselves primarily in the sense of how far they distinguish themselves from their print counterparts. She added: "In the 90s, media convergence was non-existing in today's form." She called this period Phase 1, when online media were not comparing themselves with other online media products but with 
print products. In Germany, Switzerland's big neighbor, often used for comparison, "Spiegel Online did not check whether they were better than Stern Online, but rather if they were better than the printed version of Der Spiegel; and [in Austria], Der Standard Online did not check, if they were better than Die Presse Online, but if they were better than the printed version of Der Standard." She compares the introduction of the second phase, starting around the beginning of the new millennium, with a growing-up and emancipation process, where online media rubbed themselves with print counterparts. In Phase 3, where some pragmatism started to play an increasingly important role and where nobody says anymore. "Print is bad or evil, ... I believe the industry has learned that only together - print and online and mobile and video - will we succeed." In this context, around 2009-2011 'media convergence' became a buzzword. Media executive, participant 8 , confirms the model of different phases: "At the beginning of convergence there was actually the classic question of convergence, [everybody felt the need] that channels had to be brought together. Next, the motto 'Digital First' appeared, which meant that first the online channel was served and then as a second priority we see, what we publish in print." 'Mobile First' was later on replacing this because stories on a classic desktop have to be told differently from stories on a mobile device. Participant 5 merged the opinions of the two previous speakers about a three-phase model and calls the first phase "pioneering and trial." In his opinion, this period lasted from 1998 to 2002 and was followed by a "crash" phase from 2002 to 2010 and to the "back to the roots" phase where Facebook, Mobile and Mobile Social were introduced. He further explains: "And since then, I have the feeling that the degree of professionalizing in trying out formats that run on more than one medium is increasing. An accompanying 'Who Wants to be a 
Millionaire' RTL page in Mobile and on Facebook today achieves some professionalism and a certain degree of normality." During the past five or six years he observed a development in which it became quite normal to consider accompanying mobile and social content already at the time of creating a TV show or a newspaper.

\section{Media Convergence and AZ Medien}

In the following are presented the results of interviews with five participants from AZ Medien with regards to the change of media convergence at AZ Medien since they started their current roles and with regards to the current status of media convergence .

\section{Change of Media Convergence since Start of Role}

When I asked media managers of AZ Medien as to how much media convergence changed since they started their roles I received statements ranging from "as much as in the previous three years" before he joined the company (participant 5) to "I think it is increasing, you can observe that there is an increase almost from month to month" (participant 1). Participant 3 emphasized the pronounced change of media convergence during his years of editorial service with his current employer: "When I started, it was a pure print editorial. There was a small online department which at that time was typically not part of the editorial office, but was directly attached to the publisher." Within eight years he transformed a pure print editorial office into a convergent editorial team "that thinks online, that thinks mobile, that also uses new narrative forms, that uses moving images, that really understands itself as an editorial department that has a presence on different channels." Participant 4 confirms the big change of media convergence since the days when he started his current role: "In 2007, of course, there were already online web portals, but the media coverage was much lower. Social media already existed, but they 
did not yet have their current significance. And that is, of course, quite different today. And that, of course, influences journalism and also impacts the question, what kind of competencies does a journalist have to bring along nowadays?" The observation of the change of media convergence of participant 2 since he started his current role two years ago goes into the same direction. He does not attribute the change within AZ Medien to convergence per se but rather to the appearance and importance of social media, mass media, mobile and video. "In the last two years the role of social media has changed massively, [I am talking about] the role of mass media and the role of mobile and moving images. Actually, these are three success factors that have become very central."

\section{Current Status of Media Convergence at AZ Medien}

All five interview participants of AZ Medien confirmed a structural difference of their current employer with regards to the current status of media convergence compared to the slightly larger German-Swiss media companies Ringier, NZZ and Tamedia. Participant 5 explains the different status of media convergence of AZ Medien with an underlying difference in the business model: "Among the four big ones, we are, together with NZZ, the ones who depend most strongly on the journalistic business model. We produce content and sell it, plus advertising. Ringier and Tamedia have 'digital' as a second mainstay. We do not have that." At the same time AZ Medien is the only media company which solely focuses on regional news produced for print, online, TV and radio, and who covers more types of media than their competitors. They thus increased their media outreach. "For three years now, the website of our regional newspapers by far has been the best among regional newspapers in Switzerland. Our video inventory is certainly the biggest of the regional newspapers or the regional media in Switzerland," participant 
5 adds. However, the print newspaper is still the most important source of income. Media executive, participant 3 , associates the status of media convergence with the number of readers. "The big ones, Tamedia, Ringier, NZZ, they are actually very advanced. What is common to all these who are far developed, or even more advanced, in media convergence is that they realize - that's the case with us - we've accumulated a greater print and online readership than ever before.” He explains that AZ Medien actually does not have a reader problem because "even the young ones can be reached with the traditional media brands, if you do it well." "The problem is with the revenue," he explains, since "nobody has found a business model that will finance the whole thing on a permanent basis." Another facet of media convergence at AZ Medien is pointed out by participant 4. The 'Aargauer Zeitung,' a newspaper product of AZ Medien and the newspaper 'Südostschweiz' of Somedia AG are coproducing the content of the common section of their newspapers, but each newspaper prints it afterwards in their newspapertypical layout. "This is also a certain kind of convergence," he explains, and even though "convergence is not bound to boundaries between media corporations, but organizationally, I think, it actually is still all the same.” Although media convergence at AZ Medien did not yet contribute to major organizational changes, it plays a significant strategic role as participant 2 explains: "Convergence is also here in theory and strategy and plays a very important role," he adds, comparing AZ Medien with other GermanSwiss media companies he worked for: "Everywhere there is quite a gap between aspiration and reality." In this sense, participant 1 anticipates the future development of AZ Medien: "We are aware of the fact that online is the future and that these different channels are blending more and more." According to her estimation, different media 
types will not be "separated sharply anymore" and "with time, eventually all will come together; and on your mobile phone you will be watching TV, you will be listening to the radio and you will be reading and listening and watching, and everything will be mixed together."

\section{Media Convergence and NZZ Mediengruppe}

In the following are presented the results of interviews with four participants of the NZZ Mediengruppe about the change of media convergence since they started their current roles and the status of media convergence at their company.

\section{Change of Media Convergence since Start of Role}

Two media managers of NZZ Mediengruppe who joined this media company two years before the start of my investigation, in the context of this study shared their perception that media convergence within NZZ did not change a lot since they had started working for the company. Participant 14 states: "The way convergence is being lived in media companies and what variations there are has not really changed since 2015." A slightly different view is shared by media manager, participant 13 , who joined NZZ in 2012 and who had borne the main responsibility for the implementation of the NZZ newsroom. He explains that media convergence within NZZ has changed tremendously during the past few years:

Until $2012 \ldots$ an online editorial staff operated more or less detached from the print editorial department, I believe it was 2012, 2013. Only in cases of extreme emergency, did they discuss [matters] with each other or even exchanged texts, photos and so on. It was then clear at this time that in the long run this was not a good situation, because this mutual independence had a negative impact on the brand.

This negative impact on the brand 'NZZ' eventually led to the decision of producing all NZZ products from one source, in order to ensure "that wherever NZZ is 
written on, there also NZZ should be in," participant 13 elaborates. He adds some thought about their special customer requirements and how the NZZ Mediengruppe reacted by introducing a convergent way of working: "Above all, as far as the quality is concerned, a high level is expected and that is what should be achieved in all media by producing together from one source."

\section{Current Status of Media Convergence at NZZ Mediengruppe}

All four participants of the NZZ Mediengruppe involved in the study project confirmed the strong role media convergence plays at NZZ. However, at their current employer they perceive the media convergence as being of a different quality. Participant 13 explains one of the reasons for the importance of an emphasis on media convergence for the NZZ Mediengruppe as follows: "It is one of the central themes, simply because from 1780 to 1995 , we were just managing one medium, which was a printed newspaper with text and very few pictures." The daily newspaper of the NZZ was known as a conservative print publication. Therefore, pictures were used as little as possible and in a very restricted way. Nowadays, the NZZ publishes news through different channels because of market demands. "We have to perform on different channels," participant 13 adds and underlines the importance of convergence for the NZZ Mediengruppe: "Since our audience is not responding to just one channel anymore, it is in this context that we have to play the whole multimedia palette and we have to learn to play it." A convergent way of working at NZZ does not mean that every journalist "has the same job, that everyone does the same and that everyone does everything. Instead, it means that we have specialized departments for digital media, we have a social media team, a video team," media executive, participant 14, clarifies. Therefore, for the NZZ Mediengruppe, 
media convergence means cross-media content creation of visual components, text components, moving image components, social media components. Given the fact that a journalist "can usually master one discipline, maybe two, but never all" and that "there are no such 'egg-laying wool milk pigs' ['eierlegende Wollmilchsäue,' a German expression for an impossible utopian solution, trying to include everything and more often with functional overload diluting its abilities]" participant 13 shows that at NZZ, this led to a two-folded structure. On one side, there are the news departments Business, World, National etc., or entire magazines where journalists work with a very specialized knowledge, the so-called dossier expertise, and on the other side NZZ entertains a multimedia story-teller team and a video team. Both teams work multimedia and crossdepartment and cover interactive graphics, data journalism and social media. Media convergence at NZZ is also lived in a way that "we ask each other in the case of every story, how do we tell it?" participant 13 describes and continues:

In the meantime, word has gotten around to all journalists, that you can wonderfully describe certain facts in a text, that you can also describe feelings well with a textand also analyses. In other words, what used to be the classic way of expressing yourself. But there are topics you can write ten pages about and you still do not understand them. But if you watch a ten-second video, it's clear what it's all about. And word about that has gotten around among journalists that you really have to choose the appropriate narrative form and also the appropriate narrative channel.

This new resource-optimized production approach requires a well-thought-out planning process. It is a determining factor in the NZZ media corporation and leads to a previously unprecedented and cross-departmental transparency when it comes to the stories being worked on. Participant 12 introduces another aspect as to why certain editorial offices should remain on their own, despite of the great importance the NZZ media company attaches to convergent work and even though it would make economic 
sense to merge them with other departments. The reason is "they have a [certain] DNA, because they do not have this DNA only internally, but this DNA is also perceived by customers externally. And that's why certain areas are still more disconnected."

\section{Media Convergence and Ringier}

In the following will be presented the results of interviews with four participants of Ringier concerning the change of media convergence since they started their current roles and the status of media convergence at their company.

\section{Change of Media Convergence since Start of Role}

When I asked media managers of Ringier to what extent media convergence has changed since they started their roles, two of them who both had joined the company seven years ago, observed during this time a particularly strong change in the media landscape. Participant 7 describes this change as something that came with the digitization of the media industry, with a big change which "shakes up the entire media industry." Media manager, participant 6, shares his observation as follows: "The development which I have experienced during 30 years in journalism is not as dramatic as the change I have seen in the past seven years. Yes, the change of the entire profession is striking; we have to reinvent ourselves, so to speak, in a monthly rhythm." $\mathrm{He}$ elaborates on his experience with a changing environment in the media industry during the past years as follows:

When I joined, online, of course, already was a big topic. Then they started a little bit, they started their first attempts at walking, moving pictures. So the concept of the professional reporter gradually began to change. It was a big threshold for the classic journalist to also work for the online channel. In the beginning there was quite a bit of arrogance. They perceived online quasi as a free-of-charge channel and it was their professional pride which almost forbid the long-serving print journalists to serve this online channel, as well. So back then, when I started there was a little bit of a two- 
class society. The star writers defined themselves by the way as to how strongly they were recognized in print; and they felt that they could, after all, leave online to the colleagues who were trying to gain a footing in this profession. They should do a little vacuum cleaning and the news cultivation should be left to the younger colleagues. But when it came to the more important stories, the big coverage, then it was the turn of the more experienced colleagues. This coverage then should happen in print. If there could be a secondary use online, it didn't matter. That, in a way, was the starting position, I would say, seven years ago. That was the basic thinking prevailing at that time.

A speedy shift in the importance of various media genres and revaluation of online in the context of the emergence of media convergence was also observed by participant 8 who had joined the company about a half a year before she was interviewed. Media convergence at Ringier is being "emphazised more and more, I would say, almost from month to month," she explains and adds: "In the center is the story, the journalistic story, and then the question comes, through what channel and what aspects of this story are we going to play this? It is in this context that this convergence is lived stronger and stronger. This also relates to - but that is not the nucleus of your work - the entire question of marketing which becomes increasingly convergent.” Media executive, participant 10, adds his observation of the acceleration in media convergence since he started his new role with Ringier: "Until today, it has been a rather stringent development with a tendency toward speeding up and becoming more complex, because constantly new topics are being added to this."

\section{Current Status of Media Convergence at Ringier}

All participants of Ringier interviewed during the study project attribute to their company an important industry-wide role to media convergence. Two of the study participants acknowledge the leading role of Ringier in Switzerland as they implemented the first convergent newsroom in the German-speaking part of Switzerland in 2010. 
Partipicant 6 explains: "I now naturally have a deeper insight into how things are working at our company. I have seen a few other editorial offices as well. I do believe that at Ringier we are playing a leading role." And participant 7 adds: "Ringier, with their newsroom, has indeed done a bit of pioneer work. For a long time, they had the most modern newsroom in Switzerland.” The other three study participants of Ringier endorse the importance of media convergence for Ringier in general. Media executive, participant 10 , states that media convergence plays an important role in all big media companies in the German-speaking part of Switzerland and that Ringier is asking the same strategic questions as other media corporations. Confirming this statement, participant 8 explains that media convergence at Ringier plays "a central role everywhere. It has to be everywhere. He who does not adapt quickly to this will be out of the game in a short time. She further stresses the role of media convergence and a related new competency of the management at Ringier:

And when we talk about competencies we are talking about the competencies of a media corporation. That is exactly what it is. A media corporation must be capable of adapting quickly, capable of trying out new things. Since one doesn't know in what direction things are going, one of the key competencies of a media corporation must be flexibility. That, of course, in a way, is an oxymoron, a contradiction in itself, because a traditional organization with a heritage in printing will not necessarily be flexible. But at Ringier, for example, they have learned a lot and they have become extremely flexible and they are bearing these uncertainties. Besides that, this is a central job for the leadership of any media management. [Part of it also] is taking away the anxiety of the personnel, a fear of change, and to motivate them to try out new things and to try out competencies which they have not yet been able to use - and to discover new ones on their own.

In this sense, participant 9 reports that convergent ways of working are practiced within Ringier: „I believe today this has arrived at wherever and whenever we are dealing with news journalism. I mean, newspapers, electronic media—today they all work convergently. Whatever is up to date by the day: The more something is up to date, the 
more they will work convergently." Then he shares his perception that within Ringier only Sunday newspapers which are in a greater sense weekly journals, work differently: "Whatever cannot fit into in the continuous flow of topicality is far away" from a convergent way of working.

\section{Media Convergence and Tamedia}

In the following will be presented the results of interviews with five participants from Tamedia regarding the change of media convergence since they started their current roles and status of media convergence at their company.

\section{Change of Media Convergence since Start of Role}

All the media managers of Tamedia who had joined my study project shared the view that the appearance of media convergence has changed since they started with their current roles. Participant 15, who had joined the company three years prior to my investigation, describes the situation like this: "Actually, a lot is happening and at the same time not much is happening." And participant 16, who had joined Tamedia within the last five years, links his professional career development to the evolution of media convergence and emphasized the importance of synergy utilization during the introduction of media convergence:

Before I came into my current position I was Deputy Editor-in-Chief with Newsnetz. Back then, Newsnetz was a decidedly digital editorial office which means, it was an umbrella editorial office for recording and transferring the mentioned titles. It then was integrated with the editorial offices of Tagesanzeiger. And that was the moment of convergence. 50 to 60 Newsnetz positions were merged with the Tagesanzeiger. At the same time there was a reduction of positions. Even without laying off anybody we saved $10-15 \%$ of the personnel. That was the so-called synergy effect. That always is a strong driving force, as well, of any convergence process. We must not forget that. It may even be the main issue, I believe, basically the motor behind any convergence effort. 
Participant 17 made a more impressive experience with the emergence of media convergence after starting in his current role. "In my case it was quite drastic," he states and explains, "because I started in my current position as an Editor-in-Chief for print. Today I am Editor-in-Chief for the entire editorial office. And this entire editorial office pursues a digital first/mobile first approach. Therefore, my job profile alone has changed completely. But the way the editorial office works has changed completely, as well." Even though participant 18 joined Tamedia shortly before the time of my investigation, he already had perceived a clear change regarding media convergence within Tamedia: "I can see already after three months that something has happened in the heads of people. Right now, for example, I am dialoguing a lot with the editor-in-chief. I notice that I have to produce in a completely different way; I have to think in a different way."

\section{Current Status of Media Convergence at Tamedia}

When I asked media managers of Tamedia about their perception of the status of media convergence within their company, they all confirmed that media convergence plays an important role, but they also detected a certain ambiguity: "I think it is the same everywhere. I believe that as long as there is a print product - and that still is the case in most places - that things are getting into gear in a cumbersome way. I am talking about the development towards working in a convergent way," says participant 15 and continues: "Sometimes I think it is some kind of illusion because, naturally, in the long run the needs of a print product, as long as one wants to sell it as such, are completely different from the Internet. If one has no print product one can work in an entirely different way." Participant 18 elucidates the status of media convergence at Tamedia as follows: 
In principal, the goal of any editorial office is to record everything. For the time being, video, for example, is kept separately.... If one is looking at the concept of convergence, i.e. in the sense of sending someone out to cover everything in text and picture, right now everything still is kept in silos, so to speak. I believe today one still is in the online/offline convergence and not yet in picture, sound, text. But, I am sure it will come here, too.

And critically he summarizes: "Convergence, consequently, in this house still means cost reduction, as well." This statement is argued by two participants of my study.

"Convergence with each title is omnipresent," participant 17 counters and explains:

With 20 Minuten the moment had come when we noticed that both channels, the print channel and the digital channel, had reached the number one position in their competition. And that both editorial offices had approximately the same size. Meaning, we had an editorial office for print with a headcount of approximately 60 and an online editorial office with approximately the same number. With both products we had reached the number one position. And I think that is the moment when each company should ask itself: Is there not a possibility of merging resources to somehow work more efficiently in the end?

Thus, 20 Minuten is that title of Tamedia's product portfolio which already is $100 \%$ convergent while the company's other areas are not that far yet. "After all, we are in the age of convergence," participant 16 ponders about the status of convergence at Tamedia and states: "But then there probably is a - how does one say? - contemporaneity of the uncontemporary. Naturally, there are always areas in the editorial office which have really implemented this, I mean by $100 \%$. I believe in the case of 20 Minuten this is so. And then there are other areas which are limping behind a bit." He continued to provide some further insight into the development and status of media convergence within the Tamedia media group, which is grouped mainly around the news product 20

\section{Minuten:}

I believe now, let's say probably three or four years ago or so, we still turned to the New York Times and different other media ... and we went to WELT who back then were first in having a high degree of convergence. ... We looked at what they were doing and discussed workflow and this idea with the reporter who would write a short 
piece and who then, in addition, would also write a longer print text. That is what we were looking at, as well. In that sense back then that was new enough that one would have the feeling one would have to research it. But that's over. That, even with us, is increasingly over. More and more individuals come to us - to look at our convergence processes. And we no longer go anywhere else to study these processes. Now the issue is optimizing, i.e. re-packaging. It is about sales models, especially sales and development. And that by itself is indicating that we have arrived at convergence. And it is an evidence for the fact that the editorial offices, in a way, have entered into the digitizing process. That's exactly what it is. And I would rather say that this digitizing process has really taken a hold of the editorial offices and that many already got a good handle on this. In this context I am thinking of 20 Minuten. I believe in this case we have to say that certain areas by now have arranged themselves with this. And then there probably are a few latecomers.

\section{Perception of Status of Media Convergence}

When I asked media managers about their perception of the status of media convergence in the German-speaking part of Switzerland I received answers ranging from, "The very big ones actually have progressed quite a bit: Tamedia, Ringier, NZZ" (participant 3) to "I believe most of the media corporations are not really convergent yet" (participant 1).

\section{Cost Cutting Measures}

What is common to all statements is a certain unmistakable skepticism if media convergence is an evolution of new ways of working in journalism or rather a buzzword for cost cutting measures. Media executive, participant 14, shares her perception that "the reason convergence is announced for some media corporations, I believe, is a model for saving money." She is convinced that for many media houses in German-speaking areas, which she also attributes to international media companies outside of Switzerland, convergence has the meaning of merging two teams into one "and then we can fire one and thus save money. After that, they just do everything for half the money," which, in her estimation, has a lasting negative impact on the quality of media products. 


\section{Print Versus Online}

Others, more critical voices, observe an ambiguity between media production for print versus the production for digital and online media. "Towards the public eye there are a lot of activities in the media corporations; they give the impression they are doing a lot and they all claim they are convergent. But I believe in every-day business the editorial offices nevertheless have arranged themselves in such a way that this convergence only exists in a marginal way," states participant 15 and continues to explain: "For the public, there is the image of a more or less full convergence. But if one takes a closer look there are nevertheless non-convergent teams. By the end of the day, there are individuals who are responsible for print and others who are responsible for the Internet and there are just a very few who really do both." Despite all the obstacles and the still higher reputation of print journalists compared to online journalists, nobody really wants to admit this, "nobody can avoid the subject. But it is a slow process and for many the development is not so easy," remarks participant 1 . She further explains:

Even though they try to cover these channels, and somehow, they do it with the necessary energy and creativity, nobody in the German-speaking part of Switzerland really dares to stake everything on this one card. One can see other examples abroad where newspapers radically rely on online and publish a paper version perhaps only once a week and not more. So far no one in German-speaking Switzerland dares to do that, too. I think they have recognized the importance but still hesitate a bit.

Participant 11 describes the continuing print supremacy as follows: "In the end, if it comes to a power struggle print still will win" and ponders about the thought that it should be possible "that people in editorial offices no longer give it a thought whether they are dealing with print or online, but instead that one has products or people who pit their contents through different channels" which would be the very generic idea of convergence. Participant 11 concludes: "But I believe that no media corporation 
functions that way yet - at least none of those I know in Switzerland. Nobody is that advanced yet."

\section{Business Model}

Another approach to the status of media convergence in German-speaking Switzerland revolves around the topic of convergence and corresponding business models. Concerning the status of convergence, "everything depends on the direction of the company. First of all, there are not that many media corporations in Switzerland; secondly, there is the question as to what the corporate structures and goals are," participant 13 states and elaborates:

Convergence, naturally, is a big subject for those media corporations which still have their focus on journalistic products. If a company says, in the first place, we want to make money and, as a consequence, journalistic content decreases, well, then it just decreases. Then, in turn, the issue of convergence will become less important correspondingly or it will manifest itself in a completely different way. I know they sometimes say that about Ringier or the Blick newsroom, that in the middle of the newsroom there are sitting the people of Ticket Corner. That, of course, is a completely different convergence issue if one has the entire sales team as an integral part of the newsroom.

Media executive, participant 10, also deals with the question of a corresponding business model for media companies in the context of media convergence: "Every publishing company is sitting there asking themselves the question, I have my beautiful newspaper; I have my beautiful radio and TV network - What exactly does that mean for me?" From his point of view, newspaper production in the German-speaking part of Switzerland, to a high extent, is already done in a convergent way. Elucidating the situation among the production of magazines and respective business models he explains: "When it comes to magazines I still see a great helplessness. In different ways this is quite strong. But in the majority of the magazines it does not yet exist. Why not? Because 
as far as their content concept is concerned they cannot, under the same brand, display that on the Internet." For him, therefore, the magazine market is more about the selling of journalistic competencies. "In summary, it actually is less about digitizing the brand but rather digitizing the competency I have." In this sense, the topic of convergence is becoming less important for media executive, participant 10. For him, the digitization of analogue content is certainly the predominant role and thus the relevant business model.

\section{New Media Paradigm}

According to participant 17 all media corporations that do not have a heritage in the digital world have to face the discussion about media convergence: "Whether it is $\mathrm{TV}$, radio or newspaper - for everybody who does not have a digital heritage convergence now, after all, is in the center of attention." Participant 16 even goes as far as to call media convergence a new media paradigm:

I do believe that by now it has become - how shall I call it? - a new type of paradigm. In the area of newspapers or on the news sites respectively, a news site article has general validity. I believe with Blick, AZ Medien, NZZ - and what else is there? - 20 Minuten: I believe there are no titles updated daily or by the minute which have separate titles, which still, in a way, live divergence. That by now is the same with TV and radio. They, too, work together on online articles. Yes, we have reached the age of convergence. And then, by now, there are - and this is fascinating - some digital [media] like Watson, for example.

Media manager, participant 12, complements with regards to a new media paradigm: "I believe with others it is even a bit more pronounced. I think, for example, the way Ringier operates, where a journalist no longer knows where whatever he or she has produced will be published, but where they just produce and some editor-in-chief decides on which platform and in what length and in what format it will be published it makes sense to play it out in that way. That, of course, is yet another level of 
convergence," which applies only to very unique media environments in the Germanspeaking part of Switzerland

\section{Changing Consumer Behavior}

Participant 2 raises his concern about the speed the media industry - in general and in German-speaking Switzerland in particular - is adapting to changing consumer needs: "I believe that the competency and also the development of the convergence in the media industry, in many media corporations, does not keep up with this development where and how people consume media." Media executive, participant 19, joins the concern of the missing ability of coping with changing consumer needs and states about media convergence and new media offers as follows: "It is a need. People are reading printed newspapers and digital newspaper editions. Users read differently depending on time and location. Users trust the brand and like to consume the brand's choice of offerings. Users access news everywhere, anytime, anywhere." Therefore, he summarizes: "It is impossible not to provide digital offers." In the context of changing consumer behavior, media executive - participant 14, shares her perception that media convergence is a much-discussed topic in the media industry in German-speaking Switzerland and in Germany. It offers a positive outlook towards a more consumerfriendly offer in the future. "I can see that they are thinking more about convergence, in the sense of, fortunately, dealing with the question as to how we can best reach the users and readers on all channels with the in-house expertise that we have, i.e. the resources we have, and offer them the best possible quality." 


\section{Impact of Media Convergence on How Journalists Work}

In order to gain a deeper understanding of the impact media convergence already today is having on the way journalists work in the German-speaking part of Switzerland, I asked all participants in my study project: "To what extent has media convergence already changed the way journalists work in German-speaking Switzerland?" As shown in Table 3, the biggest changes in the work of journalists were perceived in the area of the 'way of working' in general where time and space of journalistic work almost dissolves and where no dedicated time exists anymore "in which one researches and then has time to write and in which the item is being printed" (participant 11), also in the area 'speed of news,' the requirement of 'news distribution on different channels,' 'openness for new media' and 'interaction with readers.'

With a different way of working, interviewed media managers express how the work of journalists has changed during the most recent time period. "Most journalists of daily newspapers are at the same time online editors because hardly ever there are separate editorial offices," reports participant 4. A journalist, who produced for a newspaper in the past, knew that his/her story had to be finished at a certain time in the evening in order to be printed during the night. Following the premise of 'online first,' nowadays a journalist has to consider publishing part of the story already during the day. Participant 2 explains that the work of journalists also changed with regards to storytelling. The journalist already has to consider how to conduct the journalistic research "because I already have to think about the way I will implement the [one story] not just in print, but online as well." Additionally, there are "different media formats like 


\section{Table 3}

Impact on Media Convergence in the German-speaking part of Switzerland on How Journalists Work

\begin{tabular}{lc}
\hline $\begin{array}{l}\text { Type of Impact on } \\
\text { Work of Journalists }\end{array}$ & $\begin{array}{c}\text { Count of Times } \\
\text { Mentioned }\end{array}$ \\
\hline Way of working & 5 \\
Speed of news & 5 \\
Distribution of news on different channels & 5 \\
Openness for new media & 3 \\
Interaction with readers & 3 \\
Technical/Digital knowledge & 2 \\
Production of news for different channels & 2 \\
Working as a team on one media article & 2 \\
Understanding of users & 2 \\
Online first & 2 \\
Way of thinking and approaching a story & 2 \\
Usage of social media & 2 \\
Networking & 2 \\
Reduction of quality & 1 \\
Own use of new media & 1 \\
Understanding of measurability of news impact & 1 \\
Content & 1 \\
Merge online with print & 1 \\
Investigation & 1 \\
Usage of various forms of media & 1 \\
No change & 1 \\
\hline Total Number & 2 \\
\hline & 2 \\
\hline
\end{tabular}

video, live reporting, delayed reporting, for online and then again, another format for print," he explains and adds:

When an editor has finished writing an article and has sent it off, the job is not finished for him or her if one thinks convergent. Someone has to take care of the distribution which no longer is, "we print a newspaper and then it is being distributed." Instead, there are different channels which exist digitally, and one channel has to cover the article. 
In order to demonstrate what this different way of working means for a journalist, media manager, participant 6, uses the example of the airplane crash of a Brazilian football team in Colombia in November 2016: "There then is the quick response force which will cover the entire topicality online. But then the issue is what else is there? What additional research do we have to do?" This additional investigation, which according to participant 6 is the biggest challenge, has to provide some exclusivity "so that one can justify that the print consumer - unlike the online consumer - still pays. What else can we offer him? We are decidedly of the opinion that he or she is entitled to some enlargement, some staging, some additional nice presentation, some additional aspects."

The speed of media reporting is another aspect that has changed. "I think the most important aspect is speed," says media executive, participant 3, "everything is much faster, especially, when it comes to some event. Be it an accident, some assassination, but also some resignation in politics. Things in those cases are happening incredibly fast." Participant 10 adds that one has to understand "that it actually has become a business of minutes, not just a daily edition but a matter of minutes; that is how I have to pick up the people." Above all, push notifications also contribute to this time-competitive pressure. Participant 6 clarifies the challenge for media companies:

In the long run, our push news cannot permanently come two minutes after the 20 Minuten push, because there are many people who have subscribed to everything. If it is swaying back and forth in a few cases, it will not be a problem. But if we are slower by design — and in this case I am always imagining some group of young people and everywhere it is beeping and one says to the other, 'Oh, did you see Ronaldo will now transfer to Manchester after all,' and our consumer is getting it not until two minutes later. In that case it will be annoying in the long run. 
This new speed of media reporting, participant 1 adds, "naturally, leads to such a new racing mentality, as if we are in a race against the others; and that will lead to mistakes."

The distribution of news on different channels is another characteristic of the new ways journalists work in German-speaking Switzerland. The way in which messages are recorded on different channels is described by participant 13 as follows: "And then, relatively soon, one reaches the point where he or she says: 'Okay, online first. We produce online and, perhaps, later on we will produce some 'best of' edition which we then will print." Today, a journalist has to consider, participant 11 tells: "which channel will I use for which message? We are noticing that, too. It is not just about the word but is about the picture. And then there is an interaction with the reader. That means, the text actually is gone." Journalists today have not only to be fluent in different narrative forms for different channels, they also have to distribute their work to different channels, in particular "to the fast channels," participant 6 interjects and adds that a journalist also has to think about:

What is the first version I produce? And then, at the same time, he already keeps in mind what he can save - perhaps some exclusivity or a portion which I can take out. Okay, perhaps I will design an exciting background story about this segment. So in a way, one already tries to portion the story a bit into segments. I believe that is one of such principles. In the old days one went somewhere and simply covered everything, the entire story and whatever it entailed. One wrote a big story and it appeared in print. Today, our colleagues do ponder, how can we divide this into segments? That, of course, has very practical reasons because then each channel, nevertheless, has its own demands on the respective reporter. Everybody wants his own piece of exclusivity, wants to have for himself something as fast as possible and as much of it as possible. Today, there are, of course, some permanent agreements in place. We have our own "decision place" as we call it, where the online chief is located, where the one in charge of paper print is located and where the sports chief is located. And there, from morning to evening, it is decided, whenever something is happening, as to how we will share or divide it. 
In addition, today openness for new media is expected of journalists in Germanspeaking Switzerland. Media executive, participant 10, describes this expectation and an accompanying huge challenge in the following way: "That is the big buzz word. We all have heard a hundred times of the legacy. How do you actually accomplish the mind change, that the people out there no longer think of just their paper but rather of online, as well, and that they see digital as a strong point?" He further stresses: “And that has very little to do with saying, there is digital first, but that they understand it as something completely different." Participant 20 shares in this context her observation: "When I am considering, however, where the editorial offices were five years ago, I would say, there at least is a willingness to think differently."

Another manner of new ways of working concerns a certain interaction with readers. "If one thinks convergent," participant 2 states, "the job for the editor is not yet done when he has finished writing an article and when he has sent it off." A journalist can, for example, ask the reader of a digital story, "what he or she thinks about it, or he can ask him whether he has a supplement to the story," explains participant 17. "It is a matter of being accessible for the community." This interaction with users suddenly plays a role in today's media world "because the digital article, after all, triggers a much greater response or reaction. And then the question is," adds participant 2, "whether the editor is using this opportunity for engaging in an interaction with readers or not."

Additional new ways of journalistic working which are already appearing in German-speaking Switzerland are the usage of technical, digital knowledge, the production of news for different channels, teamwork on one and the same media article, the understanding of users, online first, a new way of thinking and approaching a story, 
the usage of social media, networking, a certain reduction of quality, the usage of new media by journalists, content-related new ways of working, the merging of online with print, new ways of journalistic investigation and the usage of various media formats at the same time.

\section{Location of Media Convergence}

The following section entertains the question where, primarily, 'media convergence' takes place in terms of its functional and/or physical location and whether or not the newsroom is the place where convergence takes place. Each four companies included in the study planned, designed and implemented a convergent newsroom in the past seven years. Ringier was the forerunner by implementing a newsroom in 2010, followed by AZ Medien in 2011, NZZ Mediengruppe in 2012 and Tamedia in 2013.

From the interviews, I observed that most of the participants closely link media convergence with the physical place of a newsroom and the term newsroom itself with the place where news is being produced, which participant 3 described aptly: "I think the word 'newsroom' is more or less just a modern term for editorial office, ... maybe not in the form of a single office but as an open space office."

\section{Appearance of Media Convergence}

Asked about the appearance of media convergence, participant 11, a member of the editorial office, shared her viewpoint that media convergence has to include a change of mind-set. And this has to start at the top executive level of a company and can only be implemented in a top-down-principle. She explains:

If there is nobody at the top who says, "From now on we no longer function as a print product, that is putting a few items online, but we function in such a way that we distribute our story to various channels, we work together," then this will happen in 
an inter-departmental way. If that is not being pushed through uncompromisingly, it will not happen. That is my experience.

Media executive and journalist, participant 8, supports this view: “Convergence, first of all, has to take place in the mind. It is a question of the mind-set of each individual journalist.” She adds: “A newsroom on its own does not bring convergence per se." In this sense, the importance of pioneers who motivate and inspire people to think and behave more and more multimedia was highlighted by participant 1 .

\section{Newsroom, the Personalized Convergence}

The newsroom is perceived as one form of how convergence can be implemented. Participant 4, an editor-in-chief, believes that media convergence does not depend on a location or on office buildings, instead people even in decentralized structures can work convergent and that the longer the more. "These mobile devices make it possible to produce for all channels from anywhere. That is also why the classic newsroom is also more of an initial phenomenon of the convergent age." He added that he does not support the concept of every media professional sitting in the same room, because, in order to find stories, journalists have to reach out from and to anywhere. Participant 6 , an editorin-chief of a tabloid, comments on the communication aspect of newsrooms:

In my opinion, the newsroom is a bit overrated. The newsroom basically is a big open-space office. That's a trendy name, but it's essentially not a concept or a strategy. For me, that's more of a definition about location. Where do people sit together? It is the team that is important. Hence, convergence has to be lived and it has to come from people and thus, convergence comes through discussion and through a culture of discussion. For me it has less to do with [location]. It certainly is important to sit together. Convergence would get more difficult if one would continue to sit in single offices. But for me it is more a matter of a culture of discussion, or with culture in general that prevails in an editorial office rather than a certain locality.

However, on a large scale, the participants of the study perceive the concept of newsrooms as one possible design as to how media convergence can be brought in place. 
The newsroom is "personalized convergence" as participant 14, a digital Media executive, called it. Participant 7, a media educator and former Editor-in-chief, added:

The newsroom is, so to speak, the statement of convergence. But I believe that even editorial offices who do not have a newsroom now, organize themselves a bit differently. The newsroom is, so to speak, the spatial consolidation of various channels and of various platforms. Newsrooms are actually being re-created in order to express this increased need for exchange, communication, consultation and that in a spatial form. But it is not mandatory. Today, the digital world is organized in such a way that even with single offices I can be interconnected with a lot of people.

Participant 20 confirms this statement and summarizes the discussion in a nutshell: "In principle, if the setting is correct you can also create a newsroom with a lot of single offices. It would only be extremely impractical."

Various participants defined the function of their companies' newsrooms as the physical place where media convergence takes place. It is "almost a kind of germ cell for media convergence," as participant 14 labels it. Media executive, participant 10, sees the newsroom in the media company he belongs to as "an amazingly living or breathing construct which actually has to change permanently. Firstly, it changes, it constantly has to adapt to new challenges." No matter how challenging the newsroom construct may be, "a newsroom setting simplifies matters a lot, [a place] where journalists and editors, covering different media channels, can work and sit together without any physical barriers and where they find one central location where they can exchange and develop stories together," participant 8 added.

Since newsroom implementations were in some cases flanked by reduction and rationalization measures where, in the end, media professionals were simply moved into a larger office space (i.e. an open-space office) without changing the workflow structure towards convergent work, the term newsroom has some negative connotation. Therefore, 
media managers agree that in newsroom settings one should pay attention to ways of working and less to room structures. It is important to put an emphasis on the real power of the newsroom which is "that there are so many people who can realize very intense research results in a very short time [...] That's the real power we have," participant 10 argues.

The newsroom "surely accelerates the understanding that a convergent way of working is necessary"; it "is certainly an important catalyst for understanding that it requires convergence," as editor-in-chief, participant 17 , concludes. The newsroom also "is a way of communicating with each other differently," participant 2 argues. It is an example for ways of working which are actually dissociated from space and time.

\section{Convergence Takes Place Everywhere}

Even though convergence takes place in the newsroom it does not mean that a convergent way of working is limited to the newsroom. Convergence also takes place "in the video studio, when a video editor with a graphic designer and a specialist editor work together on a video. It also takes place in product development when a storytelling tool is developed with the editorial department," participant 14 states. Convergent ways of working can also appear at smokers' corners and coffee venders, "where I always have the best ideas," participant 20 inserts, "because you talk to people you normally cannot talk to. And surprising things can happen because when I'm only talking to the people sitting next to me, people whom I know..." or in a lounge which was built by one of the four big Swiss German media companies parallel to the implementation of the newsroom. The lounge where people eat, drink, read and meet around-the-clock contributes more to convergent working then the newsroom with its big screen. Participant 9, leading project 
manager for the implementation of this newsroom, explains: "The lounge has always been the heart of the newsroom, I always said. And the big screen actually was only the visual documentation for guests, but photos where always taken in front of the screen." Editor-in-chief, participant 3, dissociates convergence even more from a dedicated location. When he was asked, 'Where does convergence take place,' he answered:

Everywhere. The journalist who goes out to create a story: Hopefully it will happen there as well. Maybe he is not only taking a notebook along, as in the past, but his iPhone, if the subject is suited for it, to make a video clip. Those can also be quite simple occasions. On the weekend, there was a big meeting with 600 classic cars in Argovia. In the pre-convergent time the journalist came and with his photo camera he took some pictures and the next morning it was published in the newspaper. Today, hopefully, he will shoot a video clip, interview the organizer, cut it, publish it - online first, which means not only, if it takes place on Saturday, for the Monday edition; already on Saturday evening something will be online. Consequently, it takes place outside, it takes place here, of course, in the editorial office, in the newsroom, also by having new departments, that you do not only have a newspaper production that creates a nice newspaper, but also an online mobile editorial office, an attractively designed portal, which pushes messages and also selects special multimedia implementation forms. Wherever journalism takes place convergence takes place.

The dissolution of space in convergent work goes so far that even media professionals working from a home office can be integrated into a convergent production process. Participant 13, a Project Director Convergence, states in regard to this:

But it also works on the opposite end, everything runs together, namely in the home office with each employee, because he sits there, is physically completely detached from the team, but organization-wise, content-wise and as far as technical aspects are concerned he is completely connected to the system. And of course, this whole convergence manifests itself at each single workstation in a home office.

Derived from the discussion presented, it can be summarized, that convergence can appear anywhere. However, the implementation of a newsroom can contribute to a redefinition of workflow processes and new convergent ways of working and communicating. But, a newsroom on its own does not make it a convergent working place as participant 20 counters: "Well, that's when you quasi say, 'you have a 
newsroom, and now everything is somehow tops. That of course, is total nonsense for people, isn't it? You have to introduce it seriously."

\section{Excursus: Newsrooms in German-Speaking Switzerland}

Two cases of newsroom implementation in the German-speaking part of Switzerland, the one of AZ Medien, built in 2011, and the other one of NZZ, built in 2012, will be presented in the following excursus. Among the forerunners for newsrooms in German-speaking Switzerland were Ringier, AZ Medien and NZZ. The Head of the Ringier School of Journalism explains: "Ringier certainly did a bit of pioneering work with its newsroom. It has been the most modern newsroom in Switzerland for a long time." And he emphasizes, that "today, it is a must in all major media companies. Meanwhile, the publicly-owned media organizations, SRG/SRF, according to what I've heard recently, work towards convergence, as well; they have discovered the newsroom."

\section{NZZ Newsroom - Smurf Layout}

Participant 13 is Project Director Convergence and responsible for the newsroom integration at NZZ Mediengruppe. During the interview he gave some background information about the planning and implementation of the newsroom at his company. Before joining NZZ, he was working with Ringier and for two and a half years leading a project group which implemented Ringier's newsroom for the Blick-Gruppe, the tabloid product group of the company. He explains: I ,exactly had the same task and when this project was completed, I changed jobs." And then he adds: "Although Ringier and NZZ offer completely different products and have a completely different corporate culture, the fundamental requirements are exactly the same." He perceives convergence as the main theme in his project portfolio, either as project manager or while working in the editorial 
office. Hence, he clearly interweaves the implementation with a statement for convergent ways of working. When he started his work at NZZ in 2012 the online editorial staff operated more or less detached from the print editorial office. Only in some exceptional or emergency cases the two groups had discussions with each other or even exchanged texts or photos. "At this time, it became clear," participant 13 notes, "that in the long run, this was not a good situation because the mutual independence had already a negative impact on the brand." Therefore, the decision was taken to produce all NZZ media products from one source in order to cope with the customers' high-quality expectations. After the decision was taken to bring all editorial resources together, a newsroom was implemented in several ad-hoc actions. "The first knee-jerking exercise was the physical construction of a common newsroom where all representatives of the editorial offices of print, news and online news were put together. But this was very half-baked and very little thought through," he comments and continues: "The cultural clash was actually quite big and it actually was very positive because it generated a fundamental readiness of all participants." Following this, they took a more systematic implementation approach and involved all participants in the creation of a reasonable and workable design of the newsroom. He created the so-called 'Smurf' layout. They designed a huge lay-out for the new newsroom and populated it with [comic] Smurf characters made of rubber. "At first, people stole a few Smurfs," participant 13 recounts, "and then they started discussing. They realized relatively quickly, that if the one with the red cap is always just standing around there, then he is of no use. He should sit in the other corner and should be sitting next to him ..." This planning process helped them to work out a design in which meetings would become redundant because the people with the most interactions where 
already seated close to each other. This lay-out also contributed to the reduction of acoustic emissions. "And in retrospect, I would say we have done a good job, because now it has been approximately two years ago that we have set up this newsroom and since then it has been left absolutely unchanged in terms of furnishings. That actually tells us that it works," participant 13 summarizes. He then adds: "Even though there are 80 work spaces, of course, they are never fully occupied. And even though it has 80 work spaces it's never really loud because all individuals present have made it a point [to] not talk on the phone. It just does not take place. Either they can chat on the phone [by texting] or they can talk with the person next to them. That's really a great place to work."

\section{AZ Medien Newsroom - Spider Project}

Participant 9, project leader for the implementation of the newsroom at AZ Medien in 2011, describes the most crucial consideration for organizational changes: "It is always important to remember that the fish stinks from its head," and confirms that the CEO of the company was in favor of the project and his superior was backing him during the project. In order to gain buy-ins he lived convergence himself. During his work for the print newspaper he started producing online reports and some small videos. As a special feature, he also integrated into the newsroom planning the company-owned television stations (Tele M1, TeleZüri and TeleBärn). He fused talks and interactive stories and tried to connect television, online and newspaper. At the time of the elections for Council of States, he created an online voting system, in which TV viewers could vote online for their favorite candidate to be included in a live-debate. "This was an attempt where it was quasi-tried, let me say, in a playful way, but still about a serious content, to make the whole story multimedia," he adds and continues: 
I have always tried to actually get virtuality physically down to earth [...] That was my pattern and that, actually, is the whole story. I have tried to carry the multimedia work, the newsroom, into the farthest corner of regional journalism. Again, it was done physically, with a small video screen in each regional office. First of all, I founded so many regional offices. I said, the more virtual the world becomes, the easier it is to write from anywhere, the more important it is to be present in these corners of the world or the corners of the regions, physically. Especially. Thanks to new technology, actually because it just needs no more equipment, we founded new one-person, two-person, three-person, four-person offices. For example, in Lenzburg, for example in Reinach, etc. and we actually demonstrated that this is a chance, through online, of getting closer to the people and not farther away from them.

It was important for participant 9 that new ways of convergent working opened new opportunities for journalists. In order to develop the editorial team of AZ Medien he enrolled them for special trainings at the MAZ School of Journalism and organized socalled 'convergent days.' After these initial steps a project by the name of 'Spidergymnastics in the web' was created. The purpose of this project was to prepare the AZ Medien's editorial staff for the new working environment and for ways of working in the company's new newsroom by external and on-the-job training measures. At the end of the project, 60 individuals, print journalists from the common part of the newspaper and from regional parts, passed the program, plus additional individuals from the company's TV and radio stations. "We went to the workplaces of the people, worked there convergent, made videos, wrote reports, developed multimedia stories in one day and added different products to them," explains the Spider project leader. It was important for him to note that participants in the Spider project had enough time for experimenting, practicing and sharing of experiences. They did that in order to perceive all actions as training and not as an additional workload and overtime. Networking was key in this project; and at the end of the training each of the participants received, as an acknowledgment of their willingness to join the project, a 'spider passport' while the 
project leader himself was called 'Mr. Spider-Man.' Asked about the success factors for this project, participant 9 responds: "I think the reason why the AZ Spider story was a success was the fact that they told a story, the Spider story. We told a story and tried to live that story. And I think if you do things like that you have to tell stories." Then he adds: "People have to be able to tell what they did when they come home in the evening. And that was easier in the past because back then it was a regular newspaper which was filled." Comparing the successful implementation of the AZ Medien newsroom which was introduced and accompanied by the 'Spider Project,' together with another newsroom project in German-speaking Switzerland, he concludes: "Up to this day, it has difficulties because it has no narrative. There is no storytelling: there is nothing positive about this newsroom." In the case of AZ Medien, there was the Spider-Man character around and he adds: "Of course, I also tried to create a bit of a myth; I tried to create a story. It is also important that you do not see it purely as a cost-cutting exercise and some horror education.” Although he does not deny the cost-saving and rationalization effect which comes along with introducing a newsroom, he demonstrated that convergent ways of working in a newsroom setting can also contribute to new opportunities for journalists.

\section{Summary}

The findings about the status of media convergence in the German-speaking part of Switzerland are summarized in the following five parts.

Four privately owned media corporation in the German-speaking part of Switzerland were included into the case study approach: AZ Medien headquartered in Aarau, Switzerland, with 1,200 employees and an annual revenue of approx. CHF 236 mio. (\$251 million, 2016), NZZ (Neue Zürcher Zeitung) Mediengruppe, headquartered in 
Zürich, Switzerland, with 1,900 employees and annual revenue of approx. CHF 423 mio. (\$451 million, 2016), Ringier headquartered in Zürich, Switzerland, with 3,100 employees and annual revenue of approx. CHF 840 mio. (\$895 million, 2016) and Tamedia, also headquartered in Zürich, Switzerland, with 3,300 employees and annual revenue of approx. CHF 1,005 bill. (\$1,07 billion, 2016).

In Switzerland, the professional title 'journalist' is not a protected professional title. Therefore, there are various ways for obtaining a journalism education. The two most renowned professional journalism training centers in the German-speaking part of Switzerland are the 'MAZ - Die Schweizer Journalistenschule' and the 'Ringier Journalistenschule.' They both offer a dual system, combining school and practical work. The publicly owned Swiss Radio and Television Corporation (SRG SSR) offers a comparable trimedia journalism-training course. In addition, four universities offer academic journalism education.

Twenty media executives and media managers, employees of the four media corporations under investigation were included in the study. Position titles of participants of the study were at the time of the interview as follows: CEO, AZ Medien; Editor-inChief, AZ Zeitungen; Deputy Editor-in-Chief, AZ Zeitungen; Editor-in-Chief, Schweiz am Sonntag; Editor-in-Chief, Limmattaler Zeitung; Freelance journalist, Consultant for the media industry, Training Manager Journalism Education; Chief Product Officer; Head of Digital Products; Project Director Convergence; Head of Magazines and Member of the Editorial Office, NZZ am Sonntag; COO Ringier AG; Head of Public Affairs; Co-Editor-in-Chief, Schweizer Illustrierte; Editor-in-Chief, Blick Sport; Head of Ringier School of Journalism; Member of the Group Management Board, Head of Paid 
Media; Member of the Editorial Office, Tages-Anzeiger and Head of Digital and Newsnet; Editor-in-Chief, 20 Minuten; Deputy Editor-in-Chief, SonntagsZeitung; Head Digital Sales Development.

All study participants shared the perception that media convergence already is playing an important role in all Swiss German media corporations. However, all of them see slight differences between the four major media players in the German-speaking part of Switzerland with regards to the status of media convergence. AZ Medien and NZZ are still to a higher degree focusing on the journalistic business model, while Ringier and Tamedia relay on digital offers as second mainstay. The biggest changes in the way editors and journalists work in this more convergent environment were perceived in the area of the 'way of working' in general, where time and space almost dissolves and where no dedicated time for research, news writing and production exists anymore. There were also changes perceived in the area 'speed of news,' the requirement of 'news distribution on different channels,' 'openness for new media' and 'interaction with readers.'

All four companies included in the study had designed and implemented a convergent newsroom in the past seven years. From the interviews, I observed that most of the participants closely link media convergence with the physical existence of a newsroom and the term newsroom itself with the place where news is being produced. However, some of my interview partners emphasized that media convergence has to start in the minds of the players involved and includes a change of mind-set. In this context, the concept of a newsroom can be perceived as the personalized convergence while 
media convergence is not limited to the newsroom and hence can take place everywhere and is dissolved from space and time. 


\section{CHAPTER 5}

\section{FINDINGS: COMPETENCIES NEEDED FOR CONVERGENT WORK}

\section{Introduction and Overview}

This chapter describes the results of the data analysis related to required competencies and skill sets for convergent journalism work today and in the future. Individual interviews and discussions with 20 media managers including the editors-inchief of four major Swiss media companies in the German-speaking part of Switzerland had one central purpose. It was to gather data for one of two central research questions: "What are the current and future competencies needed by media professionals (journalists and editors) in the convergent media environment in the German-speaking part of Switzerland?"

I used 17 interview questions divided into eight categories. The first seven questions, assigned to categories 1 to 3, provided details about the status of media convergence in the German-speaking part of Switzerland. The resulting data analysis was presented in Chapter 4. The questions of category 4 were the core questions for this study as shown in Table 1 on page 47f. These questions were asked in order to provide answers on needed competencies and skills by media professionals in a convergent environment. Here, the most important question was: "Please describe your experiences, perceptions and expectations with regards to possible competencies and skills needed for media professionals in a convergent environment in the future." The last two questions, category 
8 , concerned personal experiences with media convergence and personal viewpoints and insight about convergent competencies needed today and, in the future, in order to illuminate the research questions from another angle by including narratives of media managers of the four biggest privately-owned media companies in the German-speaking part of Switzerland.

The presentation of the findings and the data analysis about competencies for convergent work is structured in the following three parts: Competency and skill sets for convergent work, leadership and management competencies, convergent competencies derived from a quantitative content analysis of job advertisements.

\section{Competency Clusters Needed for Convergent Work}

In the following section, firstly, an overview will be given of required competencies for today and the future as seen by selected managers in the Swiss German media industry and two members of professional journalism schools. Secondly, an excursion on leadership and management skills follows. The section closes with the results of a quantitative content analysis of job advertisements in Swiss German online platforms, which will be compared to competency and skill sets described by media managers in my study.

'What are the current and future competencies needed by media professionals (journalists and editors) in the convergent media environment in German-speaking Switzerland?' That was the leading question for this part of my investigation, which I approached in four different ways: First, I asked about competencies and skills needed by media professionals in a convergent environment today in general. My second question aimed at understanding what experiences, perceptions and expectations regarding 
competencies and skills are needed for media professionals in a convergent environment today. My third question intended to understand what experiences, perceptions, and expectations concerning competencies and skills will be needed for media professionals in a convergent environment in the future, and fourth, I wanted to know which competencies and skills are needed for the respective institutional participants.

The discussion about competencies needed by journalists in a convergent environment encompasses a broad framework. Media manager, participant 6, explains: "There are basic competencies which actually do not have a lot to do with convergence. Those are basic competencies journalists must have at any time." Participant 4's arguments go into the same direction: "Actually, they are the same competencies as always and which any journalist must have. Perhaps a few were added to these. But it still is essential that there is professional expertise, i.e. that one simply knows enough about the field one is writing about, that one has such a narrational expertise that I can tell a story." However, today a certain additional competency, the so-called 'channel competency,' is required, which means: 'I must tell a story in a different way when I do it for a magazine than if I do it for a website. In that case, there certainly is a new competency that is required. I must know for what product I am actually writing," adds participant 4 and continues: "In that case I would not stress that so much because a good story which is well-written, which is technically good, in most cases works on all channels - on paper, on a smartphone, on a tablet." Finally, he summarizes, "The way it [the story] then is publicized, again, is another story. Therefore, the fields of competency actually have not changed that much." Media executive, participant 3 , brings the 
exception of a most illustrious journalist or wordsmith (in German: Edelfeder) and of a social media native into play:

If one is a top 'Edelfeder' and writes incredibly good texts and stands out against the rest of the editorial office, then one will overlook the fact that this person might not even know how to turn on the computer. If someone is a complete social media native and knows how to be present on all channels one will also overlook the fact that he or she is not an 'Edelfeder.' It is an illusion to think that everybody knows everything. There are a few exceptional talents. But then you will have to arrange your editorial office in such a way that you have all skills, that you have top individuals of all areas, that the team as a whole combines all skills.

On the other hand, participant 3 also clarifies that it is hard for a journalist in today's age of convergence if he or she only wants to write "nice texts" and is not willing to work convergent and to produce for different channels: "In that case one will have to be an incredibly exceptional talent that he or she will cut one's own path with his or her writing skills alone," he added. "However, I do not expect of everyone that he or she will acquire each skill there is out there in the digital world," counters media executive, participant 14, and explains: "I do not consider that sensible for a brand like ... because it is impossible to break at the same time into all areas of specialty, to improve oneself, write about it, be a perfect VJ [video journalist] and a social media editor and learn how to program on top." Media executive, participant 10, comments by asking: "Is the question, that the journalist has to broaden him- or herself in their skills or is the question that I will need new specialists for different jobs?," and answers himself: "Essentially, I would say, new skills will have to come in instead of completely abolishing old ones."

Another insight on newly required competencies is related to management tasks. Participant 2 argues that there are new convergent competencies needed on the level of departmental managers and on the level of the makers of newspapers. They are about "how things are being organized and planned for and how one is sketching a story 
content wise in such a way that it will work on different channels." He describes the situation of an event which is important for both online and print, an event which is being announced in advance, about which there will be live coverage and about which one also wants to offer some additional background information. And then there is the question: "Who will do what, when and how? That, of course, is a completely different challenge [for the management], compared to the pre-convergent age. Online [production] is doing this already anyway," explains participant 2 and adds: "With the newspaper we must think, what else can we do? And I simply must have a focus on something. That for me is one of the essential issues. How much can a person do by him- or herself and how much work sharing does the convergent way of working require once again?" In addition to these organizational and planning competencies, participant 4 also attaches great importance to social competency: "Depending on the respective function in the editorial office, social competency is required." But then he modifies: "There are a lot of journalists without social competency; but they, nevertheless, can be good journalists. But in a leading role, social competencies are, of course, a must."

As shown in Table 4, all answers I had gathered were clustered in seven skill-sets: 1. technical,

2. social and emotional,

3. cognitive,

4. writing and linguistic,

5. publishing and production,

6. innovation and creativity, and

7. leadership and management. 
Table 4

Competencies and skills needed by media professionals in a convergent environment as referred to by interview participants

\begin{tabular}{|c|c|c|c|c|c|c|c|}
\hline \multirow{2}{*}{$\begin{array}{l}\text { Competencies and Skills Needed } \\
\text { Skill and Competency Theme }\end{array}$} & \multirow[t]{2}{*}{ General } & \multirow[t]{2}{*}{ Today } & \multirow[t]{2}{*}{ Future } & \multicolumn{4}{|c|}{ For Media Companies } \\
\hline & & & & AZM & NZZ & Ringier & Tamedia \\
\hline \multicolumn{8}{|l|}{ 1. TECHNICAL SKILLS } \\
\hline CMS (Content Management System) & $\mathrm{x}$ & & & & & & \\
\hline Data Journalism and Analysis & $\mathrm{x}$ & & & & & & $\mathrm{x}$ \\
\hline \multicolumn{8}{|l|}{ Image Editing and Illustration Systems ${ }^{\circ}$} \\
\hline Multimedia Skills & & & & & & $\mathrm{x}$ & \\
\hline New Media Literate/Digital Knowledge and Experience & $\mathrm{x}$ & $\mathrm{x}$ & & & $\mathrm{x}$ & $\mathrm{x}$ & \\
\hline Online Skills & $\mathrm{x}$ & & & & $\mathrm{x}$ & & $\mathrm{x}$ \\
\hline Photography & $\mathrm{x}$ & & & & & & \\
\hline Programming & $\mathrm{x}$ & & & & & & \\
\hline SEO & & $\mathrm{x}$ & & & & $\mathrm{x}$ & \\
\hline Social Media & $\mathrm{x}$ & $\mathrm{x}$ & $\mathrm{x}$ & & & $\mathrm{x}$ & \\
\hline Video Recording and Production Skills & $\mathrm{x}$ & $\mathrm{x}$ & $\mathrm{x}$ & & & $\mathrm{x}$ & \\
\hline
\end{tabular}


Table 4 - Continued

\begin{tabular}{|c|c|c|c|c|c|c|c|}
\hline \multirow{2}{*}{$\begin{array}{l}\text { Competencies and Skills Needed } \\
\text { Skill and Competency Theme }\end{array}$} & \multirow[t]{2}{*}{ General } & \multirow[t]{2}{*}{ Today } & \multirow[t]{2}{*}{ Future } & \multicolumn{4}{|c|}{ For Media Companies } \\
\hline & & & & AZM & NZZ & Ringier & Tamedia \\
\hline \multicolumn{8}{|l|}{ 2. SOCIAL AND EMOTIONAL SKILLS } \\
\hline Agility/Flexibility & & $\mathrm{x}$ & $\mathrm{x}$ & & & & $\mathrm{x}$ \\
\hline Civil Courage & & & & & & $\mathrm{x}$ & \\
\hline Conscientiousness & & $\mathrm{x}$ & & & & & \\
\hline Coping With (Time) Pressure & & $\mathrm{x}$ & & & & & \\
\hline Curiosity & & $\mathrm{x}$ & & & & $\mathrm{x}$ & \\
\hline Discussion Joy & & $\mathrm{x}$ & & & & & \\
\hline Experimentation & & $\mathrm{x}$ & $\mathrm{x}$ & & & & \\
\hline Interpersonal Skills & $\mathrm{x}$ & & & & & & \\
\hline Knowledge and Embedment Into Region & & & & $\mathrm{x}$ & & & \\
\hline Networking & & & & $\mathrm{x}$ & & & \\
\hline Open-Mindedness & & $\mathrm{x}$ & $\mathrm{x}$ & & & $\mathrm{x}$ & $\mathrm{x}$ \\
\hline Openness to Change & & $\mathrm{x}$ & & & & $\mathrm{x}$ & \\
\hline Optimism & & & & & & $\mathrm{x}$ & \\
\hline Passionate and Mission Driven & & $\mathrm{x}$ & & & & & $\mathrm{x}$ \\
\hline \multicolumn{8}{|l|}{ Reliability $^{\circ}$} \\
\hline \multicolumn{8}{|l|}{ Resilience $^{\circ}$} \\
\hline \multicolumn{8}{|l|}{ Self-reliance $^{\circ}$} \\
\hline Self-Responsibility & & & $\mathrm{x}$ & & & $\mathrm{x}$ & \\
\hline Social Competency & & & & $\mathrm{x}$ & & & \\
\hline Team Player/Team Work & & $\mathrm{x}$ & & $\mathrm{x}$ & & $\mathrm{x}$ & $\mathrm{x}$ \\
\hline
\end{tabular}




\begin{tabular}{|c|c|c|c|c|c|c|c|}
\hline \multirow{2}{*}{$\begin{array}{l}\text { Competencies and Skills Needed } \\
\text { Skill and Competency Theme }\end{array}$} & \multirow[t]{2}{*}{ General } & \multirow[t]{2}{*}{ Today } & \multirow[t]{2}{*}{ Future } & \multicolumn{4}{|c|}{ For Media Companies } \\
\hline & & & & AZM & NZZ & Ringier & Tamedia \\
\hline \multicolumn{8}{|l|}{ 3. COGNITIVE SKILLS } \\
\hline Accuracy and Precise Working Method & $\mathrm{x}$ & & & & & & \\
\hline Analytical Thinking & $\mathrm{x}$ & & & & & & \\
\hline Attraction and Introduction of New Talents & & & & $\mathrm{x}$ & & & $\mathrm{x}$ \\
\hline Change Management & & & & & & $\mathrm{x}$ & \\
\hline Connected Thinking & $\mathrm{x}$ & & & & & & \\
\hline Digital Thinking & $\mathrm{x}$ & & & & & & \\
\hline \multicolumn{8}{|l|}{ Education in Journalism ${ }^{\circ}$} \\
\hline Efficiency & & $\mathrm{x}$ & & & & & \\
\hline Expertise Regarding Subject & $\mathrm{x}$ & $\mathrm{x}$ & & $\mathrm{x}$ & & & \\
\hline General Knowledge & $\mathrm{x}$ & & & & & & \\
\hline Imagination/Understanding of Customers' Need & $\mathrm{x}$ & & $\mathrm{x}$ & & & $\mathrm{x}$ & $\mathrm{x}$ \\
\hline Internet Marketing & & & & & & $\mathrm{x}$ & \\
\hline Maintain Posture & $\mathrm{x}$ & & & & & & \\
\hline \multicolumn{8}{|l|}{ Organizational Skills $^{\circ}$} \\
\hline Project Management & $\mathrm{x}$ & & & & & & \\
\hline \multicolumn{8}{|l|}{ Quality-Conscious $^{\circ}$} \\
\hline Recognition of Patterns & $\mathrm{x}$ & & & & & & \\
\hline Reflectivity $^{\circ}$ & & $\mathrm{x}$ & & & & & \\
\hline \multicolumn{8}{|l|}{ Research Skills $^{\circ}$} \\
\hline Understanding of Potential of Media Convergence & & & & & & & $\mathrm{x}$ \\
\hline Willingness and Skill to Learn & $\mathrm{x}$ & & & & & & \\
\hline Willingness to be Measured & $\mathrm{x}$ & & & & & & \\
\hline
\end{tabular}


Table 4 - Continued

\begin{tabular}{|c|c|c|c|c|c|c|c|}
\hline \multirow{2}{*}{$\begin{array}{l}\text { Competencies and Skills Needed } \\
\text { Skill and Competency Theme }\end{array}$} & \multirow[t]{2}{*}{ General } & \multirow[t]{2}{*}{ Today } & \multirow[t]{2}{*}{ Future } & \multicolumn{4}{|c|}{ For Media Companies } \\
\hline & & & & AZM & NZZ & Ringier & Tamedia \\
\hline
\end{tabular}

4. WRITING AND LINGUISTIC SKILLS

Ability to Explain Complex Interrelationships in a Simple Way $\quad \mathrm{x}$

Delivery of Background Information $\quad$ x

Dialect $^{\circ}$

Foreign Languages ${ }^{\circ}$

Investigational Skills

Journalistic Interaction With Users

Linguistic and Writing Skills

X

Multimedia \Storytelling

Narrative Skills/Storytelling

Online Journalism

x

Ontology of journalism

Quality Awareness ${ }^{\circ}$

Sense for Stories

Tabloid Journalism 
Table 4 - Continued

\begin{tabular}{|c|c|c|c|c|c|c|c|}
\hline \multirow{2}{*}{$\begin{array}{l}\text { Competencies and Skills Needed } \\
\text { Skill and Competency Theme }\end{array}$} & \multirow[t]{2}{*}{ General } & \multirow[t]{2}{*}{ Today } & \multirow[t]{2}{*}{ Future } & \multicolumn{4}{|c|}{ For Media Companies } \\
\hline & & & & AZM & NZZ & Ringier & Tamedia \\
\hline \multicolumn{8}{|c|}{ 5. PUBLISHING AND PRODUCTION SKILLS } \\
\hline Business Acumen & $\mathrm{x}$ & $\mathrm{x}$ & $\mathrm{x}$ & & & & $\mathrm{x}$ \\
\hline Convergent Working & & $\mathrm{x}$ & & & & & $\mathrm{x}$ \\
\hline Highly Paid Niche Products & & & $\mathrm{x}$ & & & & \\
\hline Mastering of Production Tools & $\mathrm{x}$ & & & & & $\mathrm{x}$ & \\
\hline Measurability of Stories/Big Data & & & $\mathrm{x}$ & & & & \\
\hline Presentation of a Story & & & $\mathrm{x}$ & & & & \\
\hline \multicolumn{8}{|l|}{ Print $^{\circ}$} \\
\hline Production for Different Channels & & $\mathrm{x}$ & $\mathrm{x}$ & $\mathrm{x}$ & & & $\mathrm{x}$ \\
\hline \multicolumn{8}{|c|}{ Professional Experience in Production/Writing ${ }^{\circ}$} \\
\hline \multicolumn{8}{|l|}{ Radio Experience ${ }^{\circ}$} \\
\hline Sense for Right Channel & $\mathrm{x}$ & & & & & & \\
\hline \multicolumn{8}{|l|}{ Shortness $^{\circ}$} \\
\hline Specialization & $\mathrm{x}$ & & & & & & \\
\hline Speed & $\mathrm{x}$ & $\mathrm{x}$ & $\mathrm{x}$ & & & & \\
\hline
\end{tabular}


Table 4 - Continued

\begin{tabular}{|c|c|c|c|c|c|c|c|}
\hline \multirow{2}{*}{$\begin{array}{l}\text { Competencies and Skills Needed } \\
\text { Skill and Competency Theme }\end{array}$} & \multirow{2}{*}{ General } & \multirow{2}{*}{ Today } & \multirow[t]{2}{*}{ Future } & \multicolumn{4}{|c|}{ For Media Companies } \\
\hline & & & & AZM & NZZ & Ringier & Tamedia \\
\hline \multicolumn{8}{|l|}{ 6. INNOVATION AND CREATIVITY } \\
\hline Creativity & & $\mathrm{x}$ & & & & & $\mathrm{x}$ \\
\hline Innovation & $\mathrm{x}$ & & & & & $\mathrm{x}$ & \\
\hline \multicolumn{8}{|l|}{ 7. LEADERSHIP AND MANAGEMENT } \\
\hline Leadership Skills and Experience & $\mathrm{x}$ & & & & & & \\
\hline Resource Management & $\mathrm{x}$ & & $\mathrm{x}$ & & & & \\
\hline Team Motivation & $\mathrm{x}$ & & & & & & \\
\hline Understanding of Convergence & $\mathrm{x}$ & & & & & & \\
\hline Understanding of Media Measurability & $\mathrm{x}$ & & & & & & \\
\hline Understanding of Online & $\mathrm{x}$ & & & & & & \\
\hline
\end{tabular}

Note: ${ }^{\circ}=$ Additional skills mentioned in Table 6 
I expected that my interview partners would be able to distinguish between experiences, perceptions, and expectations with regards to competencies and skill needed for media professionals in a convergent environment today and in the future. The results did not support my assumption that there are remarkable differences between competencies and skill-sets of today and those expected in the future nor did the study yield any noteworthy results regarding my assumption. Nevertheless, I have received insightful individual statements about required skill-sets which I will introduce in the following section.

\section{Competency Clusters Needed for Convergent Work Today}

Technical competencies which are needed today are named by media executive, participant 10, as follows: "Video, SEO, Social up and down, there is story telling; those are the things that matter nowadays," and participant 9 adds: "training in video."

Striking is the multiple mention of emotional skills as 'passionate and mission driven,' passion for the profession of a journalist and for 'curiosity,' one of the main characteristics of journalism, as participant 9 explains: "And then there are the classical concepts, curiosity, of course, and so on, in order to acquire soft skills. Curiosity, of course, is very important because only curious people will develop curiosity on any channel." Additionally, a sense of duty, 'conscientiousness' and an 'open mindset' and ultimately 'flexibility' was named. Participant 6 summarizes the current situation for many journalists:

We are coming back to the issue of flexibility. After all, whatever was sufficient six, seven years ago will not do today. Some have learned this the hard way. I can say, perhaps there are some who became casualties on this road, or people who might not quite make it - who might be a bit overwhelmed. We had a few of those, but only a very few. Actually, I am surprised how flexible professional people are. But that has to be the case in other industries, as well. 
A 'joy to discuss,' 'experimentation,' 'interdisciplinary work' and 'working in teams,' and 'stress resistance' are other skills and competencies required by journalists today. Participant 8 goes so far as to say: "But there is a need for a new breed of individuals" and explains: "in the sense of more of a team player, more open, even more flexible, even more resilient. Yes, that is the new quality required in addition."

Participant 6 shares his personal experience with the higher frequency of work of journalists today:

Yes, it has become more stressful because the output has become bigger. Perhaps because one has to cover many more channels. I am sure that is the case. The job has become much more stressful compared to the past. Well, we have reached an age when one can talk about the good old romantic days. As a reporter, I come from a time when one could sleep in and in the afternoon one could slowly start to think about what kind of story I could do for the next morning. And then, late in the afternoon, you would reach for the phone and make two, three calls, and then you would write something for print. And that was it. That is different today. If someone is on the road with the national [soccer] team, he will be challenged. At seven in the morning he will get his first call. The evening before he already has to make a plan as to what he will do for online in the morning, what is Blick am Abend bringing who has their editorial deadline at 12 . What kind of a story has he envisioned for that? What kind of a story does he quasi still have in his back hand which he could play online? In summary, the work load has become much heavier. In the end, it still is the job of a journalist, a journalistic craft. That has not changed. But the work load has become massively more.

'Openness for change' is another competency that is required of media

professionals today. "Well, I would put it this way," participant 6 explains:

The madness shock of the digital disruption, I believe, by now has drawn even the last of the Mohicans out of his cover. And it has made clear to everyone that we have to move. Perhaps like others in other industries, as well. Journalists who often have to deal with new developments do not exactly excel as the great first movers when it comes to displaying new qualities. To some extent they have been quite traditional stay-at-homes. And this pressure, this outward pressure, has brought about some mobility - mental mobility and the readiness to say: "Okay, we have to change; we have to ..." On the other hand, that does not mean that the job has become something completely different. It just has become even more challenging. 
Among skills required currently were named, "We also must become more efficient," participant 12 postulates. Participant 6 indicates a very detailed expertise of the respective editorial genre of journalists and editors today: "He must want to know everything about his field of sports."

Media executive, participant 8, adds to writing and linguistic skills needed today: "the ability to explain in simple words something that is complex and to furnish background information." However, today a more generalist journalistic approach is required. Participant 6 adds: "I recently came across someone whose editorial office has had doping as a topic for the past 20 years" and relativized: "That is an exception in today's landscape that there is someone who is dealing with the same subject for decades, that someone has a tiny team and is researching in this field in this incredible depth. Today it is more the generalist who is in demand."

Additionally, he introduced another aspect of publishing and production skill needed today:

On top of that, there is an incredible speed in this job. Some maddening, breathtaking speed has come into this job. And with it comes a non-stop presence which is demanded which then, of course, one has to manage with duty rosters. But it is this speed which has changed the job in a tremendous way.

Participant 8 introduces a completely new aspect of publishing and production skills, namely a certain 'business acumen':

In the old days, journalists did not at all pay attention to the question as to how a media corporation was making money, because money was just pouring in. Today it is important that journalists also know where the money is coming from, how a media corporation is financing itself. But they must not be guided by this alone. It still requires the classical journalistic rules. But that is something which clearly has changed. When I was a journalist I did not care whatsoever where the money came from. I didn't understand that either. And that, of course, is an additional leadership responsibility, to keep to a much greater degree an eye on the budget. 


\section{Competency Clusters Needed for Convergent Work in the Future}

The difficulty my interview partners had with naming skills and competences needed by journalists in the future is well described by participant 8: "It is extremely difficult to predict the future. We don't know what will be in five years. We don't know, for example, whether there still will be printed daily newspapers in five years." Participant 1 comments about the future as follows: “After all, we don't know what the future will hold. Judging by just the last few years we can assume that journalism and the way we do journalism will continue to change."

However, there is clarity about required technical competencies in ,Social media“ and ,video recording and production skills,' about emotional skills ,flexibility and ,open-mindedness.' Participant 1 comments with this regard: "It is necessary that journalists bring to the table an openness and that they are willing to be part of this development ... And we must continue to think in terms of innovation, we must be willing to take the issue into the future." The need for a certain sense of 'experimentation' without the fear of failure is what participant 11 considers an essential emotional skill in the future: "And then there must be the courage to try something new. And if it goes wrong, well, then it goes wrong."

Clarity also prevailed in terms of 'consumer orientation and targeting,' a cognitive skill set: "I expect that in the journalism of the future there will be an even greater focus on the target group — and that one will know even more precisely for whom one is writing a story. And that with the conviction," participant 17 explains, "that the target group no longer comes to the media, but the media must come to the people, if one is consistent in continuing to think along this line. This means, I must know, if I have a political story, 
how can I reach the 18 to 25 -year-old ones, how do I reach the 25 to 45 -year-old ones and how do I reach women and how men." The ability to put oneself in the position of the target audience and the challenge of properly addressing users is depicted vividly by participant 20: "Where are they? What do they want? It is not relevant that I say: 'I will write 30,000 characters about Syria and if you don't want to read 30,000 characters about Syria, so what? Tough luck," and adds: "We must make sure that we prepare the information, if possible, in such a way, quasi-like democratic whole-grain bread, that the people want to 'eat' this information. We are not supposed to write or broadcast this information the way it pleases us." She concludes that the balance of power has turned and that this should be considered in the future. "It is the user who has the upper hand."

The reader also is in the driver's seat when it comes to writing and linguistic skills. The interview partners for my research expect an increasing journalistic interaction with users: "I believe that is a big topic. We are still completely neglecting it. And journalists will have to change in regard to this," participant 2 carries out and continues to explain: "I believe the entire exploitation, i.e. the article is not done if one has finished writing it. The story rather continues to live because there is a feedback, and I as an editor have to deal with that and thus will become additional feedback to further develop the subject." At the same time, excellent writing skills are expected for the future. "I believe we still have do know even better what we actually are doing. This refers to our role as journalists. We have to be clear about this. We have to be really good technically. For if it is not good - the competition is just one click away," admonishes participant 17. Media professional, participant 9, goes one step further with regards to their own ethos as journalists and the nature of journalistic responsibility: 
I am actually disenchanted again because I think no specifically new qualifications and things are needed. On the contrary, I believe, we have to reveal the nucleus of the journalistic ontology. ... We must have or develop an occupational image which then will remind us of where we are coming from historically. We are dedicated to clarification and reconnoitering, we are mediators between the public and those in management responsibility in the country, i.e. mediators between state and citizen. All these things. That, after all, is quite important. And he or she who is capable of being in this function, can do it on no matter what channel. He who has no selfconcept will eventually really contribute to a culturally pessimistic apocalypse.

The interviewees were most clearly able to answer the question as to which publishing and production skills they expect and perceive as needed in the future. Among 'business acumen,' the production of 'highly paid niche products,' the knowledge about 'measurability of stories,' 'presentation of stories,' the 'production for different channels' and 'speed' were named by the participants of the research project. Media executive, participant 10, explains as follows: "Right now, the big issue for us is - and there we are still in the very beginning - the downstream competency, i.e. big data. We are talking about the usefulness of the measurability. It will become more and more important.” This measurability in the interviewee's media corporation goes as far as this:

We have experts in the area of social [media] and SEO who inform the editors, i.e. the editorial office in the morning, which subjects are sought after anywhere in the world in the Internet so that the editorial offices can say, okay, we will include this as well. We are in the process of preparing an article about this subject. This is farreaching. We are turning this around completely. While in the past the reader actually searched for certain content and he or she went to the newspaper kiosk to buy it. Today the content searches for the reader. And that is the complete reversal of everything. Yes. And for that you will need data. That will become the big, big challenge and how they will be able to handle distributed content. But in addition to that, not more can be said about that. Therefore, everything will remain terribly exciting. The question will be: How sustainable will everything be in the end?

Participant 17 confirms this tendency and the fact that a new skill-set will be required by journalists and editors in dealing with 'Big Data': "First, because there are the data which will help us. We want to know everything exactly. We not only want to 
know any longer whether or not the story worked well, but with whom it worked well and at what time did it work best?"

"Eventually," participant 11 summarizes, "we all lack the know-how. And in regard to this, the very young ones, the self-made people or the bloggers who do it themselves, they often know much more." She believes that it is a question of corporate culture, how an organization manages resources, and whether an organization will be ready in the future to dismantle hierarchies in favor of know-how:

There still is another skill which, I am convinced, will also be needed today and in the future. And that, of course, is a matter of culture which has to come from the top. Old hierarchies and networks will no longer work. Experience will no longer be a matter of long years of service. There will then be people who might come along with their orange-colored hair and purple lip stick, who might not at all fit into the company, but about whom one could say, we should actually make him or her boss. And then the old, dignified gentlemen in their suits and ties should actually learn from them. And that, of course, is crazy. It would be difficult for both sides.

\section{Competency Clusters Needed for Institutional Participants}

AZ Medien's product portfolio focuses on regional anchoring and regional embedment. Therefore, it is not surprising that the interviewees of this media corporation put an emphasis on a particularly emotional competency. Media executive, participant 3, explains: "That is an asset which a journalist can have if he or she grew up here and if he or she knows the region, and if he or she wants to work in and for the region." He continues: "It is much easier to find a domestic or political editor. I can coax him or her away from anywhere. They all find it terribly sexy if they can work in the federal government building. That is easy. But it is much more difficult to look for an editor for Fricktal or Zurzach or Brugg [small provinces]." Since the regional anchorage is the USP of the company, "a prospective journalist has either grown up in this area and then lives somewhere or has grown up somewhere else, but is interested in this region and then 
moves there." Participant 4 adds to the regional embedment and regional knowledge the concept of "journalistic networking."

For the NZZ Mediengruppe technical, writing and linguistic skills are seen as having top priority among all of the competencies. Media executive, participant 14, describes the required competencies as follows: "This rather is basic knowledge which puts everyone into a position of being a part of this rhythm, this digital system in which we work and become a part of the way we produce stories and become a part of this value-adding which we do." Participant 13 adds: "We are still talking about the same high journalistic qualities as ever" and "the same high technical skills as ever."

Ringier, the media corporation with a long tabloid history and a diverse digital product portfolio, focuses on technical skills: "Our entire environment is set up digitally in such a strong way that this part does not have to come on paper any longer ... We have an entirely new generation, a strong generation of tech-affine, multimedia journalists," participant 7 relates. In this, he is complemented by media executive, participant 10 , as follows: "And this leads to the fact that we now somehow have ended up having 28 individuals working in video. That is gigantic." Study participants of Ringier also mention social competencies like 'curiosity,' 'open-mindedness,' 'openness to change,' 'optimism,' 'self-responsibility,' and 'team work' as needed for their organization. Participant 8 adds, “And I think civil courage, for example, is something journalists also have to bring to the table." Additional tabloid-specific competencies are described by participant 6: "Journalists have to have guts. Moreover, they must enjoy exposing themselves. They often make themselves more vulnerable than others. But that is the core business of tabloid journalism." Then he refers to additional tabloid-specific 
competencies. "Well, then we have to talk about Blick. It is all about tabloid journalism. Tabloid journalism has its own peculiarities, and that requires specific competencies. That is for sure."

Technical competencies, 'data journalism and analysis' and 'online skills' also play an important role at Tamedia. Participant 18 adds 'gamification' as an additional technical skill. Customer orientation and the recognition of the potential of convergent working are other skills identified by interview participants from Tamedia. Participant 17 elaborates:

One must understand that the customer really is king. This means, the customer states how he or she would like to have it. It is not the journalist who says what he or she would have to do. This may sound a bit trivial. But, well, it has to be wrapped in such a way that the customer wants it. ... But if I see a story in print ... 15,000 characters - I somehow think, who exactly is to read this. And if then I want to sell this story online, what actually will happen precisely? Because there is no slide show to go with it. There are no graphics, no sideline interview. It actually is a chunk darn difficult to digest.

The potential of a convergent way of working for developing a story from the original idea to the final end product is, according to participant 15 , not understood by many journalists at Tamedia. "What sometimes surprises me," she explains, "is the brilliant idea that one now has a chance of also producing for online, that one can produce a total work of art. But probably too few are actually doing this." Referring to a new opportunity, she continues. "One can work up everything nicely oneself—with pictures. And it becomes exactly the way one wants it. But I believe many people do not take advantage of this opportunity. Or it is not that important to them. But it would be important, I think.” 


\section{Excursus: Leadership and Management Competencies}

When I asked the study participants about competencies and skills required for a convergent environment in general, a need for leadership and management competencies were mentioned. When I asked for current and future skills required and in particular for the media corporation they are working for, however, little emphasis was put on these skills by the interviewees. Despite that, various remarks about leadership and management challenges were mentioned during the interviews as shown in Table 4 that I am presenting in the following passage.

Participant 15 complained about missing leadership skills and leadership experience in the media industry in general. She said: "And then I believe - and that may be a dire fact of journalism in general - that [a strong leadership style] basically doesn't mean anything because at all times individuals were promoted who were good at writing. ... Perhaps they were good writers; but they were no leaders. And that holds true up to the CEOs.” Instead, she suggests, a position of leadership should be given to a person who can fill that leadership role, someone who can lead the company the best. And then she concludes: "At the end of the day the fish rots from the head down, meaning, that we nowadays have to compare ourselves with players of a totally different caliber, individuals who have a completely different understanding of management professionalism. And we come along with some home-spun matters."

The missing of another very basic leadership skill, leading by example, is testified by participant 12 :

People who want to push something have to set an example. I have to practice what I preach. You have to set an example. You have to carry the flowing flag in front of the others and communicate your cause to the others in a convincing way, giving them help and support. That is the way how we will survive a transformation. That is the 
way how corporations can hold on to a culture under these shock conditions. I believe there is a high degree of responsibility on the side of leadership.

Participant 8 explains which leadership style she would like to have for the Swiss German media industry and for a respective convergent environment: "Certainly not the typical military style of leadership. But at the same time, it is important that the leaders really have leader personalities, that they themselves radiate this serenity and security." Participant 12 intervenes and gives more details about the need for dedicated leadership: "I think it is difficult. ... I am noticing that in our environment, in the way how I lead and how other teams are being lead. That is partially diametrically opposed. On the other hand, in this rather creative environment something different is called for - as opposed to [leading in the] Controlling [department].” He further explains that different personalities with different leadership styles are wanted and continues: "It is rather difficult to learn leadership. You got it or you don't. Perhaps there is something in between, logically. But in the first place it is competency which is called for. And if someone is not so strong in leadership, he or she at least has competency. And that is good, too." He summarizes: "Nowadays an extremely high level of leadership is called for. I am convinced that we need more leaders than managers."

The same participant introduces another leadership topic and also discusses the importance of a clear vision and strategy and its communication towards the entire staff. "I believe that this also will give security to the staff ... if someone really has thought it all through" and that things are not going the way participant 20 had experienced: "And then they go to America, and when they come back, everybody has to tweet. And if you ask, why?, she counters, you remain without an answer." 
A common problem in media corporations, a certain silo thinking, is addressed by participant 8: "To me it seems that especially for a media corporation one thing is extremely important: There always has been this problem of a trench between management and editorial office. And this trench has not become any smaller - it probably has not become bigger either. But it still is there. But today it is more harmful than ever." She goes on and explains how important it is in this current crisis situation in the media industry, that both sides, management and the editorial side, understand each other and "that they at least speak the same or a similar language, and that they really, really exchange their know-how - knowing that they have different roles." She adds that often she has observed that there, nevertheless, has to be a Chinese Wall between the editorial office and management, or the editorial office and marketing so that credibility the most important asset of a media corporation - is not being destroyed. This important leadership competency is described by participant 8 as having the ability to build bridges and dissolve silo thinking:

The mix of a company, the mix of its employees keeps changing. Suddenly there are more tech people, IT people who have different ideas. They live in a different world. You have to bring them together with the legacy community of the company. And you have to create good-will on both sides. You will have to build bridges so that the new diversity will find its way to the other side and each side will not live next to each other in - so to speak - isolated ghettos.

Participant 11 also refers to the demand of the leadership competency required for dissolving silo thinking: "There still are too many who think in their own little boxes. And that we certainly have to change. It is a huge problem. And I believe that is the case in all media corporations." 
Media manager, participant 8 , explains her point of view why it is important to ensure an overall positive atmosphere among the employees, to live a participative leadership style and to mark physical presence:

It is really critical that we create a general mood in which the staff has the feeling that they [the leaders] really try and lead. That is very important - with the participative style of leadership, as well. The employee must know that the boss is leading and that he or she is present. Presence is something very important. In my opinion it partially is underestimated because many feel they are, after all, available at all times via messaging, WhatsApp, Email and whatever, Facebook, of course. But physical presence cannot be substituted by anything.

Furthermore, she expects from media managers the leadership skill of communication, that is to say: "to inform people much more, to be as transparent as possible in regard to what is happening, what is being planned, to be more transparent than in the old days." Media executive, participant 14, agrees with these considerations as follows: "And the people must be able to understand why we do what we do, why it is important and why it is important for us as a for-profit company," and adds: "and then there must be some continuous communication from the management side."

Participant 14 also attributes another important role to media managers which is the role of a change agent and a leader of transformation processes: "Besides, that is a central leadership responsibility of a media management, to also take away any fear of change from the employees and to motivate them to try something new - and for them to use competencies which they, so far, had not been able to use, and to discover in themselves new competencies."

The capability to motivate staff, according to the individuals interviewed in this study, also belongs to the leadership skills required. Study participant 8 puts a special emphasis on the motivation of staff. "To me it seems that especially today motivation is 
important, but at the same time giving your team some assurance, to encourage them to tolerate insecurity." She also mentions the importance of showing appreciation: "How do I show appreciation [to my staff]? Do I do some incentive program, for example? Why not?" Participant 12 goes as far as to demand that the competency regarding the motivation of one's staff should be one of the basic elements of any leadership philosophy of superiors.

The following statement of participant 16 leads to another important leadership qualification, the competency of resource management:

When it comes to this entire transformation process which is happening in a team within a company, we have to make sure that it is not just one part of the people who carry this convergence [process] who then might have more work to do, take over more responsibility and the rest will cop out. As a result, those who actually have good intentions and do the right thing will end up being overwhelmed by the extra work load.

Participant 8 joins in: "but to have a fine antenna, too, as to where people are overwhelmed. You will end up having human dramas of burn-outs which one should have seen coming earlier on." And then she elaborates on the topic of resource management as follows:

I continue to think along that line and come to the issue of work sharing, for example between the editor-in-chief and his deputy. I am talking in abstract terms, not about our team. The editor-in-chief always had an important role to play, in a way as the secretary of state, as someone who is selling his products to the outside world. He also is playing the role as someone who stands up for his editorial staff if they will get under pressure. An editor-in-chief must have precisely these human and social qualities. He or she must be able to better motivate and therefore protect his or her team. And I could imagine that all the other organizational skills are being contributed by the deputy editor-in-chief because not everybody will have all the skills.

This very important leadership component, a proper resource management, is required in particularly in convergent environments. "There must be some sort of 
convergence justice," participant 16 continues and suggests: "I would do that by giving guidelines and accompany it with some kind of a measuring system because we are talking about digital processes. So, we are not only talking about guidelines necessarily, but eventually some type of checking so we will find out where things are not working correctly."

This way of leading a team which works convergent also proves a settled understanding of the measurability of media output in a multimedia environment. Therefore, the requirement for future leadership, an understanding of convergent working processes and people involved in convergence seamlessly, follows: "What we need is an understanding of the people who are responsible who work in a convergent team. And both of these things are necessary," participant 17 adds. Media manager, participant 11 agrees and stresses the importance of great leadership skills: "That is why I am convinced that convergence actually can be done from the top only, because that is where the competency lies to get rid of whatever stands in the way."

Participant 20 sums up her perception of the requirement of understanding convergent working processes and staff involved by saying:

What I really wish for are leaders who dare to do things themselves. They must not know it down to the last detail, but I hear so many people saying: "Well, then you will quickly do some video," but they themselves don't even know how to press the recording button. And that annoys me. I believe when it comes to convergence, there also must be some interface skills between the boss and his or her staff - not only between the individual who covers a story for radio and the print journalist with whom he or she has to work. The boss has to be in on it, too. And that means that the self-concept of the boss naturally will have to change as well. And that is a gigantic problem. It really is a problem because the fish, indeed, rots from its head first. That is why I keep saying: "Guys, convergence is happening despite of your bosses, not because of them." 


\section{Quantitative Content Analysis Job Advertisements}

Wenger \& Owens (2012) state "employment advertisements are a genre of organizational communication that can provide insight into the characteristics of a company and its employees. Job postings can be considered representations of occupations; their language providing rich detail for researchers" (p. 11). In order to compare experiences, perceptions, and expectations of media managers with regards to competencies and skills needed by media professionals in a convergent environment in the German-speaking part of Switzerland today, with the recruiting reality, I performed a quantitative content analysis on job postings. During a period of seven months, from June 1 to December 31, 2016, I collected journalism-related job advertisements published on Swiss German online job platforms. All respective job advertisements, with a total number of 150, whereof 83 were published by media companies and 67 by non-media companies, were saved as pdf files. In order to analyze job requirements, all job ads were entered into Dedoose, a web-based qualitative data analysis software. The job postings were coded for job title, kind of job posting institution, job position, type of media and competencies and skills required. The biggest part of job advertisements was posted in order to search for editors/journalists (120), followed by the search for 23 interns, three for editorial staff and five for managers (editor-in-chief). As displayed in Table 5, 31\% of all job advertisements contained the search for journalists and editors for online and mobile media, $18 \%$ for print jobs, followed by each $11 \%$ for print and online combined jobs, radio jobs and TV/video jobs, which equates to a proportion of $30 \%$ of convergent jobs where different types of mass media are managed in one job. 
Table 5

Job Advertisements in Swiss German Online Media by Type of Media

\begin{tabular}{lcc}
\hline Type of Media & Number & \% of all \\
\hline Print & 27 & 18 \\
Print + Online* & 16 & 11 \\
Online/Mobile & 46 & 31 \\
Online + Social Media* & 4 & 3 \\
Social Media & 1 & 1 \\
Print + Online + Social Media* & 6 & 4 \\
Radio & 17 & 11 \\
TV/Video & 16 & 11 \\
Digital Media (Radio + TV/Video)* & 1 & 1 \\
Digital Media + Online* & 1 & 1 \\
Multimedia* & 15 & 100 \\
\hline Total & 150 & \\
\hline
\end{tabular}

Note: $*=$ Convergent Media Type

All required skills and competencies listed in job ads were gathered and amalgamated into 106 codes, which were regrouped into the following seven themes:

1. technical skills,

2. social and emotional skills,

3. cognitive skills,

4. writing and linguistic skills,

5. publishing and production skills,

6. innovation and creativity, and

7. leadership and management. 
Skills per theme named later were counted and weighted based on the position ratio in percent. For each theme, only the six most frequently mentioned skills were mapped in Table 6. 
Table 6

Most Frequently Required Skills and Competencies by Position in Counts and Weighted Based on the Position Ratio in \%

\begin{tabular}{|c|c|c|c|c|c|c|c|c|}
\hline \multirow{2}{*}{$\begin{array}{l}\text { Position } \\
\text { Skill and Competency Theme }\end{array}$} & \multicolumn{2}{|c|}{ Intern } & \multicolumn{2}{|c|}{ Collaborator } & \multicolumn{2}{|c|}{ Editor/Journalist } & \multicolumn{2}{|c|}{ Manager } \\
\hline & Count & $\%$ & Count & $\%$ & Count & $\%$ & Count & $\%$ \\
\hline 1. TECHNICAL SKILLS & 13 & 31.8 & 0 & 0.0 & 131 & 58.9 & 1 & 9.4 \\
\hline Social Media & 2 & & 0 & & 28 & & 0 & \\
\hline Image editing and illustration systems & 0 & & 0 & & 17 & & 0 & \\
\hline New media literate/digital knowledge & 7 & & 0 & & 17 & & 0 & \\
\hline CMS (Content Management System) & 2 & & 0 & & 15 & & 0 & \\
\hline Multimedia skills & 0 & & 0 & & 13 & & 0 & \\
\hline Video recording skills & 0 & & 0 & & 10 & & 0 & \\
\hline 2. SOCIAL AND EMOTIONAL SKILLS & 56 & 25.8 & 3 & 10.6 & 270 & 22.9 & 23 & 40.7 \\
\hline Team player/Team work & 9 & & 1 & & 43 & & 2 & \\
\hline Knowledge and embedment into region & 8 & & 1 & & 26 & & 4 & \\
\hline Self-reliance & 3 & & 0 & & 24 & & 2 & \\
\hline Resilience & 5 & & 0 & & 21 & & 1 & \\
\hline Flexibility & 2 & & 0 & & 18 & & 1 & \\
\hline Reliability & 1 & & 0 & & 17 & & 2 & \\
\hline 3. COGNITIVE SKILLS & 24 & 31.4 & 1 & 10.0 & 118 & 28.4 & 6 & 30.1 \\
\hline Education in journalism & 6 & & 0 & & 30 & & 1 & \\
\hline Precise working method & 2 & & 0 & & 21 & & 2 & \\
\hline General knowledge & 5 & & 1 & & 19 & & 0 & \\
\hline Organizational skills & 2 & & 0 & & 9 & & 1 & \\
\hline Research skills & 2 & & 0 & & 6 & & 0 & \\
\hline Quality-conscious & 0 & & 0 & & 5 & & 0 & \\
\hline
\end{tabular}


Table 6-Continued

\begin{tabular}{|c|c|c|c|c|c|c|c|c|}
\hline \multirow{2}{*}{$\begin{array}{l}\text { Position } \\
\text { Skill and Competency Theme }\end{array}$} & \multicolumn{2}{|c|}{ Intern } & \multicolumn{2}{|c|}{ Collaborator } & \multicolumn{2}{|c|}{ Editor/Journalist } & \multicolumn{2}{|c|}{ Manager } \\
\hline & Count & $\%$ & Count & $\%$ & Count & $\%$ & Count & $\%$ \\
\hline 4. WRITING AND LINGUISTIC SKILLS & 43 & 35.0 & 2 & 17.9 & 204 & 29.2 & 9 & 17.9 \\
\hline Linguistic and writing skills & 15 & & 1 & & 68 & & 2 & \\
\hline Foreign languages & 7 & & 1 & & 57 & & 1 & \\
\hline Online journalism & 8 & & 0 & & 29 & & 2 & \\
\hline Storytelling & 3 & & 0 & & 18 & & 2 & \\
\hline Sense for stories & 2 & & 0 & & 13 & & 2 & \\
\hline Dialect & 5 & & 0 & & 10 & & 0 & \\
\hline 5. PUBLISHING AND PRODUCTION SKILLS & 19 & 28.2 & 1 & 11.4 & 96 & 26.2 & 6 & 34.2 \\
\hline Professional experience in production/writing & 16 & & 1 & & 71 & & 5 & \\
\hline Speed & 2 & & 0 & & 15 & & 1 & \\
\hline Radio experience & 0 & & 0 & & 9 & & 0 & \\
\hline Print & 1 & & 0 & & 1 & & 0 & \\
\hline 6. INNOVATION AND CREATIVITY & 5 & 30.6 & 1 & 46.9 & 20 & 22.5 & 0 & 0.0 \\
\hline Creativity & 5 & & 1 & & 19 & & 0 & \\
\hline Innovation & 0 & & 0 & & 1 & & 0 & \\
\hline 7. LEADERSHIP AND MANAGEMENT & 0 & 0.0 & 0 & 0.0 & 0 & 0.0 & 2 & 100.0 \\
\hline Leadership skills and experience & 0 & & 0 & & 0 & & 1 & \\
\hline Team motivation & 0 & & 0 & & 0 & & 1 & \\
\hline
\end{tabular}


Questions regarding the validity of the required competencies and skills in the examined job advertisements arose here immediately. According to the executed content analysis, technical competencies are requested mainly of editors and journalists $(58.9 \%)$ and of interns (31.8), whereas social and emotional skills are expected of media managers (40.7\%) and interns (25.8\%) and cognitive skills mainly of interns (31.4\%) and managers $(30.1 \%)$. Writing and linguistic skills are requested of interns $(35.0 \%)$ followed by editors/journalists (29.2\%), and publishing and productions skills are requested first and foremost of managers $(34.2 \%)$ and interns $(28.2 \%)$. The fact that descriptions in job ads often are an expression of wishful thinking and barely ever seem to be consistent with reality, is also evident from the expectation with regards to innovation and creativity. In most cases employees whose jobs per se are characterized by little room for maneuvering are expected to have skills in innovation and creativity (46.9\%) followed by interns (30.6\%) while managers can neglect these skills completely. Finally, leadership skills are attributed to media managers only.

Since the analysis of competencies/skills per position related to the hierarchy level did not lead to meaningful results, all seven skills and competency themes were weighted in another analysis round which was based on the media type ratio (see Table 7). 


\section{Table 7}

Required Skills and Competencies by Skill and Competency Theme Weighted Based on the Media Type Ratio in \%

\begin{tabular}{|c|c|c|c|c|c|c|c|}
\hline $\begin{array}{l}\text { Skills and Competency Theme } \\
\text { Type of Media }\end{array}$ & 01 & 02 & 03 & 04 & 05 & 06 & 07 \\
\hline Print & 6.3 & 11.9 & 8.1 & 5.6 & 7.6 & 5.8 & 0 \\
\hline Print + Online* & 4.1 & 11.0 & 11.9 & 6.7 & 13.6 & 4.9 & 0 \\
\hline Online/Mobile & 8.3 & 6.9 & 9.9 & 5.3 & 7.5 & 22.3 & 100 \\
\hline Online + Social Media $*$ & 14.2 & 10.5 & 9.5 & 10.9 & 5.7 & 19.5 & 0 \\
\hline Social Media & 24.4 & 0 & 0 & 8.0 & 0 & 0 & 0 \\
\hline Print + Online + Social Media $*$ & 9.5 & 8.3 & 6.3 & 8.0 & 11.5 & 13.0 & 0 \\
\hline Radio & 1.9 & 9.2 & 9.5 & 6.9 & 8.8 & 4.6 & 0 \\
\hline TV/Video & 8.1 & 11.5 & 9.5 & 15.9 & 11.5 & 0 & 0 \\
\hline Digital Media (Radio + TV/Video)* & 12.2 & 6.9 & 9.5 & 8.2 & 7.2 & 19.5 & 0 \\
\hline Digital Media + Online* & 0 & 15.3 & 19.0 & 15.9 & 11.5 & 0 & 0 \\
\hline Multimedia* & 10.9 & 8.4 & 7.0 & 8.8 & 15.3 & 10.4 & 0 \\
\hline Total Convergent Media & 50.9 & 60.4 & 63.2 & 58.5 & 64.8 & 67.3 & 0 \\
\hline
\end{tabular}

Note: 01 = Technical Competencies, $02=$ Emotional Skills, 03 = Cognitive Skills, $04=$ Writing and Linguistic Skills, $05=$ Publishing and Production Skills, 06 = Innovation and Creativity, 07 = Leadership and Management; * = Convergent Media Type 
Table 1 shows that technical skills (social media knowledge, image editing and illustration systems, digital knowledge, CMS etc.) are mainly required in the area of social media production $(24.4 \%)$ and in convergent environments where online and social media production is combined (14.2\%), respectively digital media (12.2\%) and multimedia (10.9\%). Social and emotional skills, primarily the ability to be a team player and to practice teamwork, are also associated with convergent media production where digital media and online are joined together (15.3\%). With a rate of $19.0 \%$ the same convergent genre, digital media and online production combined, is related to cognitive skills (education in journalism, precise working methods, general knowledge). Writing and linguistic skills (linguistic and writing skills, foreign languages, online journalism) are mainly required of producers for non-convergent TV/video production and for digital media combined with online (each 15.9\%). According to the online job advertisements analyzed, publishing and production skills are needed for convergent multimedia production $(15.3 \%)$ and print combined with online production $(13.6 \%)$ whereas skills in innovation and creativity are required mainly of mobile/online producers $(22.3 \%)$. Leadership and management skills were attributed only to online/mobile media (100\%). The assignment of competencies and skills to media types, in essence, shows the complexity of skills expected of media professionals in convergent environments. In particular, social and emotional skills, cognitive skills and publishing and production skills achieve the highest values weighted per media type.

Another comparison, i.e. between the published online job advertisements and the responses of media managers with regards to experienced, perceived, and expected competencies needed for media professionals in a convergent environment brought the 
result of roughly matching skill and competency themes as displayed in Table 4 and Table 6. Only the stereotypical mention of requested social and emotional skills (e.g. team player/teamwork, self-reliance, resilience, flexibility, reliability), cognitive skills (education in journalism, precise working methods, general knowledge), writing and linguistic skills (linguistic skills, writing, foreign languages, online journalism), and publishing and production skills (professional experience in production/writing) in a huge proportion of online job advertisement raises some questions regarding the reliability of these statements in job ads. They sound a bit like platitudes. The reason for this typical choice of words in job ads like, "We are looking for the team-playing, resilient, stress resistant, super experienced media all-rounder with lots of experience in writing and research who can communicate fluently in seven languages and who, on the side, plays the complete keyboard of online journalism," maybe the fact that the wording of job ads often is passed from line managers to less experienced recruiters who do not understand the company's strategy and are not competency savvy. From my personal experience as an Executive Search consultant and HR Director, I can add that job advertisements very often use a flowerily language but do not have much in common with reality. Therefore, I would suggest to carefully evaluate the accumulation of these standardized individual skills. However, the basic tendencies in terms of the seven skill and competency themes presented can be used as a foundation for the development of skills and competencies needed in the convergent media world.

\section{Summary}

The purpose of this study is to discover competencies needed by media professionals (journalists and editors) in the convergent media environment in the 
German-speaking part of Switzerland now and in the future and to create a respective competency development model for the buildup of these competencies. The discussion about competencies needed by journalists in a convergent environment encompasses a broad framework which includes basic skills editors and journalists must have at any time (e.g. investigational skills, general knowledge, curiosity, coping with time pressure, linguistic and writing skills) and such which are more linked to convergent ways of working (social and multimedia literacy, data journalism, connected thinking, multimedia storytelling, team playing). All mentioned skills and competencies were grouped in seven competency themes:

1. technical skills,

2. social and emotional skills,

3. cognitive skills,

4. writing and linguistic skills,

5. publishing and production skills,

6. innovation and creativity, and

7. leadership and management. 


\section{CHAPTER 6}

\section{A MODEL FOR DEVELOPING COMPETENCIES}

\section{Introduction and Overview}

This chapter describes the results of the data analysis related to the development of competencies needed of media professionals in the future. Individual interviews and discussions with 20 media managers including the editors-in-chief of four major Swiss media companies in the German-speaking part of Switzerland had one central purpose. It was to gather data for the second central research question: "What are the most effective strategies for developing these competencies?"

I used 17 interview questions divided into eight categories. The fifth group of questions or assignments entailed two questions around training methods and training content in order to develop convergent competencies and skills. The most important question or request in this section was: "Please describe your experiences, perceptions and expectations with regards to the most effective and successful strategies and didactics for developing convergent competencies and skills." The sixth and seventh set of questions was asked in order to gain insights on company-specific training measures and on important training providers for the Swiss German media industry.

The presentation of the findings and the data analysis about competency development is structured in the following parts: Convergent competency development and the presentation of a competency model for convergent skill development. 


\section{Convergent Competency Development}

The following part of the study report gives an overview of experiences, perceptions and expectations with regards to the most effective and successful strategies and didactics for developing convergent competencies and skills. It also provides insights into the way how convergent competency clusters are currently developed at the institutions represented by the study participants. It shows what training and learning methods have to be included in any training strategy in order to develop convergent competencies. It finally closes with an enumeration of important players facilitating and supplying training and learning offers that will help develop convergent competencies.

When I asked media managers and executives of Swiss German media corporations about successful development strategies for convergent competencies I received answers ranging from, "When I think about what they have done in our corporation to develop those [convergent competencies] I must say, it was nothing except headhunting" (participant 5), through to "What doesn't work is, saying, now the entire editorial team will go into training on a particular day, and then we will show you everything, and you will know it all the next morning. It doesn't work that way. For the real challenge is not the technical part. Everybody can learn that. The challenge is to change the mindset" (participant 3).

\section{Competency Development Strategies and Didactics}

Participant 7 describes the difficulty of finding the right method, strategy or didactics for developing convergent competencies and skills: "In the face of all the digital aspects, we must not forget that we stand in a concrete life situation and this in a direct face-to-face situation with people." In the context of the question above, I understand 
"didactic" as a teaching method or educational style for presenting information to students. As shown in Table 8 and supported by participant 15: "Actually, they have been providing training for years - and are quite sad that somehow the people are not coming to them in a happy mindset, doing everything right away, if, by the end of the day, it is [the content learned] not being requested [by the employer]." Standardized class room training is not the most efficient training method for developing convergent skills. Media manager, participant 12, explains the importance of knowledge-based further development: "I believe in these areas you have to really know where someone stands, what he needs. Only then can one actually train someone with the right focus. Young people nowadays hold a Bachelor's degree. They grew up with this [technology]. Their verging point is a completely different one. And I believe we have to take that into consideration when it comes to training them." Participant 11 sees print journalists as the first target group for convergent training: "First of all, print people really have to learn how online works, I believe. That probably is the first step," a position also endorsed by participant 17 with the request of training for print journalists: "One actually would have to be ready to accept that these people, too, will understand how to operate in this new digital environment." Media manager, participant 8 , finally points out the importance of training measures for journalists:

Offers for the training of journalists, some forms of continuous education, of course, have been cut down massively. Actually, there was nothing anymore within the last few years. And that I consider a disastrous mistake because it is extremely important for the simple reason alone that additional skills are called for. [It is essential] that they are trained continuously - and that these competencies are being strengthened, or perhaps discovered. 


\section{Table 8}

\section{Convergent Competency Development Strategies}

\begin{tabular}{lc}
\hline Development Strategy & $\begin{array}{c}\text { Count of Times } \\
\text { Mentioned }\end{array}$ \\
\hline Learning by doing, curiosity and self-teaching & 13 \\
Gaining room for experimenting & 12 \\
External trainings/courses & 6 \\
Hiring people with respective skills & 6 \\
Mixing people with different competencies/ensuring diversity & 6 \\
Change of mind-set & 5 \\
Supportive leadership/superior & 5 \\
Formal journalism education/university education & 4 \\
Learning from peers & 4 \\
Learning by visitation & 4 \\
Internal training/courses & 3 \\
Learning by exchange & 3 \\
Future groups & 2 \\
Internal experts & 2 \\
Learning by observation & 2 \\
Motivation & 2 \\
Reward system/bonus for training completed successfully & 2 \\
Alignment with business strategy & 1 \\
Bridge building & 1 \\
Change management & 1 \\
Creativity & 1 \\
Fun & 1 \\
Gaining real chances to develop new skills & 1 \\
Information & 1 \\
Integration into everyday work & 1 \\
Learning by mistakes & 1 \\
Learning pro climate & 1 \\
Performance measurement & 1 \\
Projects & 1 \\
Providing learning support & 1 \\
\hline Tradink tank fairs/conventions & 1 \\
\hline & 1 \\
\hline
\end{tabular}


In detail, learning by doing, curiosity and self-teaching are mentioned most frequently as the most effective development strategies. Participant 12 explains: "One factor is the personal level. It is the level where everybody can learn for him- or herself how things work - how one can shoot movies, operate a cutting machine. [One will learn] all these things because of some personal interest." And participant 13 adds: "The most important, the most efficient thing is - I make it simple - doing it. That is what we have learned here. All kinds of theoretical approaches are no good. You have to just do it." The perception of the effectiveness of learning by doing and self-teaching is also shared by media executive, participant 3 :

Then the following will happen: You will have those who will work more convergent and others who will work less convergent. That is okay. Then, all of a sudden, they find out, I have a feedback, after all, if I do something online - and not just in print. Then somehow it is being "liked" and I have comments on Facebook. And that will be a key experience for many. And then it somehow makes "click." For every journalist does not cling to paper per se. Instead, he wants to be recognized with his or her work.

Another effective strategy according to the study participants is to give room for experimenting. "I think it is important that people will get room for trying out things, for learning - and not just having to do it on the side," explains participant 2. Media executive, participant 19, brings this method to a simple denominator: "Taking risks, being willing to try and being ready to fail," and participant 17 describes this as follows:

This room for experimenting really is important - and having the courage to try. To somehow creating for him- or herself an environment where one can try things, where one will just do an interview by iPhone and then come back to the editorial office and say: "Well, I have done this. Can someone now help me put this into an appropriate form?" I believe it is this way only that people start enjoying it. Because that way they will find out that it actually works.

External training courses and recruiting were additional strategies mentioned by participants of this study. Media executive, participant 5, mentions "Headhunting for 
special talents," and media executive, participant 10, explains: "My experience simply is, those things which you need - talking about social media, with SEO - that is what you get from outside. There are people like that. You can hardly learn that.” Participant 18 adds to this strategy: "just hiring people who already know how to do that."

Table 8 shows that mixing people with different competencies/ensuring diversity is another strategy for the development of convergent competencies and skills. Media manager, participant 7 , describes this strategy as follows:

[It is essential to realize] that not everybody has to be treated the same way, that not everybody has to do the same thing that one has a sensitivity for diversity. After all, diversity also means some can do certain things and others can do these things better

- that you play with these strengths and not level everything.

Competency Development at Institutional Participants

When asked how competency clusters needed for convergent media production currently are being developed in the four Swiss German media companies who were represented in the study respondents mentioned the following development strategies shown in Table 9. The most frequently named strategies are used in all four media companies.

Table 9

Most Frequent Convergent Competency Development Strategies at Institutional Participants

\begin{tabular}{lc}
\hline Development Strategy & $\begin{array}{c}\text { Count of Times } \\
\text { Mentioned }\end{array}$ \\
\hline Internal experts / specialists & 6 \\
Rotation and mutual learning & 4 \\
Hiring people with respective skills & 3 \\
External training / courses & 2 \\
On the job & 2 \\
Learning by example & 2 \\
\hline Total Counts & 32 \\
\hline
\end{tabular}




\section{Content of Competency Training and Learning Methods}

The leading question of this following part was, what does a training and learning method need to include in order to develop convergent competencies? The answers from media managers range from imparting of technical and writing skills to the teaching of sales skills.

The imparting of the ability of writing a good story, of producing video and of acquiring multimedia skills are key contents for training and learning methods for journalist today. Participant 17 explains that he believes, that "the concept of being a specialist is beginning to dissolve. This is partially owed to technical tools." And that is why they, together with The Swiss School of Journalism, MAZ developed a specialized training where print journalists learn how to produce "a forty-second piece by cell phone which is complementing another report." He then qualifies:

I can picture quite a number of editorial offices where it is absolutely impossible, to tell this a print editor. Because he will say this is not my job. For this there are other people. I believe this way of thinking has to somehow disappear. The matter is simple: The job of a journalist today is to produce a story - a story which will work out digitally so well that it is working.

Media executive, participant 3, adds that he expects that training institutions give journalism students an overview of multimedia opportunities: "What kind of options are out there, like multimedia, moving pictures, live ticker etc., but also teaching them how to handle all these options technically."

A close connection to the daily business and tailor-made approaches of trainings are perceived by media managers as another important requirement for successful training and learning methods. Participant 4 explains this requirement as follows: "[A training] must be very close to the output, meaning, close to the daily field of work. 
Theory is always good; but in this case it is about seeing possibilities for application and in the process having the competency of applying and acquiring them." Media executive, participant 14, emphasizes the importance of having these methods "custom-tailored." She explains that she supports generic-type digital trainings. "When it comes to knowing what is Facebook and Twitter it is quite possible to do a generic training, or when it comes to the question, how do I use an iPhone for producing videos," but what really is important according her point of view is that "the way of telling a story will match each particular medium and the corporate culture, and that it fits into the journalistic agenda which one follows. And, of course, too, how does this fit into the technical infrastructure available when it comes to tools and the like."

Various participants perceive the way of learning by doing as an important component of trainings and learning methods. "Since everything is changing at such high speed I am very much for learning on the job," states participant 4 . And participant 18 adds:

By the end of the day it is all about sending out people to do things on their own, and also giving them time to discover these things. [...] One must not expect of them that they write their story the same day. That doesn't work. Those are new worlds and I also believe there must be a willingness to deal with the story a little more on private time later on. In all these matters one can no longer strictly separate the job from private time. Somehow that doesn't work. And by the end of the day one simply has to want that.

Since in the convergent environment everything is developing quickly "there cannot be a convergent training which will stand forever," adds participant 2. Instead, "there rather is a continuous and permanent moving around and trying out." For this permanent experimenting in a convergent environment, employers have to provide the right kind of infrastructure and resources. "One has to give them sufficient space, not just 
time - space for experimenting. I wouldn't do it in such an institutionalized way, as we already have heard it from Google, that everybody has so and so much time for his or her private research. But if the company you feel that there are a few individuals who are on a super good thing, then one will have to provide them with the necessary resources," claims participant 13 and adds: "Sometimes you even might have to forbid them something because, in that case, they will do it all the more" and hence restrictions can contribute to innovation.

Last, but not least training and teaching methods should also include instructions as to how to sell a journalistic product stresses participant 13:

In the end, one also will have to sell the product well. That is a subject, as well. That is why we use measuring devices, charts and so on. It doesn't make sense if some four individuals work on a subject for two weeks, deliver a super job and then nobody will click on it because it has a stupid headline. You really have to keep the sale in mind. One has to trigger a sale in the reader, so that every reader just must want to see what you have done.

He continues to explain how important it is for journalists today who are working in a convergent environment to understand how the sale of media products works and what levers can be put in place: "One really has to turn on the sale through the reader so that each reader unconditionally must or want to see what we have done."

\section{Main Players for Convergent Competency Development}

The question that underlies the following section is "Who are important players in facilitating and supplying training/learning offers which help to develop convergent competencies?'

"One shortcoming of the training in Switzerland," according to participant 2, is "that the people who have the say in these matters are still old school" and shares his concern, that "the digital training, the convergent training comes off shortly or is much 
too theoretical." He further postulates and shares his observation as follows: "The bosses, i.e. the editors-in-chief, the heads of the departments or desks, first of all must have the competency themselves in order for them to be able to pass it on. That is very important and is still missing."

When it comes to the ranking of training players, media managers in the Germanspeaking part of Switzerland see schools of journalism and superiors in the first place, followed by chief editorial/editorial offices and academic institutions. Experts can be found in the 3rd place of important training players and human resources in the 4 th place (see Table 10).

Table 10

Important Training Players in Counts

\begin{tabular}{lc}
\hline Training Players & $\begin{array}{c}\text { Count of Times } \\
\text { Mentioned }\end{array}$ \\
\hline School of Journalism & 8 \\
Superior & 8 \\
Chief Editorial Office/Editorial Office & 6 \\
Academic Institutions & 6 \\
Experts & 5 \\
Human Resources & 4 \\
Internal Experts & 3 \\
Other Training Providers & 3 \\
Exchange with Other Media Companies & 3 \\
Know-how Sharing & 3 \\
(International) Projects & 2 \\
Employee him/herself & 1 \\
Learning from Customer-oriented Companies & 1 \\
Examples top down & 1 \\
Peers & 1 \\
Conventions / Congresses & 1 \\
\hline Total Counts & 56 \\
\hline
\end{tabular}


Why journalism schools play such an important role in training journalists and acquiring convergent competencies can be clearly derived from self-descriptions of the two main institutions in German-speaking Switzerland, the Ringier School of Journalism and the MAZ, The Swiss School of Journalism. The Head of the Ringier School of Journalism describes the orientation of the school as follows:

The Ringier School of Journalism is a small but classy school with only one class per course. And I am responsible for this program. That is my main job in the school. Naturally, I have adapted the program as well as possible to the current and future demands. That means, during the last few years we have had a real push when it comes to digital training, i.e. in the digital craft. That, of course, starts with the digital research, meaning, whatever happens at the computer in terms of research. It continues with introductions to data journalism and digital security training. [...] That, of course, very much includes the entire involvement with social media - and in regard to this, an involvement with social content. What is in demand? What is working? How do I today, in the face of all this twittering and razzmatazz, still get attention? And this attention, after all, can be measured. [...] We now have given exclusive attention to the smartphone video. The entire class by now is able to produce motion picture pieces with just this device, the smartphone - processing them on the smartphone, i.e. cutting them, in order to then surviving, with the moving pictures, in this digital communication, or being fit in multimedia story telling. This means, the basic training of journalists is becoming yet broader. Besides the classical training in writing, preparing reports, doing interviews and reportages and writing commentaries, there now has been added the video craft, pictorial design, dramaturgical composition. It is crazy how broad things have become. You need a certain technical understanding, perhaps even some technical affinity.

The Training Manager for Journalism Education for the MAZ - The Swiss School

of Journalism explains the specialization and main focus of that school:

We, after all, are training people on behalf of the industry. In a way we are carried by the editorial offices. We have yet another, broader sponsorship. But they are in a way our customers. We are training especially for smaller editorial offices. That means, our people are working very much hands down. They are on the job $80 \%$ of their time and $20 \%$ in school. If the gap becomes too deep between what we teach them and what they can do, it will blow up into our face. And my non-stop saying in the classroom is: "I am not training you for your current editorial office but rather that you will become good journalists." And I am telling them what I believe journalism to be.... The problem is that we actually are not training online journalists, even though the engrossment may be called "online." All students here have their field of operation in print. We have not a single student who is working in a pure online 
editorial office, for they are not sending anyone into training. [...] And the insider knowledge is helping me, after all, to make the students fit for their real everyday work. But, of course, I have a clear agenda. I believe that only journalists themselves can translate journalism into the digital age. If we don't do it, nobody will. ... And that is the nice thing about MAZ. We are not a college of applied sciences and not a university. If I, for instance, feel today that this course is no longer good enough, I can change it tomorrow. Or if I, for example, should feel I would like to make multimedia story telling mandatory, I just do it — naturally after agreeing with my colleagues. But actually, they always agree. We naturally have some incredible creative leeway and can respond quickly. And we actually do that, too.

Since both schools for journalism are supported by the media industry and are not subject to government regulation, they are free in designing the curriculum and hence can respond quickly to most developments in the media industry.

The concise and brief answer of media executive, participant 19, to the question, "Who are important players in facilitating and supplying training/learning offers which help to develop convergent competencies?," is: the leadership. The importance of superiors in facilitating and supplying training and learning offers is furthermore supported by the following testimonies. Media executive, participant 5, states: "Talent management is the job of the superior." And media manager, participant 1, acknowledges the responsibility of superiors with regards to talent management and people development: "It is the responsibility of those among us who are in leadership positions. We are the ones who have to offer opportunities to our people, and we have to open doors for that so they can actually do it." She further explains: "Not all are taking the initiative themselves, not all are daring to do so. Not all have the idea of doing so, after all. It is, of course, important that we [as superiors] offer the opportunity and inform about the offers there are." Media manager, participant 12, supports this statement by emphasizing the responsibility of superiors: "Employees have to be motivated by their superiors." 
Apart from direct superiors the (chief) editorial office plays another important role in facilitating and supplying training and learning offers. This view is shared among others by media manager, participant 9: "It is important that an editor-in-chief carries this," and participant 8: "And then, of course, the chief-editorial office," and participant 11: "But ultimately, it somehow is the editor-in-chief or the editor-in-chief New Media or whatever you want to call him or her." Media executive, participant 10, adds with regards to the most important actors for facilitating and offering convergent training opportunities: "That is relatively clear. It always is a matter of the managing bosses and editors-in-chief. They are the most important players. They have to want it."

Academic institutions were named as additional important resources for training and learning offers. "The ZHAW of Winterthur, the college of applied sciences, with its communications program, has become an important player," explains media executive, participant 3. And others mention the Columbia Journalism School at the Columbia University, NY, with its Sulzberger Executive Leadership Program.

Experts are another important source for training and learning opportunities. Media manager, participant 1 , stresses the significance of experts in general and in internal experts in particular: "I think it is important that one has experts, including internal ones, who can pass on something. We now have a [female] video editor. She stops by sporadically or sends out mails and gives hints and supports people, or whom you can ask for help." She adds "not everybody has to be in expert on all fields," but emphasizes how important it is to have an internal expert who can help and support. Another aspect of internal experts is specified by participant 17: "We are trying to make these people, who have taken these specialized courses, take their know-how into the 
company so that we then infect them with their enthusiasm.” Media executive, participant 14, remarks: "In our case, we actually cooperate very little with any of these institutions. Almost not at all," and explains: "I personally and we as a company, of course, have a very big network when it comes to digitally competent individuals." For training purposes, for workshops and process development "I, in most cases, get people from my network - because I know they can do it well," she adds. The advantage of external experts is expressed by participant 13 as follows: "It is clear, of course, that external experts are always of great interest if they have something to offer. With 'having something to offer,' I mean two things," he explains. "One thing clearly is inspiration. You have to inspire the people. You have to somehow get them to the point that they get into what we are doing." He also mentions the importance of the integration of external knowledge into the respective media company. "But it also is important that these external people in some form, even if it is for a limited time only, get involved directly in the production, perhaps in one project or so." Otherwise, the result is "an inspired guest presentation and after that dull routine once again," he adds.

\section{Competency Development Model}

The purpose of this study was to create a competency development model for media professionals in the convergent media environment in the German-speaking part of Switzerland, which can serve as a guide for the professional development of media professionals. In the following, a competency development model for convergent competencies and skills that is based on the results of this study, is offered. This model connects the discussed convergent competencies with established theories of leaning, includes suggestions as to what kind of trainings might be needed, and how appropriate 
training might be delivered. It presents a catalogue of measures for implementing competencies, which reflects in particular the need of the media industry in the Germanspeaking part of Switzerland.

"Workers learn more in the coffee room than in the classroom. They discover how to do their jobs through informal learning: talking, observing others, trial-and-error, and simply working with people they know" (Cross, 2007, p. 235). Does this statement of the long-term CEO of the eLearning Forum have meaning as we think about the acquisition and development of new convergent skills and competencies in the Swiss German media industry? In order to answer this question, I will unfold in the following section some basic principles of adult learning (informal and incidental learning; experiential learning) and competency development methods.

According to Knight (2006) 'learning' can be understood as a “process that produces the capability of exhibiting new or changed human behavior"' (p. 9).

'Education,' as a subset of 'learning,' aims at achieving a respective learning outcome. Both 'learning' and 'education' are lifelong processes that "may occur at any time and any place" and "can take place in an infinite variety of circumstances and contexts" (p. 10). In the same way as 'education' is a subset of 'learning,' 'training' is a subset of ‘education' (p. 11). Knight claims “most learning, education, and training take place outside the context of a formal school setting" (ibid.).

\section{Theories of Learning}

In the following section, main theories of learning are introduced. The presentation includes concepts of informal, incidental or accidental learning, Social Learning propounded by Bandura (1969), Kolb's (1984, 2015, and 2017) Experiential 
Learning Theory, and System Thinking, which originates from Von Bertalanffy (1969), Transformative Learning, Social Constructivism, and Connectivism.

Informal, Incidental and Social Learning

Concepts of informal and incidental (or accidental) learning are "typically defined in contrast with formal, structured education and that center around learning from and through experience” (Marsick, Watkins, Callahan, \& Volpe, 2008, p. 570). Cross (2007) describes 'Informal Learning' as the natural way of learning and explains, that "learning is that which enables you to participate successfully in life, at work, and in the groups that matter to you. Informal learning is the unofficial, unscheduled, impromptu way people learn to do their jobs" (p. 236). Livingstone found in a 1999 study of 1,562 Canadian adults that more than $95 \%$ of those interviewed were involved in some form of informal learning activities (Livingstone, 1999). In a most recent study from 2016 with 2,975 participants, Livingstone \& Raykov (2016) also could support the importance of informal learning at the workplace. The focus in the mentioned study was put on jobrelated informal learning. The two researches detected different kinds of job-related informal learning at $75 \%$ of their interviewees. Conner, a former information futurist, vice president of education services for PeopleSoft and senior manager of worldwide training at Microsoft, states likewise that most organizational learning does not happen in formal training programs. Instead, "more than 70 percent of learning experiences in the workplace are informal or accidental, through activities not structured or sponsored by an employer or school” (2004, p. 91).

The importance of informal learning is also shared in Europe as Malcolm, Hodkinson, and Colley (2003) note, “current EU policies in lifelong learning are raising 
the profile of informal and non-formal learning. The recognition and enhancement of such learning is seen as vital in improving social inclusion, and increasing economic productivity" (p. 313).

Cross (2007) enumerates following seven principles of informal learning which was defined from 1986 to 2000 by the Institute for Research on Learning (IRL) in Palo Alto, California, that was operating as an independent cross-disciplinary think tank: (a) learning is fundamentally social; (b) knowledge is integrated in the life of communities; (c) learning is an act of membership; (d) knowing depends on engagement in practice; (e) engagement is inseparable from empowerment; (f) 'failure to Learn' is the normal result of exclusion from participation; (g) we already have a society of lifelong learners.

The nature of informal learning Eraut (2004) characterizes as "implicit, unintended, opportunistic and unstructured learning and the absence of a teacher" (p. 250). In his 2004 research report he acknowledges that "the transfer of knowledge from education to workplace settings is much more complex than commonly perceived" ( $\mathrm{p}$. 256). Knowledge acquisition typically involves the following five interrelated stages:

1. The extraction of potentially relevant knowledge from the context(s) of its acquisition and previous use;

2. understanding the new situation, a process that often depends on informal social learning;

3. recognizing what knowledge and skills are relevant;

4. transforming them to the new situation;

5. integrating them with other knowledge and skills in order to think/act/communicate in the new situation (Eraut, 2004, p. 256). 
Eraut (2004) identified four main job-based activities that help to increase informal learning:

Participation in group activities included teamworking towards a common outcome, and groups set up for a special purpose such as audit, development or review of policy and/or practice, and responding to external changes.

Working alongside others allows people to observe and listen to others at work and to participate in activities, and hence to learn some new practices and new perspectives, to become aware of different kinds of knowledge and expertise, and to gain some sense of other people's tacit knowledge.

Tackling challenging tasks requires on-the-job learning and, if well-supported and successful, leads to increased motivation and confidence.

Working with clients also entails learning (1) about the client, (2) from any novel aspects of each client's problem or request and, (3) from any new ideas that arose from their joint consultation (p. 267).

Marsick, Watkins, Callahan, and Volpe (2008) distinguish informal and incidental learning, which is based on the theory of learning from and through experience, from "the more designed experiential learning activity described by Kolb (1984, p. 572).” Marsick et al. (2008) also perceive the embedment of work activities into the learning experience as crucial and see a main benefit of informal learning when it is linked to meaningful job activities. "But it requires greater attention to making the most of the learning opportunity, something that might involve planning and almost certainly involves some conscious attention, reflection, and direction (p. 572)." They then elaborate: "incidental learning, while occurring by chance, can be highly beneficial when one moves accidental learning opportunity closer into the informal learning realm though conscious attention, reflection and direction" (Marsick et al., 2008, p. 572).

As early as in the late 1960s Alfred Bandura (1969) already had introduced an additional term of informal learning, the expression 'Social Learning' Bingham \& 
Connor (2010) explain the term social learning: It "is what it sounds like - learning with and from others. It has been around for a long time and naturally occurs at conferences, in groups, and among old friends in a café as easily as it does in classroom exercises or among colleagues online who have never met in person." They add that "we experience it when we go down the hall to ask a question and when we post that same question on Twitter anticipating that someone will respond" (p. 6). In this context, Eraut (2004) provides important insights on factors affecting learning in the workplace. He identified a "triangular relationship between challenge, support and confidence" and explains his findings by stating: "if there is neither a challenge nor sufficient support to encourage a person to seek out or respond to a challenge, then confidence declines and with it the motivation to learn" (p. 269). Other determining factors for a successful informal learning experience are 'feedback,' 'value of the work' and 'commitment.' Eraut writes:

Other factors that emerged from our data: feedback, because we found that this was more than just one form of support, and was, or needed to be, provided by people who were not seen as having any particular support role; the value of the work (both for clients and for career progress) as an additional motivating factor; and commitment. Given our focus, commitment to learning was soon recognized as a complementary factor to confidence, which affects the extent to which workers are proactive in taking advantage of the learning opportunities available to them. However, we also found that commitment to clients, colleagues, their work group and their organization were sometimes important factors that could not be taken for granted. Commitment is generated through social inclusion in teams and by appreciating the value of the work for clients and for the workers themselves. Moreover, concerns about career progress that arise from inadequate feedback of a normative kind can weaken motivation and reduce commitment to the organization. (p. 270)

The status that informal learning occupies in scientific analysis is summed up well by Clardy (2018): "It is now widely accepted that informal learning plays a critical role in all workplace learning" (p. 153). He adds, "Since the 1990s, scholarly and practitioner interest in the nature of employee learning and development shifted from the classical 
focus on organizationally structured and provided training to that of learning at, through, and on the job apart from any formal instructional events" and explains: "Broadly, this change can be characterized as a shift in emphasis from formal training and education programs to informal learning practices and processes" (p. 153).

The 70-20-10 learning and development model, which is attributed to the U.S. American Center for Creative Leadership (CCL), describes learning achievement by challenging assignments (70\%), learning achievement by developmental relationships (20\%) and learning achievement by coursework and training (10\%). Even though this model is often cited, it is critiqued because of a lack of empirical supporting data and the use of perfectly even numbers. However, the importance of informal learning is not disputed. Kotter (1988) found that "a surprisingly large number of the items are developed on the job as a part of one's post educational career" (p. 34). In their guidebook, 'Learning in Adulthood,' Merriam, Caffarella, and Baumgartner (2007) support the importance of informal and incidental or accidental learning as follows:

The very nature of informal learning is what makes it so difficult for adults to recognize. Embedded as it is in our everyday activities, whether we are at work, at home, or in the community, and lacking institutional sponsorship, adults rarely label these activities as learning. However, studies of informal learning, especially those asking about adults' self-directed projects, reveal that upwards of $90 \%$ of adults are engaged in hundreds of hours of informal learning. (p. 35)

Experiential Learning and System Thinking

Kolb (2015) defines learning as the "major process of human adaption" (p. 43), "whereby knowledge is created through the transformation of experience" (p. 49) and attributes 'Experiential Learning' with a special form of learning from life experience which stays in contrast with classroom learning and lecture. His experiential learning theory is "a holistic integrative perspective on learning that combines experience, 
perception, behavior and cognition" (p. 31). He describes the process of adaptation and transformation of knowledge and experience through a four-stage cycle or spiral learning model, which has "its intellectual origins in the social psychology of Kurt Lewin in the 1940s" (1976, p. 21). The first phase of this model, as seen in Figure 2, depicts the "hereand-now concrete experience' (2015, p. 32) of learners. This phase is the basis for the next stage of the model, which is observation and reflection. From here the learner moves on to a third stage, where active reflections can impregnate and build an abstract concept, an idea, or theory about the experience, observation and reflection. During the fourth stage, active experimentation, the learner tests implications and validity of newly developed ideas and concepts in new situations in order to solve practical problems. Kolb (2015) claims that it is a "fact that learning is a continuous process grounded in experience," which "implies that all learning is relearning" (p. 39). Hence, the cycle continues and can thus be transferred into double-loop learning (Argyris, 2002), multileveled learning (Loverde, 2005) or even N-loop learning (Simonin, 2017).

In a treatise about experiential learning theory research today Kolb (2015) explains that "organizations need new ways to renew and revitalizes themselves and to forestall obsolescence for the organization and the people in it" (p. 2). Since it is part the purposes of my research to help prepare the Swiss media industry in getting ready for the future, Kolb's (2015) estimation in this context is pointing the way: "the future learning society represents a personal challenge for millions of adults who find learning is no 


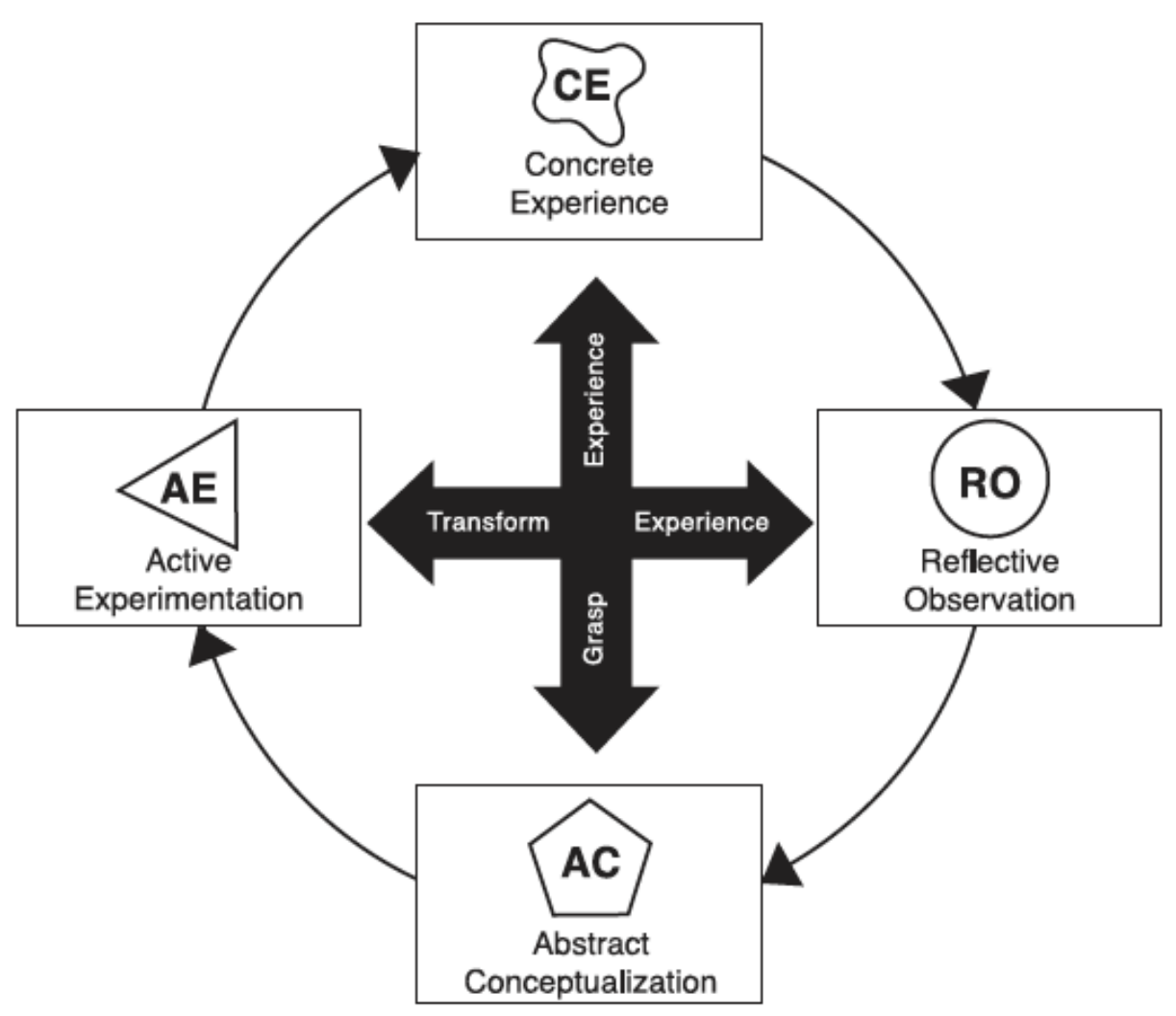

Figure 2. The Experiential Learning Cycle (Kolb \& Kolb, 2017, p. 11)

longer 'for kids' but a central lifelong task essential for personal development and career success" (p. 3). Kolb (2017) sees John Dewey (1938), Kurt Lewin (1942), and Jean Piaget as trailblazers for experiential learning. In 1938 in 'Experience and Education' Dewey wrote: "I take it that the fundamental unity of the newer philosophy is found in the idea that there is an intimate and necessary relation between the process of actual experience and education" (p. 20). Lewin's research about experiential learning in training and organizational development contributed to the understanding on how important the integration of experiences is. Lewin (1942) states: "Following the experiences of the past is one way of learning from experiences" (p. 224) and sets the following limitation: "However, frequently one has to learn not to follow the same 
procedure one used previously; one must learn to be guided instead by something like a theoretical analysis of the present situation" (p. 224).

Senge (2006) sustains this statement by stating "the most powerful learning comes from direct experience" and adds restrictively: "but what happens when we can no longer observe the consequences of our actions?" (p. 23). What happens if we reach our 'learning horizon'? "When our actions have consequences beyond our learning horizon," Senge challenges, "it becomes impossible to learn from direct experience" (Senge, 2006, p. 23). He identifies herein a 'core learning dilemma' for many organizations and explains it as follows: "We learn best from experiences but we never directly experience the consequences of many of our most important decisions" (Senge, 2006, p. 23). Therefore, he introduces 'system thinking' among 'personal mastery,' 'mental models,' 'building shared vision' and 'team learning' as the crucial fifth learning discipline for learning organizations. 'System Thinking' is a concept which originates from Von Bertalanffy's (1969) 'General System Theory.' The Austrian biologist shared his observation that "we are forced to deal with complexities, with 'wholes' or 'systems,' in all fields of knowledge" and adds: "This implies a basic re-orientation in scientific thinking" (p. 5). In the general theory of systems he saw "a useful tool providing, on the one hand, models that can be used in, and transferred to, different fields, and safeguarding, on the other hand, from vague analogies which often have marred the progress in these fields" (p. 34). He went on to state that this can serve as "a regulatory device to distinguish analogies and homologies, meaningless similarities and meaningful transfer of models" (p. 85). 
A leading proponent of System thinking is Peter Senge. He believed that System Thinking was "a discipline for seeing wholes," and went on to elaborate: "It is a framework for seeing interrelationships rather than things, for seeing patterns of change rather than static "snapshots"” (Senge, 2006, p. 68). This "leads to experiencing more and more of the interconnectedness of life and seeing wholes rather than parts" (p. 384). He emphasizes that "system thinking is needed more than ever because we are becoming overwhelmed by complexity" (p. 69), but that the "art of system thinking lies in being able to recognize increasingly (dynamically) complex and subtle structures" (p. 124). By using the metaphor of being unable to "see the forest for the trees" (p. 124), he stresses: "In fact, the essence of mastering system thinking as a management discipline lies in seeing patterns where others see only events and forces to react to" (p. 124) and to see problems "arising from underlying structures rather than from individual mistakes or ill will” (p. 385).

Transformative Learning and Social Constructivism

In a 1998 article in the PAACE Journal of Lifelong Learning Dirkx (1998) explains that "transformative learning has emerged within the field of adult education as a powerful image of understanding how adults learn" and "reflects a particular vision for adult education and a conceptual framework" of adult learning (p. 1). Transformational educators perceive the aim and process of learning different than more instrumentallyoriented educators, who tend to see learning as mere knowledge transfer. The first group is guided by the persuasion that transformative learning includes the implementation of experiences, which the learner gains by naming, reflecting on, and reconstructing various aspects of one's self and one's relationship with the world (Dirkx, 1998). One of the 
pioneering works with regards to the study of transformational learning was Jack Mezirow's research in the early 1980s. Mezirow (1997) states: "in contemporary societies we must learn to make our own interpretations rather than act on the purposes, beliefs, judgments, and feelings of others. Facilitating such understanding is the cardinal goal of adult education" (p. 5). The process of constructing and making meaning helps to develop "autonomous thinking" (ibid). Mezirow (2003) states the definition of 'Transformative Learning' more precisely as "learning that transforms problematic frames of reference - sets of fixed assumptions and expectations (habits of mind, meaning perspectives, mindsets) - to make them more inclusive, discriminating, open, reflective, and emotionally able to change" (p. 58). He informs that "a key proposition of transformative learning theory recognizes the validity of Habermas's (1984) fundamental distinction between instrumental and communicative learning" (p. 59). Instrumental learning can be understood as the 'how' and 'what' of learning, the acquisition of skills, competencies and knowledge (e.g. mastering tasks, problem solving, controlling and manipulating the environment). In contrast, communicative learning "refers to understanding what someone means when they communicate with you. This understanding includes becoming aware of the assumptions, intentions and qualifications of the person communicating" (ibid.). Mezirow (2003) emphasizes that there is a cardinal difference between instrumental and communicative learning: "In instrumental learning, the developmental logic is hypothetical-deductive, and empirical methods are more often appropriate for research. For communicative learning, the developmental logic involves analogic-abductive inference" (p. 59). In this context, transformative learning, in which prior interpretation and assumption are critically examined and reflected, forms new 
meaning, the 'why.' According to Mezirow (1981) the transformation is perceived through a disorienting dilemma, critical reflection, rational dialogue and action. He describes a perspective transformation by passing through following 10 steps:

1. Disorienting dilemma,

2. self examination,

3. critical assessment of personally internalized role assumptions and a sense of alienation from traditional social expectations,

4. relating discontent to others,

5. exploring options for of new ways of acting,

6. building confidence and self-confidence in new roles,

7. planning a course of action,

8. acquiring knowledge and skills for implement plans,

9. provisional efforts to try new role and to assess feedback,

10. reintegration into society on the basis of conditions dictated by the new perspective (p. 7).

Von Glasersfeld (1989) describes constructivism as "a theory of knowledge with roots in philosophy, psychology, and cybernetics" (p. 162). The constructivist learning perspective is based on the presumption that knowledge is constructed when new information comes together with existing knowledge, which had been developed by experiences. This means, that knowledge is constructed by the individual through his interactions with his environment. Ertmer and Newby (1993) explain: "Constructivists do not deny the existence of the real world but contend that what we know of the world stems from our own interpretations of our experiences. Humans create meaning as 
opposed to acquiring it. Since there are many possible meanings to glean from any experience" (p. 55). Based on Albert Bandura's Theory of Social-Learning (1969) and closely associated with Lev S. Vygotsky’s (1978) Social Development Theory and John Mezirows's $(1997,2003)$ Transformative Learning Theory, 'Social Constructivism' accentuates that all cognitive functions including learning are dependent on interactions with others. Derived from the concept of social constructivism, the quality of collaboration with others is critical for the learning process. In the context of competency development with regards to convergent skills, learning is more than the acquisition of new knowledge by individuals, but moreover the process how individual knowledge can be integrated into a larger knowledge community.

\section{Connectivism}

In connection with my research question "how can convergent competencies be developed?' the new theory of learning, connectivism, in particularly is worth having a closer look at. 'Connectivism' is a learning theory for the digital age, which explains how new digital technologies have created new ways and opportunities of learning and sharing information. Originators and proponents for connectivism are George Siemens (2005) and Stephan Downes (2010). New technologies include web browsers, email, wikis, social networks and social media (Facebook, Google+, Instagram, LinkedIn, Snapchat, Skype, Twitter, WeChat, WhatsApp, Youtube etc.), online discussion forums, opensource learning platforms (etc. Moodle), open educational resources, virtual reality (e.g. Second Life), and other tools which facilitate sharing of information and collective and collaborative learning. In a milestone article, Siemens (2005) demonstrates the limitation of most of learning theories by the central tenet of learning occurring outside of a person. 
Even social constructivist views, which hold that learning is a socially enacted process, promotes the principality of the individual (and her/his physical presence i.e. brain-based) in learning. These theories do not address learning that occurs outside of people (i.e. learning that is stored and manipulated by technology). They also fail to describe how learning happens within organizations. (p. 5)

Learning in a digital age often happens across online networks and can be derived from building networks and "forming connections," Siemens adds (2005, p. 5). He defines network as "connections between entities" and elaborates, "computer networks, power grids, and social networks all function on the simple principle that people, groups, systems, nodes, entities can be connected to create an integrated whole" (Siemens, 2005, p. 6). "The core of social network technology," Downes (2010) carries out, "is the capacity to create links between members in a community - to create, in other words, social networks" and explains: "These links are usually created explicitly, through the declaration of each of the users as 'Friends.' Often, the creation of links is associated with the creation of content, as in content management systems" (p. 28). Learning in an environment of connectivism is not any longer totally controlled by the individual but also can "reside outside of ourselves (within an organization or a database), is focused on connecting specialized information sets, and the connections that enable us to learn more are more important than our current state of knowing” (Siemens, 2005, p. 7). Siemens lists the following principles of connectivism:

Learning and knowledge rests in diversity of opinions.

Learning is a process of connecting specialized nodes or information sources.

Learning may reside in non-human appliances.

Capacity to know more is more critical than what is currently known.

Nurturing and maintaining connections is needed to facilitate continual learning. 
Ability to see connections between fields, ideas, and concepts is a core skill.

Currency (accurate, up-to-date knowledge) is the intent of all connectivist learning activities.

Decision-making is itself a learning process. Choosing what to learn and the meaning of incoming information is seen through the lens of a shifting reality. While there is a right answer now, it may be wrong tomorrow due to alterations in the information climate affecting the decision. (p. 7)

In a digital age like ours, where data is available in unbelievable quantities, many organizations face challenges in managing knowledge and in the flow of information. For this reason, it is crucial that knowledge which exists in an organization, probably stored in some kind of database, will be "connected with the right people in the right context in order to be classified as learning" (Siemens, 2005, p.7). Nevertheless, "the starting point of connectivism is the individual. Personal knowledge is comprised of a network, which feeds into organizations and institutions, which in turn feed back into the network, and then continue to provide learning to [the] individual," Siemens (2005, p. 8) adds and explains: "This cycle of knowledge development (personal to network to organization) allows learners to remain current in their field through the connections they have formed."

\section{Convergent Competency Development Model}

Ennis (2008) describes competencies as the "capability of applying or using knowledge, skills, abilities, behaviors, and personal characteristics to successfully perform critical work tasks, specific functions, or operate in a given role or position" ( $p$. 4f).

A three-skill approach was followed by Katz (1974) by grouping competencies as follows: 
1. Technical or functional skills (specialized knowledge, analytical ability and facility in use of tools and techniques in respective disciplines),

2. Human skills (knowledge, ability, attitude required to work effectively in a group and also to motivate and develop people) and

3. Conceptual skills (ability to see an organization as a whole, an understanding of interrelations in systems and visualization of the future).

Carroll and McCrackin (1998) organized competencies into four main categories:

1. Key or core competencies (competencies that are important for all employees and which support organizational values and performance expectations like customer service, continuous improvement, teamwork, personal responsibility),

2. Team competencies (specific capabilities and characteristics of a team as work unit),

3. Functional competencies (more specialized knowledge and job-specific skills required to perform a particular job role or profession)

4. Leadership and Management competencies (competencies related to leading, managing and developing organizations and people, e.g. communication, visionary and strategic thinking).

Competency research and applications appeared first in the early 1970s and is frequently associated with Harvard Professor David McClelland (1973) and his famous article Testing for Competence Rather Than for Intelligence. Prahalad \& Hamel (1990) revived the debate about competencies with their publication 'The core competence of the corporation' in which they state:

The most powerful way to prevail in global competition is still invisible to many companies. During the 1980s, top executives were judged on their ability to 
restructure, declutter, and delayer their corporation. In the 1990s, they'll be judged on their ability to identify, cultivate, and exploit the core competencies that make growth possible - indeed, they'll have to rethink the concept of the corporation itself. (p. 79)

The discussion of competencies sought to find a key to the origin of successful people in the job and strove to bundle the knowledge of individuals into organizational excellence. In this context, competency models were developed. According to Ennis (2008) "a competency model is a descriptive tool that identifies the competencies needed to operate in a specific role within a(n) job, occupation, organization, or industry" (p. 5). Competency development or competency modeling, "refers to the process of identifying a set of competencies representative of job proficiency," Chen \& Naquin (2006, p. 266) explain. Competency development has the capacity to "enhance various human resources (HRs) and organizational development activities," Chen \& Naquin add, and enumerate “personnel selection, job promotion, training and development, training needs analyses, performance appraisal, individual career planning, HR planning, placement, strategic planning, succession planning, compensation, and recruitment" (Chen \& Naquin, 2006, p. 266). On an operational level, Chouhan \& Srivastava (2014) argue "a competency model is a valid, observable, and measurable list of the knowledge, skills, and attributes demonstrated through behavior that results in outstanding performance in a particular work context" (p. 18). Therefore, a competency model normally includes key behaviors required for high performance for respective jobs. The process of identifying key competencies for jobs and functions within an organization or institution is called 'competency mapping' (Chouhan \& Srivastav, 2014, p. 18). Chouhan \& Srivastava (2014) explicate that the process of competency mapping "envisages development and 
sustainability of competency, based on the changing organizational requirements."

Additionally, they provide a detailed organization of competency models:

Depending on the work and organizational environment, a group of 7 to 9 total competencies are usually required for a particular job and depicted in a competency model .... A competency model is an organizing framework that lists competencies required for effective performance in a specific job, job family (e.g., a group of related jobs), and organization. The model is organized into tiers of competencies and includes descriptions of the activities and behaviors associated with each competency. Competency models are often highly tailored to the organization. As such, the elements of a competency model communicate, in clear terms, the circumstances and conditions of performance. Individual competencies are organized into competency models to enable people in an organization or profession to understand, discuss, and apply the competencies to workforce performance (p. 18).

"The most important point about competency models is that the formats be governed by the collective wisdom of the people that need and built them," suggests Richard Mirabile (1997), former president, CEO and co-founder of Success Factor Systems. Success Factors was acquired by SAP in 2011 and today belongs to the market leaders in cloud-based human capital solutions. In order to follow the above-mentioned principle, 20 media managers and media executives, representing the four major media corporations in the Swiss German part of Switzerland were included into this study and asked about their perception of competencies needed by a journalist in the future.

As shown in Table 6, all answers gathered during the case study investigation were clustered in seven skill-sets:

1. technical,

2. social and emotional,

3. cognitive,

4. writing and linguistic,

5. publishing and production, 
6. innovation and creativity, and

7. leadership and management.

Derived from the above-mentioned literature I understand a competency model as a framework that defines knowledge, skills and abilities required for a job or job family (editors and journalists) and as a compilation of competencies that corporately ensure successful job performance. I applied this principle to the developing of a competency development model for convergent editorial and journalistic competencies. The competency development model for the Swiss German media industry which I elaborated as a recommendation for the development of convergent competencies is composed of seven competency clusters, competency details for each cluster, development strategies for these clusters from study participants and learning and training strategies per competency cluster (see Figure 3). 


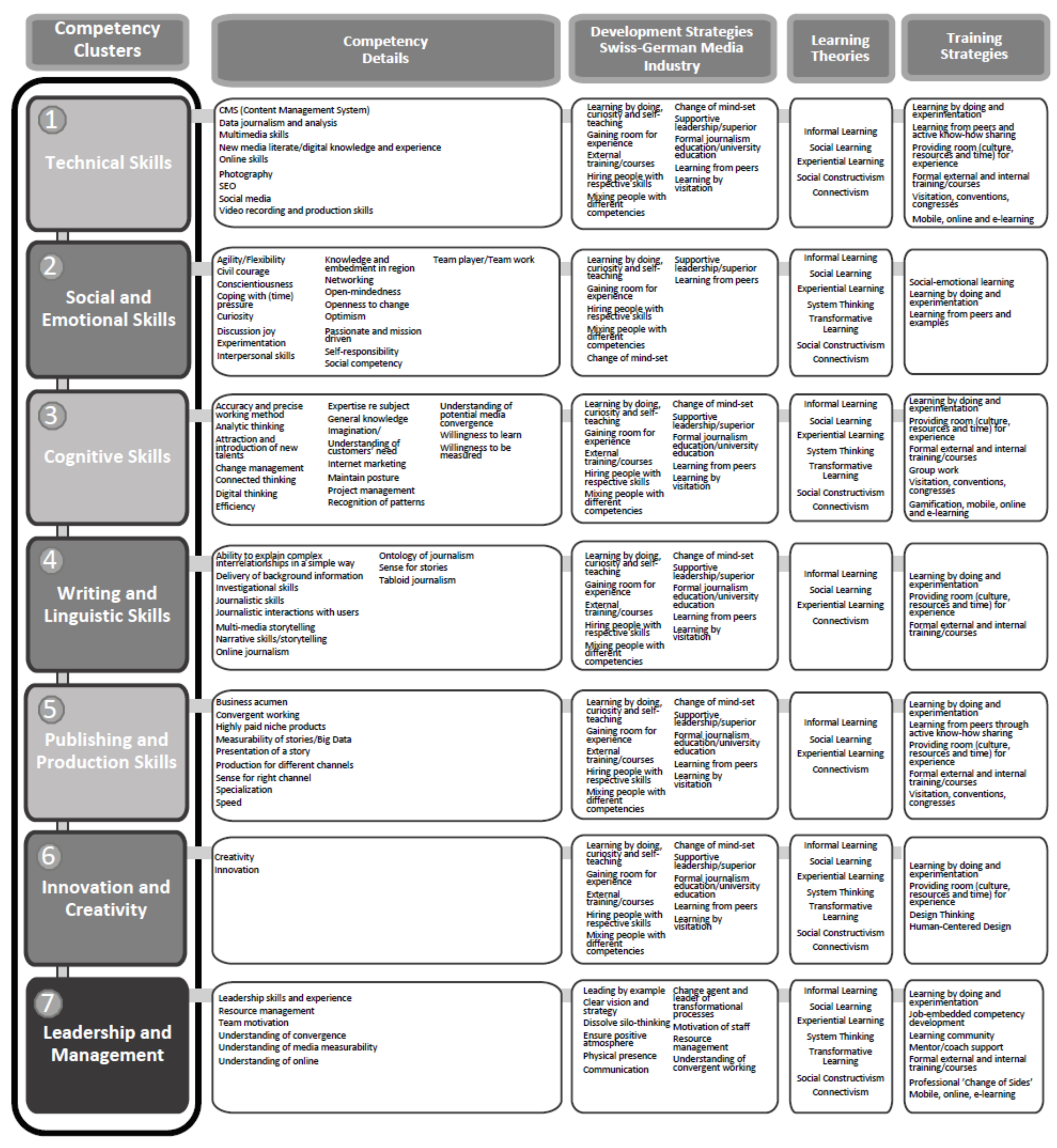

Figure 3. Competency Development Model for the Swiss German Media Industry 
The following section presents all seven competency clusters related to media convergence.

\section{Competency Cluster 1: Technical Skills}

Technical skills needed by journalists in the future range from fluency in 'content management systems (CMS)' to 'video recording and production skills.' The study participants applied the development strategies listed in Table 11 to the development of technical skills. Appropriate learning theories to acquire technical skills are according to my observation, experience and investigation about informal learning, social learning, experiential learning, social constructivism and connectivism. I suggest to follow the

principles of blended learning and learning by doing as well as experimentation, learning from peers and active know-how sharing, providing room (culture, resources and time) for experience, formal external and internal training/courses, visitation of other media companies, conventions, congresses and mobile, online and e-learning as appropriate learning strategies to gain technical skills as shown in Table 11.

\section{Competency Cluster 2: Social and Emotional Skills}

The participants in this case study enumerated various social and emotional skills they perceive as being needed of editors and journalists in a convergent media environment in the future. They applied the development strategies listed in Table 12 to the development of social and emotional skills. Appropriate learning theories to acquire social and emotional skills are according to my observation, experience and investigation informal learning, social learning, experiential learning, system thinking, transformative 
Table 11

Competency Cluster 1: Technical Skills

\begin{tabular}{|c|c|c|c|}
\hline Competency Details & $\begin{array}{l}\text { Development Strategies } \\
\text { Swiss German Media } \\
\text { Industry }\end{array}$ & Learning Theories & $\begin{array}{l}\text { Training } \\
\text { Strategies }\end{array}$ \\
\hline $\begin{array}{l}\text { - New media } \\
\text { literate/digital } \\
\text { knowledge and } \\
\text { experience } \\
\text { - Online skills } \\
\text { - } \text { Photography } \\
\text { - SEO } \\
\text { - Social media } \\
\text { - Video recording } \\
\text { and production } \\
\text { skills }\end{array}$ & $\begin{array}{l}\text { - } \text { Learning by doing, } \\
\text { curiosity and self-teaching } \\
\text { - } \text { Gaining room for } \\
\text { experience } \\
\text { - } \text { External training/courses } \\
\text { - } \text { Hiring people with } \\
\text { respective skills } \\
\text { - } \text { Mixing people with } \\
\text { different competencies } \\
\text { - } \text { Change of mind-set } \\
\text { - Supportive } \\
\text { - leadership/superior } \\
\text { - Formal journalism } \\
\text { education/university } \\
\text { - } \text { Leacation } \\
\text { - } \text { Learning from peers } \\
\text { - }\end{array}$ & $\begin{array}{l}\text { - Informal } \\
\text { Learning } \\
\text { - Social Learning } \\
\text { - Experiential } \\
\text { Learning } \\
\text { - Social } \\
\text { - Constructivism } \\
\text { - Connectivism }\end{array}$ & $\begin{array}{l}\text { - Learning by doing } \\
\text { and experimentation } \\
\text { - Learning from peers } \\
\text { and active know- } \\
\text { how sharing } \\
\text { - Providing room } \\
\text { (culture, resources } \\
\text { and time) for } \\
\text { experience } \\
\text { - Formal external and } \\
\text { internal } \\
\text { training/courses } \\
\text { - Visitation, } \\
\text { conventions, } \\
\text { congresses } \\
\text { - Mobile, online and } \\
\text { e-learning }\end{array}$ \\
\hline
\end{tabular}

learning, social constructivism and connectivism. Cristóvão, Candeias, \& Verdasca (2017) define 'Social and Emotional Learning (SEL)' as “the capacity to recognize and manage emotions, solve problems effectively, and establish positive relationships with others" (p. 1) and also includes the ability to set and achieve goals and make responsible decisions. Therefore, I suggest to follow the principles of blended learning and socialemotional learning, learning by doing and experimentation, learning from peers and examples as appropriate learning strategies to gain social and emotional skills as tabulated in Table 12. 
Table 12

Competency Cluster 2: Social and Emotional Skills

\begin{tabular}{|c|c|c|c|}
\hline Competency Details & $\begin{array}{l}\text { Development Strategies } \\
\text { Swiss German Media } \\
\text { Industry }\end{array}$ & $\begin{array}{l}\text { Learning } \\
\text { Theories }\end{array}$ & $\begin{array}{l}\text { Training } \\
\text { Strategies }\end{array}$ \\
\hline $\begin{array}{l}\text { - } \text { Agility/Flexibility } \\
\text { - } \text { Civil courage } \\
\text { - } \text { Conscientiousness } \\
\text { - } \text { Coping with (time) pressure } \\
\text { - } \text { Curiosity } \\
\text { - Discussion joy } \\
\text { - Experimentation } \\
\text { - Interpersonal skills } \\
\text { - Knowledge and embedment } \\
\text { in region } \\
\text { - Networking } \\
\text { - Open-mindedness } \\
\text { - Openness to change } \\
\text { - Optimism } \\
\text { - Passionate and mission } \\
\text { driven } \\
\text { - Self-responsibility } \\
\text { - Social competency } \\
\text { - Team player/Team work }\end{array}$ & $\begin{array}{l}\text { Learning by doing, } \\
\text { curiosity and self- } \\
\text { teaching } \\
\text { - Gaining room for } \\
\text { experience } \\
\text { - Hiring people with } \\
\text { respective skills } \\
\text { - Mixing people with } \\
\text { different } \\
\text { competencies } \\
\text { - Change of mind-set } \\
\text { - Supportive } \\
\text { leadership/superior } \\
\text { - Learning from peers }\end{array}$ & $\begin{array}{ll}\text { - Informal } \\
\text { Learning } \\
\text { - Social } \\
\text { Learning } \\
\text { - Experiential } \\
\text { Learning } \\
\text { - System } \\
\text { Thinking } \\
\text { - Transformative } \\
\text { Learning } \\
\text { - Social } \\
\text { - Constructivism } \\
\text { - Connectivism }\end{array}$ & $\begin{array}{ll}\text { - } & \text { Social-emotional } \\
\text { learning } \\
\text { - } & \text { Learning by } \\
\text { doing and } & \text { experimentation } \\
\text { - } & \text { Learning from } \\
\text { peers and } \\
\text { examples }\end{array}$ \\
\hline
\end{tabular}

\section{Competency Cluster 3: Cognitive Skills}

Cognitive skills needed by journalists in the future range from fluency in 'accuracy and precise working method' to 'willingness to be measured.' The study participants applied the to the development of cognitive skills the development strategies listed in Table 13. Appropriate learning theories to acquire technical skills are according to my observation, experience and investigation informal learning, social learning, experiential learning, system thinking, transformative learning, social constructivism and connectivism. I suggest to follow the principles of blended learning and learning by doing and experimentation, providing room (culture, resources and time) for experience, formal 
external and internal training/courses, group work, visitation, conventions, congresses, gamification, mobile, online and e-learning as appropriate learning strategies to gain cognitive skills (see Table 13).

Table 13

Competency Cluster 3: Cognitive Skills

\begin{tabular}{|c|c|c|c|}
\hline Competency Details & $\begin{array}{l}\text { Development Strategies } \\
\text { Swiss German Media } \\
\text { Industry }\end{array}$ & $\begin{array}{l}\text { Learning } \\
\text { Theories }\end{array}$ & $\begin{array}{l}\text { Training } \\
\text { Strategies }\end{array}$ \\
\hline $\begin{array}{l}\text { - Accuracy and precise } \\
\text { working method } \\
\text { - Analytic thinking } \\
\text { - Attraction and introduction } \\
\text { of new talents } \\
\text { - Change management } \\
\text { - Connected thinking } \\
\text { - } \text { Digital thinking } \\
\text { - Efficiency } \\
\text { - Expertise re subject } \\
\text { - General knowledge } \\
\text { - Imagination/ } \\
\text { - Understanding of } \\
\text { - } \text { Internet marketing } \\
\text { - Maintain posture } \\
\text { - Project management } \\
\text { - Recognition of patterns } \\
\text { - Understanding of potential } \\
\text { - } \text { media convergence } \\
\text { - Willingness to learn } \\
\text { Willingness to be measured }\end{array}$ & $\begin{array}{l}\text { - Learning by doing, } \\
\text { curiosity and self- } \\
\text { teaching } \\
\text { - } \text { Gaining room for } \\
\text { experience } \\
\text { - External training/courses } \\
\text { - Hiring people with } \\
\text { respective skills } \\
\text { - Mixing people with } \\
\text { different competencies } \\
\text { - Change of mind-set } \\
\text { - Supportive } \\
\text { leadership/superior } \\
\text { - Formal journalism } \\
\text { education/university } \\
\text { education } \\
\text { - Learning from peers } \\
\text { - Learning by visitation }\end{array}$ & $\begin{array}{l}\text { - Informal } \\
\text { Learning } \\
\text { - Social } \\
\text { Learning } \\
\text { - Experiential } \\
\text { Learning } \\
\text { - System } \\
\text { Thinking } \\
\text { - Transformative } \\
\text { Learning } \\
\text { - Social } \\
\text { Constructivism } \\
\text { - Connectivism }\end{array}$ & $\begin{array}{l}\text { - } \begin{array}{l}\text { Learning by } \\
\text { doing and } \\
\text { experimentation }\end{array} \\
\text { - Providing room } \\
\text { (culture, } \\
\text { resources and } \\
\text { time) for } \\
\text { experience } \\
\text { - Formal external } \\
\text { and internal } \\
\text { training/courses } \\
\text { - Group work } \\
\text { - Visitation, } \\
\text { conventions, } \\
\text { congresses } \\
\text { Gamification, } \\
\text { mobile, online } \\
\text { and e-learning }\end{array}$ \\
\hline
\end{tabular}

\section{Competency Cluster 4: Writing and Linguistic Skills}

'Ability to explain complex interrelationships in a simple way,' 'delivery of background information,' 'investigational skills,' 'journalistic skills,' 'journalistic interactions with users,' 'multimedia storytelling,' 'narrative skills/storytelling,' 'online 
journalism,' 'ontology of journalism,' 'sense for stories' and 'tabloid journalism' as needed writing and linguistic skills were named as needed skills for convergent ways of working. They applied the listed development strategies as listed in Table 14, to the development of writing and linguistic skills. Appropriate learning theories in this context are according to my observation and investigation informal learning, social learning, experiential learning, social constructivism and connectivism. I suggest to follow the principles of blended learning and of learning by doing and experimentation, providing room (culture, resources and time) for experience, formal external and internal training/courses as appropriate learning strategies to gain and develop writing and linguistic skills (see Table 14).

Table 14

Competency Cluster 4: Writing and Linguistic Skills

\begin{tabular}{llll}
\hline Competency Details & $\begin{array}{l}\text { Development Strategies Swiss } \\
\text { German Media Industry }\end{array}$ & $\begin{array}{l}\text { Learning } \\
\text { Theories }\end{array}$ & $\begin{array}{l}\text { Training } \\
\text { Strategies }\end{array}$ \\
\hline - Ability to explain & - Learning by doing, curiosity & - Informal & - Learning by \\
complex interrelationships & and self-teaching & Learning & doing and \\
in a simple way & - Gaining room for & - Social & Learning \\
- Delivery of background & experience & Providing room \\
information & - External training/courses & - Experiential & (culture, \\
- Investigational skills & - Hiring people with & Learning & time) for \\
- Journalistic skills & respective skills & - Social & experience \\
- Journalistic interactions & - Mixing people with & Constructivism & Formal external \\
with users & different competencies & Connectivism & and internal \\
- Multimedia storytelling & - Change of mind-set & & \\
- Narrative & - Supportive & & \\
- skills/storytelling & leadership/superior & & \\
- Online journalism & - Formal journalism & & \\
- Ontology of journalism & education/university & & \\
- Sense for stories & education & & \\
\hline
\end{tabular}




\section{Competency Cluster 5: Publishing and Production Skills}

Publishing and production skills needed by journalists in the future range from fluency in 'business acumen' to a 'sense for right channel,' 'specialization' and 'speed.' The study participants applied the development strategies listed in Table 15 to the development of publishing and production skills. Appropriate learning theories to acquire publishing and production skills are according to my observation and investigation informal learning, social learning, experiential learning and connectivism. I suggest to follow the principles of blended learning and learning by doing and experimentation, learning from peers and active know-how sharing, providing room (culture, resources and time) for experience, formal external and internal training/courses and visitation, conventions, congresses to gain publishing and production skills (see Table 15).

\section{Competency Cluster 6: Innovation and Creativity}

The participants in this case study named 'innovation' and 'creativity' as an important skill for editors and journalist in order to cope with future challenges in the Swiss German media industry linked to convergent working set-ups. They applied the development strategies to the development of innovation and creativity (displayed in Table 16). Appropriate learning theories to develop innovation and creativity are according to my observation, experience and investigation informal learning, social learning, experiential learning, system thinking, transformative learning, social constructivism and connectivism. I suggest to follow the principles of blended learning and learning by doing and experimentation, providing room (culture, resources and time) for experience, Design Thinking and Human-Centered design to develop innovation and creativity as shown in Table 16. 
Table 15

\section{Competency Cluster 5: Publishing and Production Skills}

\begin{tabular}{|c|c|c|c|}
\hline Competency Details & $\begin{array}{l}\text { Development Strategies Swiss } \\
\text { German Media Industry }\end{array}$ & $\begin{array}{l}\text { Learning } \\
\text { Theories }\end{array}$ & $\begin{array}{l}\text { Training } \\
\text { Strategies }\end{array}$ \\
\hline $\begin{array}{l}\text { - } \text { Business acumen } \\
\text { - } \text { Convergent working } \\
\text { - } \text { producty paid niche } \\
\text { - } \text { Measurability of } \\
\text { stories/Big Data } \\
\text { - Presentation of a story } \\
\text { - Production for } \\
\text { different channels } \\
\text { - Sense for right } \\
\text { channel } \\
\text { - Specialization } \\
\text { - Speed }\end{array}$ & $\begin{array}{l}\text { - Learning by doing, curiosity } \\
\text { and self-teaching } \\
\text { - Gaining room for experience } \\
\text { - External training/courses } \\
\text { - Hiring people with respective } \\
\text { skills } \\
\text { - Mixing people with different } \\
\text { competencies } \\
\text { - Change of mind-set } \\
\text { - Supportive } \\
\text { - } \text { leadership/superior } \\
\text { - } \text { eormal journalism } \\
\text { - education/university } \\
\text { - Learning from peers } \\
\text { - Learning by visitation }\end{array}$ & $\begin{array}{ll}\text { - Informal } \\
\text { Learning } \\
\text { - Social } \\
\text { Learning } \\
\text { - Experiential } \\
\text { Learning } \\
\text { - Connectivism }\end{array}$ & $\begin{array}{l}\text { - Learning by doing } \\
\text { and } \\
\text { experimentation } \\
\text { - Learning from } \\
\text { peers and active } \\
\text { know-how sharing } \\
\text { - Providing room } \\
\text { (culture, resources } \\
\text { and time) for } \\
\text { experience } \\
\text { - Formal external } \\
\text { and internal } \\
\text { training/courses } \\
\text { - Visitation, } \\
\text { conventions, } \\
\text { congresses }\end{array}$ \\
\hline
\end{tabular}

Table 16

Competency Cluster 6: Innovation and Creativity

\begin{tabular}{|c|c|c|c|}
\hline $\begin{array}{l}\text { Competency } \\
\text { Details }\end{array}$ & $\begin{array}{l}\text { Development Strategies Swiss German } \\
\text { Media Industry }\end{array}$ & $\begin{array}{l}\text { Learning } \\
\text { Theories }\end{array}$ & $\begin{array}{l}\text { Training } \\
\text { Strategies }\end{array}$ \\
\hline $\begin{array}{l}\text { - } \text { Creativity } \\
\text { - Innovation }\end{array}$ & $\begin{array}{l}\text { - Learning by doing, curiosity and self- } \\
\text { teaching } \\
\text { - Gaining room for experience } \\
\text { - External training/courses } \\
\text { - Hiring people with respective skills } \\
\text { - Mixing people with different } \\
\text { - } \text { Competencies } \\
\text { - Shange of mind-set } \\
\text { - } \text { Fupportive leadership/superior } \\
\text { - education journalism education/university } \\
\text { - Learning from peers } \\
\text { - Learning by visitation }\end{array}$ & $\begin{array}{ll}\text { - Informal } \\
\text { Learning } \\
\text { - Social } \\
\text { Learning } \\
\text { - Experiential } \\
\text { Learning } \\
\text { - System } \\
\text { Thinking } \\
\text { - Transformative } \\
\text { Learning } \\
\text { - Social } \\
\text { - Constructivism } \\
\text { - Connectivism }\end{array}$ & $\begin{array}{l}\text { - Learning by } \\
\text { doing and } \\
\text { experimentation } \\
\text { - Providing room } \\
\text { (culture, } \\
\text { resources and } \\
\text { time) for } \\
\text { experience } \\
\text { - Design } \\
\text { Thinking } \\
\text { - Human } \\
\text { Centered } \\
\text { Design }\end{array}$ \\
\hline
\end{tabular}


'Design Thinking' is a method for a practical and creative process of problem solving and is attributed to the British mechanical engineer and Professor of Design Research at the Royal College of Art, Leonard B. Archer, who mentioned this term for the first time in the early 1960s (Boyd Davis \& Gristwood, 2016). 'Human-Centered Design,' also called 'HCD,' is a design and management framework the most prominent proponent of which is the Hasso Plattner Institute of Design at Stanford University that develops ideas, approaches and solutions by including the human perspective in all steps of a problem-solving process. Human involvement in a solution-finding Human-Centered Design process can take place in contextual considerations, brainstorming, conceptualization, solution development and solution implementation.

\section{Competency Cluster 7: Leadership and Management}

Are leaders made or born? This chicken-or-egg question is partially answered by Robbins \& Judge (2001) when the authors explain: “A number of companies have recently turned to executive coaches to help senior managers improve their leadership skills" (p. 470). They encouraged the elaboration of the importance and development of leadership and managerial skills in convergent environments.

The study participants, in the context of media convergence, requested following leadership and management competency details: 'leadership skills and experience,' 'resource management,' 'team motivation,' 'understanding of convergence,' 'understanding of media measurability,' 'understanding of online.' They relate to the succeeding leadership and management development strategies and measurements: 'leading by example,' 'clear vision and strategy,' 'dissolve silo-thinking,' 'ensure positive atmosphere,' 'physical presence,' 'communication,' 'change agent and leader of 
transformational processes,' 'motivation of staff,' 'resource management,' and 'understanding of convergent working.' Appropriate learning theories to acquire leadership and managerial skills are according to my observation, experience and investigation informal learning, social learning, experiential learning, system thinking, transformative learning and connectivism. I suggest to follow the principles of blended learning and learning by doing and experimentation, job-embedded competency development, learning community, mentor/coach support, formal external and internal training/courses, professional 'Change of Sides,' mobile, online, e-learning to gain and develop leadership and managerial skills as can be seen in Table 17.

\section{Table 17}

Competency Cluster 7: Leadership and Management

\begin{tabular}{|c|c|c|c|}
\hline Competency Details & $\begin{array}{l}\text { Development Strategies } \\
\text { Swiss German Media } \\
\text { Industry }\end{array}$ & $\begin{array}{l}\text { Learning } \\
\text { Theories }\end{array}$ & $\begin{array}{l}\text { Training } \\
\text { Strategies }\end{array}$ \\
\hline $\begin{array}{l}\text { Leadership skills } \\
\text { and experience } \\
\text { - Resource } \\
\text { management } \\
\text { - Team motivation } \\
\text { - Understanding of } \\
\text { convergence } \\
\text { Understanding of } \\
\text { media measurability } \\
\text { Understanding of } \\
\text { online }\end{array}$ & 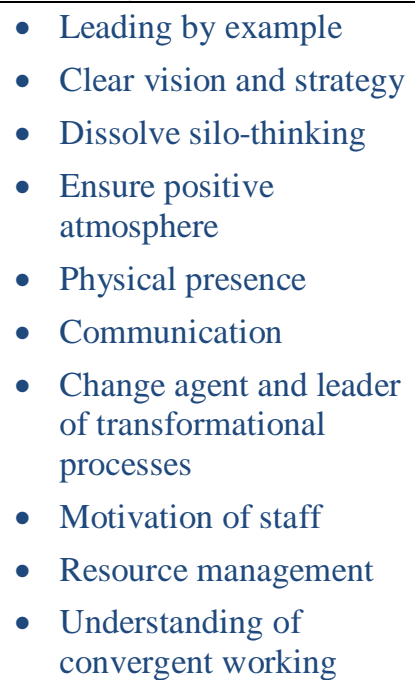 & $\begin{array}{l}\text { - Informal } \\
\text { Learning } \\
\text { - Social } \\
\text { Learning } \\
\text { - Experiential } \\
\text { Learning } \\
\text { - System } \\
\text { Thinking } \\
\text { - Transformative } \\
\text { Learning } \\
\text { - Social } \\
\text { Constructivism } \\
\text { - Connectivism }\end{array}$ & $\begin{array}{l}\text { Learning by doing } \\
\text { and experimentation } \\
\text { - Job-embedded } \\
\text { competency } \\
\text { development } \\
\text { - Learning community } \\
\text { - Mentor/coach support } \\
\text { - Formal external and } \\
\text { internal } \\
\text { training/courses } \\
\text { - Professional 'Change } \\
\text { of Sides' } \\
\text { - Mobile, online, e- } \\
\text { learning }\end{array}$ \\
\hline
\end{tabular}


In particular I want to emphasize the Andrews University leadership program (Covrig \& Baumgartner, 2010) which is biographically anchored, job-embedded, competency driven, supported by a learning community (so called 'learning groups') and personal coach/mentor ('advisor'), and based on continued individualized feedback. This program's approach enables excellent leadership development success and could be applied perfectly to a convergent context.

\section{Summary}

The purpose of this study is to discover competencies needed by media professionals (journalists and editors) in the convergent media environment in the German-speaking part of Switzerland now and in the future and to create a respective competency development model for the buildup of these competencies.

Looking at the development of convergent competencies, 'learning by doing,' 'curiosity' and 'self-teaching' were mentioned most frequently as the most effective development strategies. Another effective strategy, according to the study participants, consists in 'giving room for experimenting.' 'External training courses' and 'headhunting' for individuals with the desired skills were additional strategies mentioned by participants of this study. 'Mixing people with different competencies/ensuring diversity' is, according to my study, another strategy for the development of convergent competencies and skills. When asked how competency clusters needed for convergent media production currently are being developed in the four Swiss German media companies who were represented in the study, I received a listing of the following development strategies: 'internal experts / specialists,' 'rotation and mutual learning,' 'hiring people with respective skills,' 'external training / courses,' 'learning on the job' 
and 'learning by example.' An essential prerequisite for the content of convergent training is teaching how to 'write a good story,' 'video producing' and 'multimedia skills.' All training should have a close connection to the daily business and tailor-made training approaches are preferred. Various participants perceive the way of learning by doing as an important component of trainings and learning methods. This requires the provision of respective infrastructure and resources.

The presented competency model for convergent skill development is composed of seven competency clusters, competency details for each cluster, development strategies for these clusters from study participants and learning and training strategies per competency cluster. 


\section{CHAPTER 7}

\section{SUMMARY, FINDINGS, DISCUSSION, CONCLUSIONS AND RECOMMENDATIONS}

Chapter 7 provides a summary and a discussion of the main findings of this study and elaborates on the conclusions and recommendations. The background of the problem is linked to a tremendous change of media consumption during the past 20 years and the merging of different media production genres. The study answers the question about which competencies are needed by media professionals in a convergent media environment in the German-speaking part of Switzerland and how these competencies can be developed. The main findings, including a competency development model, are presented and discussed in this part of the study report.

\section{Summary}

This summary contains the background of the study problem, the purpose of the study, the research design, the theoretical and conceptual framework and an overview of media convergence in literature.

\section{Background of the Problem}

"Newsroom employment dropped nearly a quarter in less than 10 years, with greatest decline at newspapers." With this article headline, based on a recent evaluation of the U.S. American Bureau of Labor Statistics, Elizabeth Grieco (2018) from the Pew 
Research Center caught attention on July 30, 2018. But yet this trend also applies to Switzerland where printed newspaper editions are in a dramatic decline.

In 2012 I started a new assignment as Head of Human Resources of AZ Medien, one of the major media players in the German-speaking part of Switzerland, and was instantly confronted with an unprecedented development in this industry. Responsible for a workforce of approximately 1,200 I was most interested in understanding mechanisms and reasons for this dire situation and a threatening forecast in order to develop and provide a strategy, concepts and solutions for the company's human capital. In my search for the causes of this development I immediately got to the bottom of the most disruptive change in the media industry ever that is shaking the very foundations of this industry. For the first time I heard the legendary expression media convergence. This term describes a new phenomenon, which appeared during the last two decades and that involves the collapse of boundaries between the production of content for print, online, radio and television. Media convergence has clearly emerged in newsrooms where journalists from different genres work together closely, or where individual journalists use different media production methods.

Based on an initial observation I assumed that media convergence would have a big impact on the way editors and journalists work and equally strong implication for competencies and skills required by media professionals now and in the future. In order to prepare the workforce of AZ Medien I intended to design, implement and offer a respective training program for our staff to get them ready for the digital future. So, I addressed the management with the question, what competencies exactly do we need for a convergent future? I got as many answers to my question as the number of senior 
executives we had. But the most intriguing answer came from of the Editor-in-Chief who explained to me that beyond strong writing and communication skills and web and multimedia publishing skills, a high stress resistance would be demanded from editors and journalists in the future. Immediately, I realized that this statement of the Editor-inChief had a lot of undiscovered truth in it and would lead me way beyond an average competency assessment and development process which I ran in various company settings before this new Human Resources leadership assignment. I sensed that writing and technical skills needed in a convergent environment would only cover one part of the future requirements, the so-called 'soft skills' and leadership skills would also play an important role.

In order to explore and understand the competencies needed by future journalists for coping with media convergence - not only for my employer at the time, but for the entire Swiss German media industry -, I decided to dedicate a proper research set-up to the elaboration of these questions.

The appearance of media convergence has been explored in various case studies in the U.S. and in some European countries showing the current state of convergence in the field of news production. However, not much information was available on media convergence in the German-speaking part of Switzerland. At the same time, very little evidence existed for helping to decipher to what extent findings from previous studies in the U.S. are applicable to the Swiss media environment. In various informal talks players in the Swiss German media industry insisted that news consumption in the Germanspeaking Switzerland is different from consumer behavior in Germany and in the U.S. The information acquired through these discussions supported my assumption that there 
is very little empirical evidence to determine which kinds of competencies will be required for future journalists. This situation leaves both media managers and editorial staff with a great deal of uncertainty. Little understanding exists as to how these future convergent competencies can be gained and developed. For strategic planners this fact creates an almost unbearable tension between coping with contemporary challenges and preparing for the future. I concluded that a competency model is needed to guide the preparation of future media professionals in the German-speaking Swiss media environment. Therefore, I decided to focus my study on the current status of media convergence in major media players in the German-speaking part of Switzerland, on convergent competencies needed by media professionals in order to cope with the ongoing media convergence and on the development of convergent competencies in the media industry in Switzerland.

\section{Purpose of the Study}

The purpose of this study was to gain insights on media convergence in the Swiss German media industry and to create a competency development model for media professionals in the convergent media environment in the German-speaking part of Switzerland that can serve as a guide for the professional development of media professionals. In this context, I portrayed the current status of media convergence in main media companies in the German-speaking part of Switzerland and described experiences, perceptions and expectations that media managers have of the media professionals they engage and hire to cope with today's market needs in the context of a convergent media environment in German-speaking Switzerland. Media managers are print, TV, radio and digital editors-in-chief, heads of media profit centers, that media companies employ to 
lead media industry firms. Media professionals are the editorial staff who work on the production of the actual news items to be dispersed in online, TV and the newspaper media. The study identified the perceptions of media managers of the necessary competencies in the convergent media environment today as well as their expectations of the competencies needed in the future. I also explored how the media industry develops this new cluster of competencies in their existing media professionals and how media training institutions and professional media schools approach the development of these new convergent skills. Future competencies needed in the Swiss German media industry were defined generally as convergent media competencies. I studied the process of competency development in selected cases in the Swiss German media industry in order to create a development model.

\section{Research Design}

In order to explore and understand the competencies needed by journalists in the future to cope with media convergence I conducted a qualitative case study evaluating the Swiss German media industry. A case study is a qualitative research method "that facilitates exploration of a phenomenon within its context using a variety of data sources" (Baxter \& Jack, 2008, p. 544). Case studies were already applied centuries ago to explore scientific phenomena. Today, case studies enjoy popularity in the scientific world as well as in teaching and professional development. In the last decades the Harvard Business School gained a great reputation in regard to case studies in business science. According to Yin (2003), a case study design might be appropriate when (a) the focus of the study is on answering "how" and "why" questions, (b) the behavior of those involved in the study cannot be manipulated, (c) contextual conditions should be covered because they are 
perceived as being relevant to the phenomenon under study, or (d) the boundaries between the phenomenon and its context are not clear. All those conditions applied to my intended research subject about competencies needed in an environment of media convergence in the German-speaking part of Switzerland. Creswell (2013, p. 98f) suggests that case study research start with the identification of a specific case (single case or multiple cases) and have the intention to illustrate a case which gains interest because of its specific nature (intrinsic case) or for understanding a specific issue, problem or concern (instrumental case).

I therefore chose as research design the collective case study approach in which I integrated these Swiss media companies in the German-speaking part of Switzerland that already have introduced a newsroom (four cases).

The exploration of the related complex phenomena 'media convergence in the Swiss German media industry' included (a) experiences, perceptions and expectations that media managers in the Swiss German media industry have in regard to convergent competencies needed by media professionals in order to cope with future needs, and their experiences, perceptions and expectations on effective strategies for developing these competencies, (b) experiences, perceptions and expectations that media professionals in the Swiss German media industry have about convergent competencies needed in the future and their experiences, perceptions and expectations on effective strategies for developing these competencies, (c) the planning and implementing of newsrooms in three of the big media companies in the German-speaking part of Switzerland, (d) visitation of operating newsrooms and observation of working processes, (e) evaluation of requirements in published job ads in Switzerland during a certain time period, (f) analysis 
of job descriptions and job requirements for different kinds for journalists of different Swiss German media companies, and (g) biographical and autobiographical testimonies ("life stories") of editors-in-chief and individual journalists, who are working in convergent environments.

Data sources 1 and 2 were acquired in 20 face-to-face, semi-structured interviews that I conducted with media managers and media professionals between August 2016 and March 2017. All interviews were audio recorded on two Apple iPhones, using the app Voice Memos and were afterwards transcribed with the use of the online service transcribe from Wreally Studios Inc. After transcription, they were analyzed with the help of Dedoose, a web-based qualitative data analysis software developed by academics of UCLA, for common themes in order to answer the questions about their perceptions of the currently and in the future needed competencies of media professionals that work in a convergent media environment in German-speaking Switzerland.

\section{Theoretical and Conceptual Framework}

In order to find reality as a researcher I refer to Grajales \& Gonzales (2008) who distinguish between truth and reality. "Truth is the understanding of reality through a process of a self-correcting search made by the intellectual community throughout the ages." They further carry out that "reality exists independent of human searching" and that "there is more than one way to approach knowledge but only one reality" (p. 162). I support their position that "reality is the what 'is' and the truth is what the subject considers that reality to be” (p. 162) and James' (1908) explanation that an absolute 'truth' is not as important as what we perceive as truth (p. 455). In order to understand which "reality" underlies a postulate for media convergence and competencies needed in 
the future, I conducted a qualitative research project. Charmaz (2010) compares a qualitative research approach with the use of different lenses of a camera through which one can observe an object with different foci and granularity. In this sense the first part of my research, the literature review, worked like the 'wide angle lens of a camera.' The second part of my research, which can be compared to the 'research camera lens,' is focused on experiences, perceptions and expectations which newspaper, online and TV editors-in-chief and educators have of convergent competencies needed by journalists and editors in order to cope with future needs in the Swiss German media industry. The choice of analyzing main media players in Switzerland works in this sense like the use of a 'camera flash.' In the third part of this research I worked on my understanding of the 'histogram of the research camera' and hence integrated all observations and findings into a competency development model for journalists in the Swiss German media industry.

\section{Media Convergence in the Literature}

The tremendous change in the media industry in Europe and the USA during the past two decades where traditional borders between the production of content for print, online, radio and television have been dissolved, seems according to Avilés \& Carvajal (2008), to be "related to industry convergence" and "is reshaping the landscape of journalism in a variety of ways" (p. 222). The phenomenon of this change is called 'media convergence' and is very often connected to the appearance of 'newsrooms.' Avilés \& Carvajal (2008) present three essential activities that "take place within the value chain of any [media] business: information gathering, news production and content aggregation, and distribution" (p. 225). Convergence can be found on the information 
gathering stage in that manner that journalists produce content for different platforms and share it with their peers. On the level of news production and aggregation content from various sources is repackaged for different media platforms. Media distribution appears when a single company uses different platforms of content distribution.

Gordon (2003) developed a model, which is based on five different appearances of media convergence:

1. ownership convergence

2. tactical convergence

3. structural convergence

4. information gathering convergence

5. presentation convergence.

Ownership convergence is linked to multiple content and distribution channels by media corporations "while tactical convergence involves cooperation and collaboration in areas such as content, marketing, and revenue enhancement" (Mishra, 2014, p. 2). Media companies introducing convergence often change ways of working and assignment of roles. The forth characteristic of Gordon's model has to do with a new convergent way of gathering news and the fifths with new ways of presenting content and story-telling using new multimedia tools. Contrary to Gordon, Kolodzy (2009) describes a model of media convergence which consists of three aspects: (a) technological, which focuses on media technological change and media digitalization, (b) economic, which covers the influence of convergence on a structural level, including cross-promotion and (c) journalistic, which includes the merging of traditional print journalism with online, television and radio journalism. A third model of newsroom convergence, called 'the convergence 
continuum' is presented by Dailey et al. (2005a) This hierarchical model includes (a) cross-promotion, (b) cloning, (c) coopetition, (d) content sharing and (e) full

convergence. It assumes an interaction and cooperation among cross-media partners. The lowest level of convergence is found on cross-promotion where only promotion of each other's content is found but no interaction. Cloning covers a way of collaboration where the material of others is republished with minor adjustments. Coopetition "is the level where cooperation in content production is coupled with competition based on cultural differences" (Yin \& Liu, 2014, p. 563). Content sharing contains sharing of gathered information, repackaging of content and common planning, reporting and producing of content. Avilés \& Carvajal (2008), based on a case study about two Spanish multimedia companies, developed another model of newsroom convergence, which contents of two facets: (a) the integrated model and (b) the cross-media model. The integrated model follows the objective to create "a single journalistic culture transgressing traditional media boundaries" (p. 235). In contrast, the cross-media model is a resource and organizational strategy, "where multimedia production based on synergies is the desired ideal" (p. 235). According to the previously mentioned researchers, "cross-media work is not regarded as a goal itself, rather as a tool" where "managers express a desire to strengthen the company as a news provider on the whole, regardless of media platform" (p. 235).

All major media companies in the German-speaking part of Switzerland currently employ a model that ranges between the cross-media model and the fully integrated model. None of the bigger players practices yet a fully integrated model. 
In order to define competencies required in the media industry of the future Beyers (2004) conducted a survey showing that the majority of online news visitors were only reading messages (63.9 per cent). Other services offered by newspapers, like portable digital assistance, texting services, WAP/i-mode, were hardly ever used. However, various studies on mass media suggest that news content on television websites could increase user loyalty and that the trend for increased online consumption has not yet reached its peak (Cahn-Olmstead \& Kim, 2001; Dwyer, 2010; Cremedas \& Lysak, 2011; Mitchell et al, 2012; Stenport, Markstedt, \& Crain, 2014). Therefore, it is appropriate to ask, what kind of mass media elements and competencies should be covered by a training, which prepares journalist for the future. Tanner et al. (2012) maintain that most recently "educators attempt to find ways to prepare students for an increasingly complex media environment" (p. 219). However, since there were no more precise suggestions in the literature available for the content of relevant training activities in order to gain convergent competencies and skills, the elaboration of this question was implemented in my collective case study.

\section{Findings}

The findings of this study are divided in three parts. The first part gives an overview of institutional and individual study participants. The second part describes the main findings of the study and is structured in 11 short paragraphs. This part also includes a competency model for the media industry in the German-speaking part of Switzerland. The last part brings the research questions of the study in relation with key findings of the study. 


\section{Institutional and Individual Participants}

In the German-speaking part of Switzerland there are six leading media companies: SRG SSR, Tamedia, Ringier, NZZ, AZ Medien and Somedia. SRG SSR, which is a non-profit organization funded mainly through radio and television viewer fees, a company with more than 6,000 employees; the privately owned media companies AZ Medien headquartered in Aarau, Switzerland, with 1,200 employees and an annual revenue of approx. CHF 236 mio. (\$251 million, 2016), NZZ (Neue Zürcher Zeitung) Mediengruppe, headquartered in Zürich, Switzerland, with 1,900 employees and annual revenue of approx. CHF 423 mio. (\$451 million, 2016), Ringier headquartered in Zürich, Switzerland, with 3,100 employees and annual revenue of approx. CHF 840 mio. (\$895 million, 2016), Somedia AG, headquarted in Chur, Switzerland, with 950 employees and annual revenue of approx. CHF 133 mio. (\$137 million, 2016), and Tamedia, also headquartered in Zürich, Switzerland, with 3,300 employees and annual revenue of approx. CHF 1,005 bill. (\$1,07 billion, 2016).

The companies chosen for the purpose of this study were selected by the criteria that they had implemented a newsroom in the last decade and accompanied the implementation with some actions. Ringier implemented the first convergent newsroom in the German-speaking part of Switzerland in 2010, AZ Medien followed this development in 2011, the NZZ Mediengruppe in 2012, and Tamedia, which until 2010 still speaking out against a convergent newsroom, introduced its own in 2013. The media companies SRG SSR (publicly owned) and Somedia have convergent working departments but did not have a newsroom in a pure form during the period of the study. 
Therefore, this research is delimitated to the four media corporations AZ Medien, NZZ Mediengruppe, Ringier and Tamedia with the editors-in-chief and media managers of these main players in the Swiss German media industry serving as spoke persons.

Altogether, with 20 individuals semi-structured interviews were conducted. Position titles of participants of the study were at the time of the interview as follows: CEO, AZ Medien; Editor-in-Chief, AZ Zeitungen; Deputy Editor-in-Chief, AZ Zeitungen; Editor-in-Chief, Schweiz am Sonntag; Editor-in-Chief, Limmattaler Zeitung; Freelance journalist, Consultant for the media industry, Training Manager Journalism Education; Chief Product Officer; Head of Digital Products; Project Director Convergence; Head of Magazines and Member of the Editorial Office, NZZ am Sonntag; COO Ringier AG; Head of Public Affairs; Co-Editor-in-Chief, Schweizer Illustrierte; Editor-in-Chief, Blick Sport; Head of Ringier School of Journalism; Member of the Group Management Board, Head of Paid Media; Member of the Editorial Office, TagesAnzeiger and Head of Digital and Newsnet; Editor-in-Chief, 20 Minuten; Deputy Editorin-Chief, SonntagsZeitung; Head Digital Sales Development.

\section{Main Findings}

The purpose of this study was to discover competencies needed by media professionals (journalists and editors) in the convergent media environment in the German-speaking part of Switzerland now and in the future, and to create a respective competency development model that will effectively facilitate the acquisition of these competencies.

Four privately owned media corporations in the German-speaking part of Switzerland were included into the case study approach: AZ Medien, NZZ (Neue Zürcher 
Zeitung) Mediengruppe, Ringier and Tamedia. 20 media executives and media managers, employees of the four above mentioned media corporations under investigation were included in the study.

The main findings of this study are summarized in the following 11 paragraphs:

1. In Switzerland, the professional title 'journalist' is not a protected professional title. Therefore, there are various ways for obtaining a journalism education. The two most renowned professional journalism-training centers in the German-speaking part of Switzerland are the MAZ - Die Schweizer Journalistenschule and the Ringier Journalistenschule. They both offer a dual system, combining school and practical work. The publicly owned Swiss Radio and Television Corporation (SRG SSR) offers a comparable trimedia journalism-training course. In addition, four universities offer academic journalism education.

2. When I asked how much the emergence of media convergence changed since they started their current roles, some of the media managers and executives interviewed were brooding about the change of the media landscape during the past few decades and shared their very personal observations about media convergence. They all shared the perception that the emergence of media convergence appeared in phases, starting at the end of the 20th century. Phase 1 is described when online media were not comparing themselves with other online media products but with print products, Phase 2 when online media rubbed themselves with print counterparts, and Phase 3 when 'media convergence' became between 2009 and 2011 a buzz word, when Mobile and Social Media (with the emergence of Facebook) were introduced and when the discussion about 'Digital First' and channel spanning work arose. 
3. All study participants shared the perception that media convergence already is playing an important role in all Swiss German media corporations. However, all of them see slight differences between the four major media players in the German-speaking part of Switzerland concerning the status of media convergence. AZ Medien and NZZ are still focusing more on the journalistic business model, while Ringier and Tamedia relay on digital offers as second mainstay.

4. The biggest changes in the way how editors and journalists work in this more convergent environment were perceived in the area of the 'way of working' in general, where time and space almost dissolves and where no dedicated time for research, news writing and production exists anylonger, in the area 'speed of news,' the requirement of 'news distribution on different channels,' 'openness for new media' and 'interaction with readers.' Other changes in journalistic work is the requirement of 'technical and digital knowledge' and 'production of news for different channels,' that new set-up that a group of people have to work together as a team on the production of one article compared to the past where the research and writing of one article was done by one editor/journalist, a higher user orientation including the understanding of the needs and customer behavior and the production postulate of 'Online first,' 'networking' and the 'usage of social media.'

5. All four companies included in the study planned, had designed and implemented a convergent newsroom in the past seven years. From the interviews, I observed that most of the participants closely link media convergence with the physical place of a newsroom and the term newsroom itself with the place where news is being produced. However, some of my interview partners emphasized that media convergence 
has to start in the minds and includes a change of mind-set. In this context, the concept of a newsroom can be perceived as the personalized convergence while media convergence is not limited to the newsroom and consequently can take place everywhere and is dissolved from space and time.

6. The development of competency clusters needed for convergent work I approached in two different ways. First, by dedicated this research topic various questions during the face-to-face interviews with media managers of media corporations in the German-speaking part of Switzerland and second, by collecting and analyzing all online published job advertisements for editors and journalists in Swiss German online media. The discussion about competencies needed by journalists in a convergent environment encompasses a broad framework which includes basic skills editors and journalists must have at any time (e.g. investigational skills, general knowledge, curiosity, coping with time pressure, linguistic and writing skills) and such which are more linked to convergent ways of working (social and multimedia literacy, data journalism, connected thinking, multimedia storytelling, team playing). All mentioned skills and competencies were grouped in seven competency themes: (a) technical skills, (b) social and emotional skills, (c) cognitive skills, (d) writing and linguistic skills, (e) publishing and production skills, (f) innovation and creativity, and (g) leadership and management.

7. As the most effective development strategies for the development of convergent competencies, 'learning by doing,' 'curiosity' and 'self-teaching' were mentioned most frequently. Another effective strategy, according to the study participants, consists in 'giving room for experimenting.' 'External training courses' and 
'headhunting for individuals with the desired skills' were additional strategies mentioned by participants of this study. 'Mixing people with different competencies/ensuring diversity' is, according to my study, another strategy for the development of convergent competencies and skills.

8. When asked how competency clusters needed for convergent media production currently are being developed in the four Swiss German media companies who were represented in the study, I received a listing of the following development strategies: 'internal experts / specialists,' 'rotation and mutual learning,' 'hiring people with respective skills,' 'external training / courses,' 'learning on the job' and 'learning by example.'

9. An essential prerequisite for the content of convergent training is teaching how to 'write a good story,' 'video producing' and 'multimedia skills.' All training should have a close connection to the daily business and tailor-made training approaches are preferred. Various participants perceive the way of learning by doing as an important component of trainings and learning methods. This requires the provision of respective infrastructure and resources. It was also stressed by study participants that training and teaching methods should include instructions as to how to sell a journalistic product.

10. According to the study participants the main players for convergent competency development for editors and journalists in the German-speaking part of Switzerland are first, the schools of journalism and superiors, second, chief editorial/editorial offices and academic institutions, third, experts, and fourth, human resources. 
11. The presented competency development model (see Figure 4) for convergent skill development at media corporations in the German-speaking part of Switzerland is composed of seven competency clusters, competency details for each cluster and the most effective learning and training strategies per competency cluster. A competency specific mixture of learning methods, according to the blended learning approach, is suggested to lead to the best results in gaining media convergence excellence.

\section{Research Questions and Key Findings}

The core questions of this study are:

Question 1. What are the current and future competencies needed by media professionals (journalists and editors) in the convergent media environment in the German-speaking part of Switzerland?

Question 2. What are the most effective strategies for developing these competencies?

The two sub questions of the study are:

Sub Question 3-A. How are the new competency clusters needed for convergent media production currently being developed?

Sub Question 3-B. What does such training need to include in order to develop convergent competencies? 

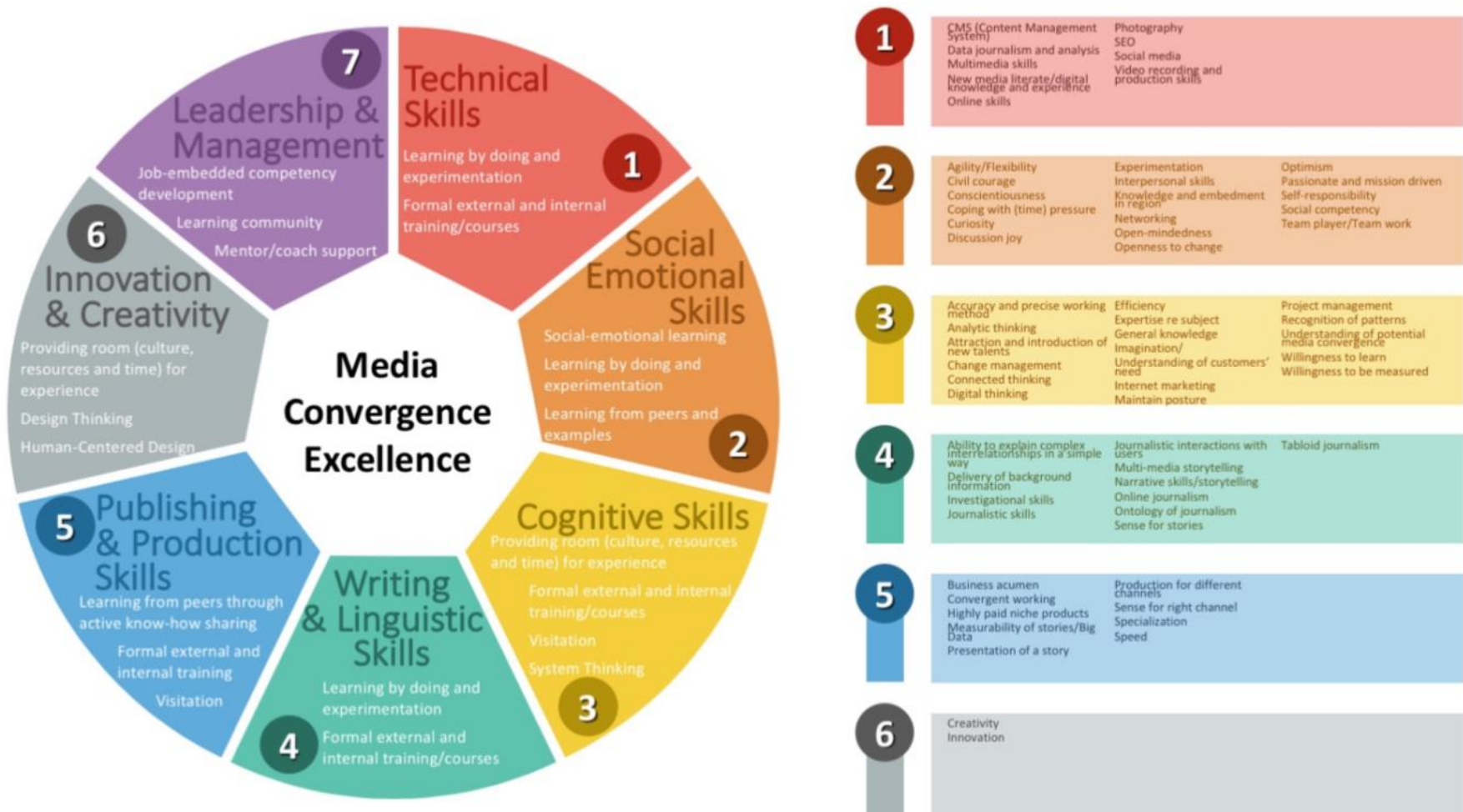

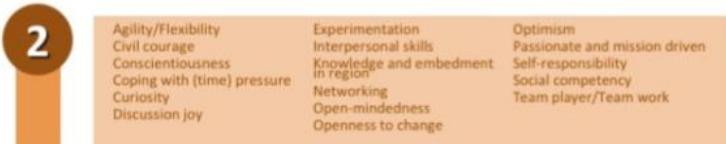

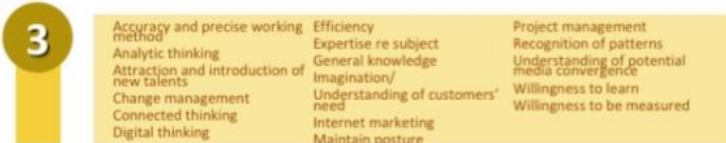

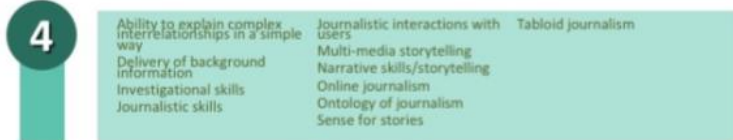

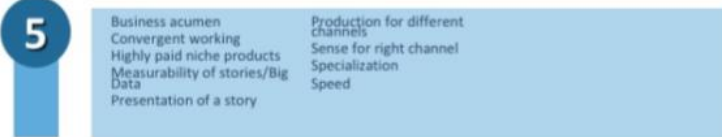

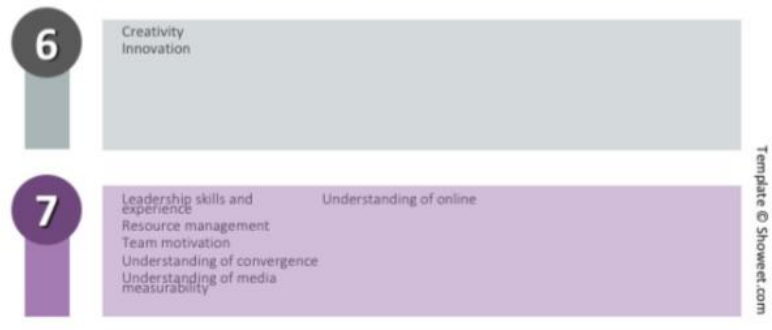

Figure 4. Convergent Competency Development Model 
The key findings of this study relate to the research questions as follows:

Answers to Question 1 of this case study 'What are the current and future competencies needed by media professionals (journalists and editors) in the convergent media environment in the German-speaking part of Switzerland?' did not support my assumption that there are remarkable differences between competencies and skill-sets of today and those expected in the future - not even in the distinction between experiences, perceptions, and expectations, did the results of the study yield any noteworthy findings. I nevertheless received insightful individual statements with regards to required skill-sets which enabled the grouping of seven competency themes required for convergent work:

1. Technical skills,

2. Social and emotional skills,

3. Cognitive skills,

4. Writing and linguistic skills,

5. Publishing and production skills,

6. Innovation and creativity, and

7. Leadership and management.

Question 2 'What are the most effective strategies for developing these competencies?' led to the most frequently mentioned strategies of 'learning by doing,' 'curiosity' and 'self-teaching' that were followed by the strategy 'giving room for experimenting.' 'External training courses' and 'headhunting for individuals with the desired skills' were additional strategies mentioned by participants of this study. 'Mixing people with different competencies/ensuring diversity' is, according to my study, another strategy for the development of convergent competencies and skills. 
Sub Question 3-A of the study 'How are the new competency clusters needed for convergent media production currently being developed?' carried a result which was very close to the results of the extrapolating Question 1. However, Question 1 suggested a much bigger variety of possible development strategies compared to how competencies are currently developed in Swiss German media corporations.

The results of Sub Question 3-B, 'What does such training need to include in order to develop convergent competencies?' showed much less strategic development concepts than concrete measures. Expectations of the study participants for the content of a convergent training are the imparting of the ability of writing a good story, of producing video and of acquiring multimedia skills plus a close connection of the training content to the daily business and tailor-made training approaches.

\section{Discussion and Unexpected Findings}

Media convergence plays a key role in the Swiss German media industry of today. This, with no exception, was confirmed by all my interview partners. At the same time, each of the four main players in the private media landscape in the German-speaking part of Switzerland have a different position in regard to media convergence. Nevertheless, some study participants have raised the question as to whether media convergence really is the panacea for the current crisis in the media industry, or whether media convergence might not be nothing else but a buzz word or a temporary fad. It is undisputed that my interviewees see a continuing trend in the digitalization of work environments and the consolidation of the various steps in news production. At the same time, in my inquiries I found support for the notion that journalism in the future no doubt will continue to hold on to some extent to the noble elitism of the journalist, the 'Edelfeder' (German, stands 
for illustrious journalist or wordsmith), and this simultaneously to the existence of armies of journalistic "soldiers." This, for instance, was expressed by participant 11 . He referred to the army of journalists who manage the journalistic mass business such as data and social media journalism. It is becoming apparent that, compared to the past, editors and journalists will have to become more flexible and versatile in the future. But in which direction will the journey go? Currently, the media industry is facing the emergence of new types of media use and, at the same time, is lacking a sustainable business model for quality journalism. In addition to their standard journalistic program and their mission of news distribution, some media providers in German-speaking Switzerland have built up a second mainstay with digital service offerings. In order to cope with this situation, it is important for media managers und media professionals to understand what media convergence will demand of them competency-wise and where media convergence appears. Where exactly media convergence in Switzerland can be located, in my opinion, does not only depend on the decision of a media corporation, to produce from now on convergent and to introduce a newsroom, but rather on how media professionals handle the ongoing social change. Various personal stories of study participants have colorfully demonstrated what this tremendous social and technological change of the last two decades has demanded from media professionals. The fact that the phenomenon of media convergence is not limited to the physical place of a newsroom, but can take place anywhere and is dissolved from space and time, indicates that media convergence starts in the minds of media managers and media professionals; it requires a change of mindset. In the light of all these circumstances, media professionals have to find their way and have to create a bridge between competencies needed in the past, the present and the 
future. In which direction the qualifications and requirements for editors and journalists will go was the driving force and leading question for my research work.

\section{Participants Experience with Media Convergence}

In order to understand how the emerging media convergence affected the professional lives of interview participants individually and to find some hints for effective strategies to gain convergent competencies, I asked for personal convergence stories. I was surprised that media managers and executives were quite at ease when it came to sharing their personal media convergence stories. I take this experience as a takeaway. It became clear in the course of my study that it was much easier for the interviewees to talk about their convergent life stories than to distinguish between their experiences, perceptions and expectations regarding media convergence. I did not expect that in most cases positive experiences with media convergence were reported, that the experience with media convergence was seen as a journey of which participants wanted to be a part, and that media convergence was perceived as providing new opportunities for journalism. This valuation is confirmed by Gordon (2003): “Journalists involved in tactical convergence had a wide range of reactions. At newspapers, some embraced the partnership as a way to increase their audiences. And on the TV side, the newsroom often saw the advantage of adding many more 'feet on the street' to report the news" (p. 65).

Convergent Competencies Needed Today and in the Future While working at AZ Medien, having the overall Human Resources responsibility, I observed an ongoing shift in requirements for new media personnel to be hired towards new media knowledge and digital skills (video, SEO, online and social media). I therefore assumed that there are remarkable differences between competencies 
and skill-sets of today and those expected in the future. The results of my study did not support my assumption. The difficulty my interview partners had with naming skills and competencies needed by journalists in the future was unexpected and is well described by participant 8: "It is extremely difficult to predict the future. We don't know what will be in five years. We don't know, for example, whether in five years there still will be printed daily newspapers.” Participant 1 comments about the future as follows: „After all, we don't know what the future will hold. Judging by just the last few years, we can assume that journalism and the way we do journalism will continue to change." Dwyer (2010), in a way, joins this discussion and questions the future media usage: "How will people access media content in the future? What combination of TV, computer or mobile device, and what kind of content will become common?" (p. 1). He continues to ask, "which screen device will be used to view specific shows, genres and websites. And how much news, sport, music videos, games, drama documentary, reality or social networking will there be?"

\section{Requirement of Social and Emotional Skills}

Another unexpected finding of this study was the importance interview participants attribute to social and emotional skills when it comes to convergent competencies. As a result of my study, I expected to receive mainly skills linked to technical and social media, writing and linguistic and publishing and production competencies. To me it was striking to hear the multiple mention of social and emotional skills, commonly referred to as soft skills, like 'passionate and mission driven,' passion for the profession of a journalist and for 'curiosity,' one of the main characteristics of journalism. Additionally, a sense of duty, 'conscientiousness' and an 'open mindset' and 
ultimately 'flexibility' was named. A comparison between published online job advertisements and the responses of media managers' competencies needed for media professionals in a convergent environment, brought the result of roughly matching skill and competency themes (Tables 4 and 6). However, the stereotypical mention of requested social and emotional skills (e.g. team player/teamwork, self-reliance, resilience, flexibility, reliability) in a large proportion of online job advertisements raises some questions regarding the validity of these statements in job ads. The reason for this typical choice of words in job ads often is based on the fact that the wording of job ads is passed from line managers to less experienced recruiters who do not very well understand the company's strategy and are not competency savvy. From my personal experience as an Executive Search Consultant and HR Director, I can add that job advertisements often use a flowerily language but do not have much in common with reality. Therefore, I suggest to carefully evaluate the accumulation of these standardized individual skills. However, the mentioning of basic tendencies like social and emotional skills found support among media managers and executives.

\section{Development Strategy "Headhunting”}

The most surprising result of my study was the explicit and repeated mention of 'headhunting for individuals with the desired skills' as a development strategy for convergent competencies. Media executive, participant 5, answered my question about the most effective development strategies as follows: "Headhunting for special talents," and media executive, participant 10, explains: "My experience simply is, those things which you need - talking about social media, with SEO - that is what you get from outside. There are people like that. You can hardly learn that." Participant 18 adds to this 
strategy: "just hiring people who already know how to do that." For someone like me who has a personal passion for people development and life-long-learning it is somewhat difficult to acknowledge that headhunting was repeatedly reported as an efficient convergent development strategy. Hiring new people with required skills and neglecting the development of the existing staff or denying offering a chance for development is for me a professional no-go. Of course, there will always be cases where highly specialized knowledge and experience can only be found on the job market, but in my opinion, this should be isolated cases only and not the standard for the development strategy of a company.

\section{Leadership and Management Skills}

Another unexpected finding was the clear postulate for the requirement of an enhancement of leadership and management skills among media managers. Participant 15 opens a respective discussion by sharing her observation: "I believe - and that may be a dire fact of journalism in general - that [a strong leadership style] basically doesn't mean anything because at all times individuals were promoted who were good at writing. ... Perhaps they were good writers; but they were no leaders. And that holds true up to the CEOs." Instead, she suggests, a position of leadership should be given to a person who can fill that leadership role, someone who can lead the company the best. The study participants had an explicit expectation and understanding of what kind of competencies leadership in the media industry has to entail: leading by example, leading with a clear vision and strategy, having the ability to build bridges and dissolve silo thinking, ensuring an overall positive atmosphere among employees, living a participative leadership style and marking physical presence, being specifically skilled in 
communication, performing the role of a change agent and leading transformation processes, having the gift of motivating staff, having the knowledge of resource management, and understanding the measurability of media output in a multimedia environment and hence understanding convergent working processes and people involved in convergence. Additionally, the importance of superiors facilitating and supplying training and learning opportunities was put on the list of leadership and managerial skills. I did not expect that the media managers interviewed would have such a clear picture on missing leadership and management skills. I observed this lack of leadership skills during my time as the Head of Human Resources for one of the major Swiss German private media corporations. I found support for my personal impression of desperately needed leadership skills in Robert Boyatzis, who in 2011 published a research about the importance of emotional, social and cognitive intelligence for leaders and managers: "Outstanding leaders, managers, advanced professionals and people in key jobs, from sales to bank tellers, appear to require three clusters of behavioral habits as threshold abilities and three clusters of competencies as distinguishing outstanding performance." He names the three threshold clusters as: 1) expertise and experience; 2) knowledge (i.e., declarative, procedural, functional and meta-cognitive); and 3) an assortment of basic cognitive competencies, such as memory and deductive reasoning. Boyatzis continues:

"There are three clusters of competencies that differentiate outstanding from average performers in many countries of the world" and enumerates them as: "1) Cognitive competencies, such as systems thinking and pattern recognition; 2) Emotional intelligence competencies, including self-awareness and self-management competencies, such as emotional self-awareness and emotional self-control; 3) Social intelligence 
competencies, including social awareness and relationship management competencies, such as empathy and teamwork" (p. 92f). This statement is consistent with my observations; it was the basis for a leadership curriculum I had developed and implemented for the entire management staff at AZ Medien. Participant 12 describes the current leadership challenges in the media industry well:

I find this matter a difficult one. I see that in our company. The way I manage and the way others are managing teams - in some cases it is diametrical. In our company, though, in this rather creative environment, something is expected which differs from what is expected, for instance, in Controlling. In our case different personalities are required, personalities with different styles of leadership. I find it rather difficult to learn leadership. You either got it or you don't. Perhaps there still is a little bit in between - of course. But in the first place, it is made up of competency. And if someone is not a good leader, he or she still has competency. That is okay, too. One doesn't, after all, want to be the boss's new friend. That doesn't have to be the case. But I believe in today's world an extremely high level of leadership is required. Meaning, we need a lot more leaders than managers. That I am convinced of.

\section{Conclusions}

In view of the research purposes of this study, the following conclusions can be derived:

1. In Switzerland, the professional title 'journalist' is not a protected professional title. Therefore, there are various ways for obtaining a journalism education. The two most renowned professional journalism-training centers in the German-speaking part of Switzerland are the MAZ - Die Schweizer Journalistenschule and the Ringier Journalistenschule.

2. Each participant of the study had his/her own peculiar way as to how they got involved in convergence, which ranges from an involuntarily slipping-in to a trying-out by curiosity. Media convergence is perceived as providing new opportunities for journalism that requires intensive rethinking. 
3. The emergence of media convergence in the German-speaking part of Switzerland appeared in phases, starting at the end of the 20th century. Phase 1 is described when online media was comparing themselves with print products; Phase 2 when online media rubbed themselves with print counterparts, and Phase 3 when mobile and social media (with the emergence of Facebook) were introduced and when the discussion about 'Digital First' and channel spanning work arose (between 2009 and 2011).

4. Media convergence already is playing an important role in all Swiss German media corporations. However, all of them see slight differences between the four major media players in the German-speaking part of Switzerland concerning the status of media convergence.

5. The biggest changes in the way how editors and journalists work in this more convergent environment were perceived in the area of the 'way of working,' 'speed of news,' the requirement of 'news distribution on different channels,' 'openness for new media' and 'interaction with readers.'

6. Media convergence is closely linked to the physical place of a newsroom and the term newsroom itself with the place where news is being produced. However, some interview partners emphasized that media convergence starts in the minds of individuals and includes a change of mind-set. In this context, the concept of a newsroom can be perceived as the personalized convergence while media convergence is not limited to the newsroom and hence can take place everywhere and is disconnected from space and time.

7. Competencies needed by journalists in a convergent environment encompass a broad framework which includes basic skills editors and journalists must have at any 
time. All skills and competencies mentioned were grouped in seven competency themes: (a) technical skills, (b) social and emotional skills, (c) cognitive skills, (d) writing and linguistic skills, (e) publishing and production skills, (f) innovation and creativity, and (g) leadership and management.

8. As the most effective development strategies for the development of convergent competencies were named, 'learning by doing,' 'curiosity,' 'self-teaching,' 'giving room for experimenting,' 'external training courses,' 'headhunting for individuals with the desired skills,' and 'mixing people with different competencies/ensuring diversity.'

9. Competency clusters needed for convergent media production currently are being developed by 'internal experts/specialists,' 'rotation and mutual learning,' 'hiring people with respective skills,' 'external training/courses,' 'learning on the job' and 'learning by example.'

10. An essential prerequisite for the content of convergent training is teaching how to 'write a good story,' 'video producing' and 'multimedia skills.'

11. Main players for convergent competency development in the Germanspeaking part of Switzerland are schools of journalism, superiors, chief editorial/editorial offices, academic institutions, experts and human resources.

12. The presented competency development model is composed of seven competency clusters. A competency specific mixture of learning methods, according to the blended learning approach, is suggested to lead to the best results in gaining excellence in media convergence. 
13. The development of leadership and management competencies is given high importance and should contain a huge bandwidth of cognitive skills as well as social and emotional intelligence competencies.

\section{Recommendations}

As a result of the findings that emerged from this research, which explored competencies needed by media professionals (journalists and editors) in the convergent media environment in the German-speaking part of Switzerland now and in the future, the following recommendations are given.

\section{For Media Professionals}

If the results of this study are taken into consideration, they might have implications for practitioners. Therefore, the following recommendations can be given:

1. Consider new ways of working, new media presentation and production in connection with media convergence as personal professional enrichment.

2. Test new technologies and try out new systems on an ongoing basis.

3. Put yourself in the driver's seat of your personal professional development, be curious and alert for new trends and practice learning-by-doing and self-teaching.

4. Contribute to team-learning activities and share knowledge with your colleagues.

5. Be mindful of your work-life-balance. 


\section{For Media Managers}

These recommendations, derived from interviews with media managers in the study and my personal experience as Human Resources responsible in the media industry, are directed to media executives and media managers:

1. Practice convergence yourself and gain experience with existing and new digital tools, apps and systems coming up (e.g. Android, iOS or Windows 10 Mobile devices, social media, Twitter, Instagram.)

2. Implement a system of change agents and become a change master.

3. Provide room and a safe place for experimenting (honeymoon period), encourage free-thinking, initiate or encourage experiential projects with respective "play money" and allow failures of pilots.

4. Practice the full range of blended learning when planning and running any learning activities.

5. Plan and provide a sizeable annual budget for the full range of training and learning activities according to blended learning by putting an emphasis on the development of technical, social and emotional, cognitive, and leadership and management skills.

6. Invite and involve young people in your company's management (the average age of media managers interviewed was 46.75 years).

7. Provide retreat opportunities and individual work islands etc. for employees working in a newsroom setting.

8. Equip media professionals for convergent work with the right electronic tools, systems and services. A 16 GB device is not enough for recording videos and a desktop 
PC is not mobile enough. Today, company phone contracts with flat rates for voice and data are available for small fees.

9. Assess emotional intelligence and social and emotional competencies of a potential candidate before nominating a new manager.

10. Communicate the company's vision and strategy in a way that is available for all your employees and which is understood by everybody.

11. Organize innovation labs with Design Thinking and Human Centered Design approaches and implement a creativity prone culture.

12. Implement a culture where failure is perceived as a chance and where failures are reviewed diligently, and taken as basis for solution development.

13. Run cross-department, interdisciplinary and intercompany projects.

14. Allow and get yourself involved in a temporary professional switching of sides.

15. Provide healthy food and beverage offers and make them accessible 24 hours a day.

\section{For Policy Makers}

For those making policies and considering the underlying question of convergent ways of working, it might be worthwhile to consider the following suggestions:

1. Implement a leadership development aims at developing leadership and management competencies by supporting learning communities and personal coaches, mentors, or advisors, a program which is based on continued individualized feedback. 
2. Encourage your Human Resources department put an emphasis on people development. Implement and maintain a company-wide Talent Management system that focusses on convergent development of internal talents.

3. Develop and implement a "Mobile Working Policy" with clear guidelines regarding telework and data security.

4. Develop and implement a Policy for "Flexible Working" with models for annual and life-span working hours or adjusted to Swiss Labor Law.

5. Develop and implement a salary system with equal pay for digital and print journalism work.

6. Assess skills of your entire workforce and implement and maintain a skills management system that focusses on convergent competencies and internal mobility.

7. Ensure that a remarkable part of the budget is spent for off-the-classroom learning opportunities (networking and social events, conferences and congresses, visitation of other media corporations, and similar industry sectors).

8. Develop a bonus and/or reward system that acknowledges successfully developed and applied leadership skills and business success (not only for sales representatives).

9. Develop and implement team incentives in connection with convergent efforts.

10. Implement and maintain an incentive system for creativity and innovation (e.g. continuous improvement process (CIP), Kaizen etc.).

11. Implement a Corporate Health Management program. 


\section{Recommendations for Future Research}

This study provides several topics and questions warranting more study. Thus, the following recommendations have emerged for further research:

1. A study on competencies needed by media professionals (journalists and editors) in the convergent media environment in the German-speaking part of Switzerland now and in the future covering all types of media (Print, Radio, TV/Video, Online, Social media).

2. A study on competencies needed by media professionals (journalists and editors) in the convergent media environment in the German-speaking part of Switzerland now and in the future from the point of view of media professionals.

3. A study of the convergent job reality and needs for development/training and respective most effective development strategies from the point of view of media professionals.

4. A study exploring Swiss German news users' consumer behavior (different age groups with a focus on young media users; panel of focus group based).

5. A study on competencies needed by media professionals (journalists and editors) in the convergent media environment in all of Switzerland (including the French and Italian speaking parts) now and in the future.

6. A study on competencies needed by media professionals (journalists and editors) in the convergent media environment in Germany and Austria now and in the future.

7. A study measuring the validity of the presented convergent competency development model. 
8. A study to elaborate convergent competencies per job profile (editor, print journalist, digital journalist, online journalist, manager, intern etc.).

9. A study measuring the impact of leadership and management skills on effective changes in the media industry.

10. A study of perceptions of media professionals in the German-speaking part of Switzerland about challenges and implications of media convergence.

11. A study on the impact of "Mobile Working Policies," "Flexible Working Policies," equipment with digital power tools, retreat opportunities, leadership style of superiors, on job satisfaction of editors and journalists working in convergent media environments.

\section{Quo Vadis Convergence Competency Development?}

Although the 70-20-10 rule, which describes learning achievement by challenging assignments (70\%), learning achievement by developmental relationships (20\%) and learning achievement by coursework and training (10\%), is widely disputed and certainly has its flaws, it does contain some truth when it comes to the fact that much of the learning is not taking place in a classroom setting. However, employees who are in the coffee corner too often and for too long and who at that location have lively discussions with their colleagues or a journalist who, instead of sitting in front of the screen, on the search for ideas jogs around the block or someone who via a mobile device is permanently connected with the outside world, are frowned at. Multitudes of educational and psychological learning researchers have demonstrated that learning happens informally, incidentally, embedded in a social framework, through social constructivism 
or connectedness, or is experiential. Nevertheless, almost all prospective journalists are sent to schools of journalism or academic journalism training institutions.

The fact that it is not necessarily given to everyone to learn how to deal with the latest and most hip digital tools and systems also concerns the German-speaking media industry. Hence, all hope is resting on a single generation, namely on the 'Digital Natives.' And if this strategy does not work, one searches for the established convergent experts from competitors by headhunting.

How much longer will it be the case that companies do not see a need for practicing life-long-learning and for opening their mind for a blended learning approach, where the variety of learning strategies is linked to respective competencies to acquire?

Our present society needs transformational managers and fore thinking leaders. It is not too late yet, but the future should start now where media corporations in the German-speaking part of Switzerland draw from the full range of development opportunities for convergent competences for media professionals.

With the overview of expected convergent skills and the linkage with possible development and learning strategies, the present study aims at providing suggestions in this direction. Siemens (2005) states: "The pipe is more important than the content within the pipe. Our ability to learn what we need for tomorrow is more important than what we know today" (p. 8).

The future of the Swiss German media industry depends on leaders who, like mountain guides, will take their crew over an unknown territory to a still uncertain summit. Such leaders must be experienced on one hand, and visionary and creative on the other hand. They need to have the ability to adapt quickly to strategy changes, function as 
change agents and communicate in a way that can keep their crew on the track. They must closely accompany the weakest team members, they need to have the ability to motivate people and provide enough room for development and to send out forerunners as scouts to explore the site, trends and new developments and opportunities. Ultimately, they themselves must be able and willing to keep up with social changes and technology developments, they must be ready for innovation, open for new learning experiences and be themselves learning practitioners and experts in acquiring new competencies.

The Swiss media industry will only be able to keep up with the imminent change in the media world if it succeeds in quickly developing new competencies required by journalists and editors. And they will only be able to do this by using a variety of learning strategies and by being in close connection with new business models as well as with new technology. Hence the competency to build and develop competencies in the future will be the most competitive advantage for media corporations in the German-speaking part of Switzerland. 
APPENDICES 


\section{APPENDIX A}

\section{GLOSSARY}

Media Convergence

Competency

Convergent competency

Media manager

Media professionals

Story

Storytelling
The coexistence and merging process of different types of mass media

Competency in this study consists of 'knowledge,' 'skills' and 'abilities' and also as a set of 'knowledge,' 'skills' and 'abilities'

Competencies that are necessary to compete in an increasingly convergent media environment Print, TV, radio and digital editors-in-chief, heads of media profit centers, media executives, presidents of media associations, and human resources managers or talent development managers media companies employ to lead media industry firms

Editorial staff who work on the production of the actual news items to be dispersed in online, TV and the newspaper media

A story in journalism is a function of news distribution.

Stories are created in order to pass on a piece of information to readers, viewers, or listeners.

Also referred as narrative journalism is the art of captivating readers, viewers, or listeners by drawing them into a story with greater detail than is found in traditional news stories. Storytelling is often linked to digital storytelling which uses images, video, infographics or/and other visual elements in order to create a tangible experience for media consumers 
INTERVIEW PROTOCOL

\author{
INTERVIEW PROTOCOL
}

Questions and Field Notes

Interviewee:

Organization:

Date/Time:

Setting for Interview and Observations:

Central Research Questions: What are the current and future competencies needed by media professionals (journalists and editors) in the convergent media environment in the German speaking part of Switzerland?

What are the most effective strategies to develop these competencies?

Sub questions of the study: How are the new competency clusters needed for convergent media production currently being developed? More specifically, what does such training need to include in order to develop convergent competencies?

Interview Questions

1. How long have you served in your current role as Current Function ?

2. How much did the emergence of media convergence change since you started your current role?

3. Which role does media convergence play in large Swiss German / German media companies today?

4. Which role does media convergence play in Name of Media Company today?

5. How far media convergence has already changed the way journalists work in the German speaking part of Switzerland / Germany today?

6. Is the newsroom the place where convergence takes place?

7. Which competencies and skills are needed in a convergent environment?

8. Please describe your experiences, perceptions and expectations with regards to competencies and skills needed for media professionals in a convergent environment today?

9. Please describe your experiences, perceptions and expectations with regards to possible competencies and skills needed for media professionals in a convergent environment in the future?

10. Please describe possible competencies and skills needed for Name of Media Company. 
11. Please describe your experiences, perceptions and expectations with regards to the most effective and successful strategies and didactics to develop convergent competencies and skills.

12. How are the new competency clusters needed for convergent media production currently being developed in Name of Media Company?

13. What does such training/learning method need to include in order to develop convergent competencies?

14. Who are important players to facilitate and supply training/learning offers in order to develop convergent competencies?

15. Do you have any other comments/insights/thoughts you want to share with me with regards to media convergence and convergent competencies in the media industry?

16. What is your personal professional experience with media convergence? 


\section{INTERVIEW-PROTOKOLL}

Fragen und Feldnotizen

Interviewter:

Organisation:

Datum/Zeit:

Setting für das Interview und Beobachtungen:

\section{Zentrale Forschungsfragen}

Was sind die aktuellen und zukünftig benötigten Kompetenzen von Medienprofis (Journalisten und Redakteure), die in einer konvergenten Medienlandschaft im deutschsprachigen Teil der Schweiz benötigt werden?

Was sind wirksamste Strategien, um diese Kompetenzen zu entwickeln?

\section{Unter-Fragen der Studie}

Wie werden diese neuen Kompetenzen-Gruppen (Cluster), die für eine konvergente Medienproduktion benötigt werden, derzeit entwickelt? Genauer gesagt, was muss eine entsprechende Ausbildung beinhalten, die die Entwicklung von konvergenten Kompetenzen erreicht? 
Definition Medien-Konvergenz

Die Koexistenz und der Prozess des Zusammenwachsens von verschiedenen Arten von Massenmedien (traditionelle Zeitung, Online-und Web-Content, TV)

Definition Kompetenzen

Im Rahmen dieses Forschungsprojektes werden Kompetenzen im Lichte der Personalund Organisationsentwicklung betrachtet. In diesem Zusammenhang werden die Leistungsfähigkeit einer Organisation und die Eigenschaften von Kernkompetenzen mit dem Wettbewerbsvorteil eines Unternehmens in Verbindung gebracht. Clardy (2008) erweitert die enge Definition von Kompetenz als "Wissen", "Fertigkeiten" und "Fähigkeiten" in Richtung eines ressourcenbasierten Modells, in denen Kompetenzen eine Vielzahl von zusätzlichen Faktoren wie Persönlichkeit, Verhalten, Mehrwert für den Kunden usw. umfassen. Das ressourcenbasierte Modell unterstützt die Annahme, dass Kernkompetenzen von Organisationen deren

Wettbewerbsfähigkeit bestimmen. Ein ressourcenbasierter Ansatz erweitert die Definition von Kernkompetenzen um folgende Merkmale von

Kompetenzen (1) die typisch für die Organisation sind und die Grundlage für einen nachhaltigen Wettbewerbsvorteil sind, (2) langfristige organisatorische Leistungsfähigkeit zeigen, (3) Eigenschaften einer Organisation oder eines Systems sind, die mit Einzelpersonen verknüpft sind, (4) die nur schwer von Akteuren ausserhalb der Organisation zu erwerben oder zu erhalten sind, und (5) die einer Organisation eine asymmetrische und differenzierende Position im Vergleich zu Wettbewerbern schaffen.

\section{Konvergente Kompetenzen}

Im Rahmen dieses Forschungsprojektes werden Kompetenzen, die notwendig sind, um in einem zunehmend konvergenten Medien-Umfeld konkurrieren zu können, "konvergente Kompetenzen" genannt. 


\section{Interview-Fragen}

1. Wie lange sind Sie in Ihrer aktuellen Rolle als aktuelle Funktion tätig?

2. Wie stark hat sich das Auftreten von Medien-Konvergenz verändert, seitdem Sie in Ihre aktuelle Rolle begonnen haben?

3. Welche Rolle spielt Medien-Konvergenz heute bei aktuelles Unternehmen?

4. Welche Rolle spielt Medien-Konvergenz heute in grossen Deutschschweizer Medienunternehmen? 
5. Wie weit hat Medien-Konvergenz bereits die Art und Weise verändert, wie Journalisten heute im deutschsprachigen Teil der Schweiz arbeiten?

6. Wo findet "Medien-Konvergenz"in Bezug auf seinen funktionellen und / oder physischen Standort in erster Linie statt? Ist der Newsroom der Ort, wo Konvergenz stattfindet?

7. Welche Kompetenzen und Fähigkeiten werden von Medien-Profis in einem konvergenten Umfeld benötigt?

8. Bitte beschreiben Sie Ihre Erfahrungen, Wahrnehmungen und Erwartungen in Bezug auf Kompetenzen und Fähigkeiten, die von Medien-Profis in einem konvergenten Umfeld heute benötigt werden?

Erfahrungen

Wahrnehmungen

Erwartungen 
9. Bitte beschreiben Sie Ihre Erfahrungen, Wahrnehmungen und Erwartungen in Bezug auf mögliche Kompetenzen und Fähigkeiten, die von Medien-Profis in einem konvergenten Umfeld in der Zukunft benötigt werden?

Erfahrungen

Wahrnehmungen

Erwartungen

10. Bitte beschreiben Sie mögliche Kompetenzen und Fähigkeiten, die für Name des Medienunternehmens benötigt werden.

11. Bitte beschreiben Sie Ihre Erfahrungen, Wahrnehmungen und Erwartungen in Bezug auf die effektivsten und erfolgreichsten Strategien und Lernmethoden um konvergente Kompetenzen und Fähigkeiten zu entwickeln.

Erfahrungen

Wahrnehmungen

Ewartungen

12. Wie werden die Kompetenzen-Gruppen (Cluster), die für eine konvergente Medienproduktion benötigt werden, derzeit bei Name des

Medienunternehmens entwickelt? 
13. Was muss eine entsprechende Ausbildung / Lernmethode beinhalten, die die Entwicklung von konvergenten Kompetenzen erreicht?

14. Wer sind wichtige Akteure in der Durchführung und Versorgung mit Lernangeboten, die helfen, konvergente Kompetenzen zu entwickeln?

15. Haben Sie weitere Kommentare / Erkenntnisse / Gedanken, die Sie im Hinblick auf Medien-Konvergenz und konvergente Kompetenzen in der Medienbranche für die nahe oder ferne Zukunft mit mir teilen wollen?

nahe Zukunft

ferne Zukunft

16. Was ist Ihre persönliche professionelle Erfahrung mit Medien-Konvergenz?

Herzlichen Dank für Ihre Zeit und Unterstützung meines Forschungsprojektes! 


\section{INSTITUTIONAL CONSENT FORMS}

\section{ars AEITUNG}

Institutional Review Board Andrews University

4150 Administrative Drive

Room 322

Berrien Springs, MI 49104-0355

Aarau, 5. Juli 2016

Forschungsarbeit Christiane E. Theiss

Sehr geehrtes Institutional Review Board der Andrews University

Im Namen der Chefredaktion der „az Nordwestschweiz", gewähren wir Christiane E. Theiss die Erlaubnis, im Rahmen ihrer Forschungsarbeit an der Andrews University mit dem Thema "Adopting to Change in the Swiss German Media Industry: Identifying and developing competencies needed by journalists and editors to cope with future market needs - a collective case study" zwischen Juli und September 2016 ein halbstrukturiertes ca. 1,5 stündiges Interview mit unserem Chefredaktor, Herrn Christian Dorer, durchzuführen. Dieses Interview kann von der Forscherin auf einem Tonträger aufgenommen werden, im Rahmen ihrer Forschungsarbeit ausgewertet und anonymisiert in ihrem Forschungsbericht veröffentlicht werden.

Wir freuen uns, an dieser Studie teilzunehmen und somit einen Beitrag zu dieser Forschung zu leisten.

Freundliche Grüsse AZ Zejtangen AG

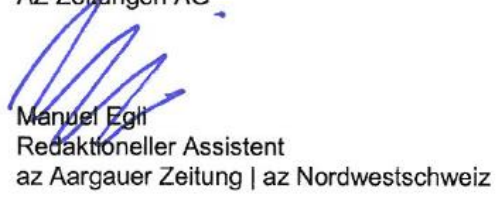




\section{azmedien}

Institutional Review Board Andrews University

4150 Administrative Drive

Room 322

Berrien Springs, MI 49104-0355

Aarau, 24. Oktober 2016

Sehr geehrtes Institutional Review Board der Andrews University

Im Namen von AZ Medien, gewähren wir Christiane E. Theiss die Erlaubnis, im Rahmen ihrer Forschungsarbeit an der Andrews University mit dem Thema "Adopting to Change in the Swiss German Media Industry: Identifying and developing competencies needed by journalists and editors to cope with future market needs - a collective case study" in unserem Haus ca. 1,5 stündige Interviews mit Schlüsselpersonen durchzuführen. Diese Interviews können von der Forscherin auf einem Tonträger aufgenommen werden, im Rahmen ihrer Forschungsarbeit ausgewertet und anonymisiert in ihrem Forschungsbericht veröffentlicht werden.

Wir freuen uns, an dieser Studie teilzunehmen und somit einen Beitrag zu dieser Forschung zu leisten.

Freundliche Grüsse

AZ Medien AG

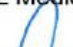

$(1$

hainh

AxetWüstmann

CEO 


\section{$\mathrm{NZZ}$ Mediengruppe}

\section{NZZ Management AG
Falkenstrasse 11. Postfach. CH-8021 Zürich}

Institutional Review Board Andrews. University 4150 Administrative Drive

Room 322

Berrien Springs, MI 49:104-0355

Zürieh, 05. Dezember 2016

\section{Bestätigung anonymisierte Interviews}

Sehr geehrtes Institutional Review Board der Andrews University

Im Namen der NZZ Mediengruppe gewähren wir Christiane E. Theiss die Erlaubnis, in Rahmen ihrer Forschungsarbeit an der Andrews University mit dem Thema "Adopting to Change in the Swiss German Media Incustry: Identifying and developing competencies needed by journalists and editors to cope with future market needs - a collective case study" in unserem Haus ea. 1,5 stündige Interviews mit Schlüsselpersonen durchzuführen.

Diese. Interviews können von der Forscherin auf einem Tonträger aufgenommen werden, im Rahmen ihrer Forschungsarbeit ausgewertet und anonymisiert in ilrem Forschungsbericht veröfentlicht werden.

Wir freuen uns, an dieser Studie teilzunehmen und somit einen Beitrag zu dieser Forschung zu leisten.

Freundliche Grüsse

Petra Feigl-Fässle

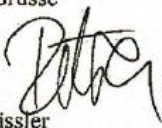

Leiterin Personal NZZ Mediengruppe

NZZ MANAGEMENT AG

Falkenstrasse 11 - Postfach - $\mathrm{CH}-8021$ Zürich

Zentrale +4144258:1111. Direkt +412581700

petra.feigl@nzz.ch · www.nzzmediengruppe.ch - www.nzz.ch 


\section{$0 \circ$ Ringier}

Institutional Review Board Andrews University

4150 Administrative Drive

Room 322

Berrien Springs, MI 49104-0355

Zürich, 18. Oktober 2016

Sehr geehrtes Institutional Review Board der Andrews University

Im Namen von Ringier AG, gewähren wir Christiane E. Theiss die Erlaubnis, im Rahmen ihrer Forschungsarbeit an der Andrews University mit dem Thema "Adopting to Change in the Swiss German Media Industry: Identifying and developing competencies needed by journalists and editors to cope with future market needs - a collective case study" in unserem Haus ca. 1,5 stündige Interviews mit Schlüsselpersonen durchzuführen. Diese Interviews können von der Forscherin auf einem Tonträger aufgenommen werden, im Rahmen ihrer Forschungsarbeit ausgewertet und anonymisiert in ihrem Forschungsbericht veröffentlicht werden.

Wir freuen uns, an dieser Studie teilzunehmen und somit einen Beitrag zu dieser Forschung zu leisten.

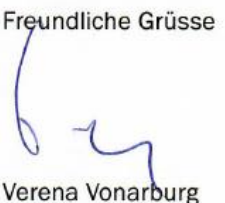

Head of Public Affairs

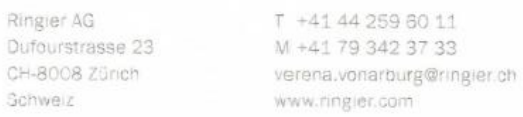


Institutional Review Board Andrews University

4150 Administrative Drive

Room 322

Berrien Springs, MI 49104-0355

Zürich, 6. Dezember 2016

\section{Forschungsarbeit Christiane E. Theiss}

Sehr geehrtes Institutional Review Board der Andrews University,

Im Namen der Tamedia AG gewähren wir Christiane E. Theiss die Erlaubnis, im Rahmen ihrer Forschungsarbeit an der Andrews University mit dem Thema "Adopting to Change in the Swiss German Media Industry: Identifying and developing competencies needed by journalists and editors to cope with future market needs - a collective case study" zwischen Dezember 2016 und Januar 2017-strukturierte ca. 1,5 stündige Interviews in unserem Haus durchzuführen. Diese Interviews können von der Forscherin auf einem Tonträger aufgenommen werden, im Rahmen ihrer Forschungsarbeit ausgewertet und anonymisiert in ihrem Forschungsbericht veröffentlicht werden.

Wir freuen uns, an dieser Studie teilzunehmen und somit einen Beitrag zu dieser Forschung zu leisten.

Mit freundlichen Grüssen

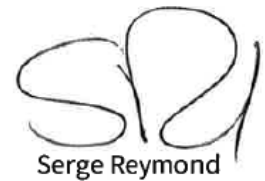

Mitglied der Unternehmensleitung

Leiter Bezahlmedien 


\section{APPENDIX D}

\section{PARTICIPANT CONSENT FORM}

\begin{tabular}{c}
\hline ANDREWS UNIVERSITY \\
INFORMED CONSENT FORM \\
\hline
\end{tabular}

Title of Project: Adopting to change in the Swiss German Media Industry

Name of Researcher: Christiane E. Theiss, Doctoral candidate, Andrews University

\section{Introduction}

My name is Christiane Theiss. I am a doctoral candidate from the Department of Leadership at the Andrews University, Berrien Springs/Michigan, U.S. I am conducting a research project in partial fulfillment of my doctoral program. This research is an investigation of media managers and media professionals in the German speaking part of Switzerland. It is focused on understanding of competencies needed by media professionals in order to cope with the ongoing media convergence and constant development of new forms of media in the media industry in Switzerland.

\section{Purpose of the research}

The purpose of this research is to explore the understanding of competencies needed by media professionals in order to cope with the ongoing media convergence and constant development of new forms of media in the media industry in Switzerland. Your participation in this study is greatly appreciated and will help to answer two questions: What are the current and future competencies needed by media professionals (journalists and editors) in the convergent media environment in the German speaking part of Switzerland? What are the most effective strategies to develop these competencies?

\section{Procedures:}

You are being asked to read the informed consent form, to ask questions for clarification, and to understand the informed consent form and to give your own informed consent for participation in the study. The process will involve your participation in a semi-structured interview that will take about one and a half hours of your time. The interview will be recorded (audiotaped), and the researcher will also take handwritten notes.

\section{Participant Selection}

I have been informed that in order for me to participate in the research project I have to be either a media manager or a professional in the German speaking part of Switzerland.

\section{Voluntary Participation}

I have been informed that participation in this study is voluntary, that refusal to participate involves no penalty or loss of benefits to which I may otherwise be entitled, and that I may discontinue my participation at any time without penalty or loss of benefits to which I may otherwise be entitled

\section{Duration}

I have been informed that the duration of my participation may last for one to one and a half hours. 
Risks

I have been informed that the research involves no more than minimal risk to subjects.

Benefits

I have been informed that there will be no direct benefit to me.

\section{Confidentiality}

I have been informed that my identity in this study will not be disclosed in any published document. And that the researcher will keep the records in a secure and safe place with limited access to researcher alone for a period not less than 3 years.

Contact Information:

I have been informed that should I have questions about the study, that I may willingly contact the researcher, Christiane E. Theiss at Tel. +4179 796-7001, email

theiss@andrews.edu; or the advisor - Dr. Erich W. Baumgartner at Tel.+1 269-471-2523, email baumgartner $@$ andrews.edu; OR irb $a$ andrews.edu

I have read the contents of this Consent and received verbal explanations to questions I had. My questions concerning this study have been answered satisfactorily. I hereby give my voluntary consent to participate in this study. I am fully aware that if I have any additional questions I can contact researcher, and or the advisor

Date 


\begin{tabular}{c} 
ANDREWS UNIVERSITY \\
EINWILLIGUNGSERKLÄRUNG \\
\hline Titel des Projekts: Anpassung an Veränderungen in der Deutschschweizer Medienbranche
\end{tabular}

Name des Researchers: Christiane E. Theiss, Doktorandin, Andrews University

\section{Einführung}

Mein Name ist Christiane Theiss. Ich bin Doktorand am Department für Leadership an der Andrews Universität in Berrien Springs / Michigan, U.S.A. Im Rahmen meines

Promotionsvorhabens führe ich ein Forschungsprojekt durch. Diese Studie umfasst eine

Untersuchung von Medienmanagern und Medienproduzierenden im deutschsprachigen Teil der

Schweiz. Sie konzentriert sich auf das Verständnis von Kompetenzen, die von

Medienproduzierenden benötigt werden, um mit der laufenden Medienkonvergenz und ständigen

Entwicklung neuer Medienformen in der Medienbranche in der Schweiz mithalten zu können.

\section{Ziel der Studie}

Das Ziel dieser Studie ist es, das Verständnis von Kompetenzen zu erkunden, die von Medienproduzierenden benötigt werden, um die laufende Medienkonvergenz und ständige Entwicklung neuer Medienformen in der Medienbranche in der Schweiz zu bewältigen. Ihre Teilnahme an dieser Studie wird sehr geschätzt und wird dazu beitragen, zwei Fragen zu beantworten: Was sind die aktuellen und zukünftigen Kompetenzen, die von Medienproduzierenden (Journalisten und Redakteuren) in der konvergenten Medienlandschaft im deutschsprachigen Teil der Schweiz benötigt werden? Was sind die wirksamsten Strategien, um diese Kompetenzen zu entwickeln?

\section{Vorgehensweise}

Sie werden gebeten, die Einwilligungserklärung zu lesen, bei Unklarheiten Fragen zur Klärung zu stellen, ihren Inhalt nachvollziehen zu können und Ihre eigene Zustimmung für die Teilnahme an der Studie zu geben. Der Forschungsprozess wird Ihre Teilnahme an einem halbstrukturierten Interview beinhalten, das etwa eineinhalb Stunden dauert. Das Interview wird aufgezeichnet (Tonträger) werden und der Forscher wird zusätzlich handschriftliche Notizen anfertigen.

\section{Auswahl von Studienteilnehmern}

Sie wurden darüber informiert, dass Sie entweder ein Medienmanager oder ein Medienproduzierender im deutschsprachigen Teil der Schweiz sein müssen, um an der Studie teilzunehmen zu können.

\section{Freiwillige Teilnahme}

Sie wurden darüber informiert, dass die Teilnahme an dieser Studie freiwillig ist, eine Teilnahmeverweigerung keinen Nachteil oder den Verlust von Leistungen, auf die Sie sonst Anrecht hätten, zur Folge hat und dass Sie Ihre Teilnahme, ohne Nachteil oder den Verlust von Leistungen, auf die Sie sonst Anrecht hätten, jederzeit beenden können.

Dauer

Sie wurden darüber informiert, dass die Dauer Ihrer Teilnahme zwischen einer Stunde und eineinhalb Stunden ist. 
Risiken

Sie wurden darüber informiert, die Studie nicht mehr als ein minimales Risiko für Teilnehmer beinhaltet.

Vorteile

Sie wurden darüber informiert, dass Sie durch diese Studie keinen direkten Vorteil haben werden.

\section{Vertraulichkeit}

Sie wurden darüber informiert, dass Ihre Identität in dieser Studie in keinem publizierten Dokument offengelegt werden wird und dass der Forscher die Datensätze an einem sicheren Ort, der nur dem Forscher zugänglich ist, über einen Zeitraum von nicht weniger als 3 Jahren aufbewahren wird.

\section{Kontakt-Information:}

Sie wurden darüber informiert, dass Sie sich bei Fragen über die Studie gerne an den Forscher, Christiane E. Theiss, über Tel.+41 79 796-7001, E-Mail theiss@andrews.edu; oder an den Berater der Studie, Dr. Erich W. Baumgartner, über Tel. +1 269-471-2523, EMail baumgartner@andrews.edu ODER an irb@andrews.edu wenden können.

Ich habe den Inhalt dieser Einwilligung gelesen und erhielt mündlich Erklärungen zu meinen Fragen. Meine Fragen zu dieser Studie wurden zufriedenstellend beantwortet. Ich gebe meine freiwillige Zustimmung zur Teilnahme an dieser Studie. Ich weiss, dass ich bei weiteren Fragen den Forscher oder den Berater der Studie kontaktieren kann.

Unterschrift (Interviewpartner)

Datum 


\title{
IRB APPROVAL LETTER FOR RESEARCH
}

\section{Andrews 1 University}

July 15, 2016

Christiane E. Theiss

Tel: +41 79-796-7001

Email: Christiane.theiss@gmail.com

\begin{abstract}
RE: APPLICATION FOR APPROVAL OF RESEARCH INVOLVING HUMAN SUBJECTS IRB Protocol \#: 16-076 Application Type: Original Dept.: Leadership Review Category: Expedited Action Taken: Approved Advisor: Erich Baumgartner Title: Adopting to change in the Swiss German media industry: Identifying and developing competencies needed by journalists and editors to cope with future market needs - A collective case study.
\end{abstract}

This letter is to advise you that the Institutional Review Board (IRB) has reviewed and approved your IRB application for research involving human subjects entitled: "Adopting to change in the Swiss German media industry: Identifying and developing competencies needed by jourmalists and editors to cope with future market needs-A collective case study" IRB protocol number 16-076 under Expedited category. This approval is valid until July 15, 2017. If your research is not completed by the end of this period you must apply for an extension at least four weeks prior to the expiration date. We ask that you inform IRB whenever you complete your research. Please reference the protocol number in future correspondence regarding this study.

Any future changes (see IRB Handbook pages 10-11) made to the study design and/or consent form require prior approval from the IRB before such changes can be implemented. Please use the attached report form to request for modifications, extension and completion of your study.

While there appears to be no more than minimum risk with your study, should an incidence occur that results in a research-related adverse reaction and/or physical injury, (see IRB Handbook page 11) this must be reported immediately in writing to the IRB. Any projectrelated physical injury must also be reported immediately to the University physician, Dr. Reichert, by calling (269) 473-2222. Please feel free to contact our office if you have questions.

Best wishes in your research.

Sincerely

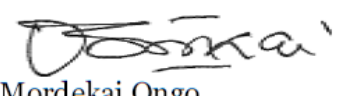

Mordekai Ongo

Research Integrity \& Compliance Officer

Institutional Review Board - 4150 Administration Dr Room 322 - Berrien Springs, MI 49104-0355 Tel: (269) 471-6361 Fax: (269) 471-6543 E-mail: irb@andrews.edu 


\section{REFERENCE LIST}

Argyris, C. (2002). Double-loop learning, teaching, and research. Academy of Management Learning \& Education, 1(2), 206-218.

Avilés, J. A. G., \& Carvajal, M. (2008). Integrated and cross-media newsroom convergence: Two models of multimedia news production - the cases of novotécnica and la Verdad multimedia in Spain. Convergence: The International Journal of Research into New Media Technologies, 14(2), 221-239.

Bandura, A. (1969). Social-learning theory of identificatory processes. In David. A. \& Goslin E. D. (Eds.), Handbook of socialization theory and research (pp. 213262). Chicago, IL: Rand McNally.

Baxter, P., \& Jack, S. (2008). Qualitative case study methodology: Study design and implementation for novice researchers. The Qualitative Report, 13(4), 544-559.

Beyers, H. (2004). Interactivity and online newspapers: A case study on discussion boards. Convergence: The International Journal of Research into New Media Technologies, 10(4), 11-20.

Bingham, T., \& Conner, M. (2010). The new social learning: A guide to transforming organizations through social media. Oakland, CA: Berrett-Koehler.

Boyatzis, R. E. (2011). Managerial and leadership competencies: A behavioral approach to emotional, social and cognitive ntelligence. Vision, 15(2), 91-100.

Boyd Davis, S., \& Gristwood, S. (2016). The structure of design processes: Ideal and reality in Bruce Archer's 1968 doctoral thesis. Proceedings of DRS 2016, 7(16), 2593-2611.

Caldwell, J. (2004). Convergence television: aggregating form and repurposing content in the culture of conglomeration. Television after TV: Essays on a Medium in Transition, 41-74.

Carroll, A., \& McCrackin, J. (1998). The competent use of competency based strategies for selection and development. Performance Improvement Quarterly, 11(3), 4563.

Chan-Olmsted, S. M., \& Kim, Y. (2001). Perceptions of branding among television station managers: An exploratory analysis. Journal of Broadcasting \& Electronic Media, 45(1), 75-91. 
Charmaz, K. (2010). Grounded theory: objectivist and constructivist methods. In W. Luttrell (Ed.), Qualitative educational research. Readings in reflexive methodology and transformative practice. (pp. 183-207). New York, NY: Routledge.

Chouhan, V. S., \& Srivastava, S. (2014). Understanding competencies and competency modeling - A literature survey. IOSR Journal of Business and Management, $16(1), 14-22$.

Clardy, A. (2018). 70-20-10 and the dominance of informal learning: A fact in search of evidence. Human Resource Development Review, 17(2), 153-178.

Conner, M. L. (2004). Informal learning: Developing a value for discovery. In M. Goldsmith, H. Morgan, \& A. J. Ogg (Eds.), Leading organizational learning: Harnessing the power of knowledge (pp. 91-102). San Francisco, CA: JosseyBass.

Covrig, D., \& Baumgartner, E. (2010). Learning while leading: The Andrews University leadership program. Journal of Applied Christian Leadership, 4(1), 26-55.

Cremedas, M., \& Lysak, S. (2011). "New media" skills competency expected of TV reporters and producers. Electronic News, 5(1), 41-59.

Creswell, J. W. (2013). Qualitative inquiry and research design: Choosing among five approaches. Thousand Oaks, CA: Sage Publications Inc.

Cristóvão, A. M., Candeias, A. A., \& Verdasca, J. (2017). Social and emotional learning and academic achievement in portuguese schools: A bibliometric study. Frontiers in Psychology, 8(1913), 1-12.

Cross, J. (2007). Informal learning: Rediscovering the natural pathways that inspire innovation and performance. San Francisco, CA: John Wiley \& Sons.

Dewey, J. (1938). Experience and education: The Kappa Delta Pi lecture series. New York, NY.

Dirkx, J. M. (1998). Transformative learning theory in the practice of adult education: An overview. PAACE journal of lifelong learning, 7, 1-14.

Downes, S. (2010). New technology supporting informal learning. Journal of emerging technologies in web intelligence, 2(1), 27-33.

Dupagne, M., \& Garrison, B. (2006). The meaning and influence of convergence: A qualitative case study of newsroom work at the Tampa News Center. Journalism Studies, 7(2), 237-255.

Dwyer, T. (2010). Media convergence. Berkshire, U.K.: McGraw-Hill International. 
Ennis, M. R. (2008). Competency models: a review of the literature and the role of the employment and training administration (ETA). Office of Policy Development and Research, Employment and Training Administration, US Department of Labor.

Eraut, M. (2004). Informal learning in the workplace. Studies in continuing education, 26(2), 247-273.

Ertmer, P. A., \& Newby, T. J. (1993). Behaviorism, cognitivism, constructivism: Comparing critical features from an instructional design perspective. Performance Improvement Quarterly, 6(4), 50-72.

Fahmy, S. (2008). How online journalists rank importance of news skills. Newspaper Research Journal, 29(2), 23-39.

Gordon, R. (2003). Implications of convergence. In K. Kawamoto (Ed.), Digital journalism: Emerging media and the changing horizons of journalism (pp. 5773). Lanham, MD: Rowman \& Littlefield Publishers, Inc.

Grajales, T. E., \& Gonzalez, S. (2008). Towards a new concept of research. Journal of Research on Christian Education, 17(2), 153-172.

Grieco, E. (2018). Newsroom employment dropped nearly a quarter in less than 10 years, with greatest decline at newspapers. Pew Research Center Fact-Tank. Retrieved from https://pewrsr.ch/2M2sB4s, accessed on July 30, 2018.

Habermas, J. (1984). The theory of communicative action. Reason and rationalization in society, 2.

Holton, E. F., Coco, M. L., Lowe, J. L., \& Dutsch, J. V. (2006). Blended delivery strategies for competency-based training. Advances in Developing Human Resources, 8(2), 210-228.

Howe, K. \& Eisenhardt, M. (1990). Standards for qualitative (and quantitative) research: A prolegomenon. Educational Researcher, 19(4), 2-9.

Huang, E., Rademakers, L., Fayemiwo, M. A., \& Dunlap, L. (2004). Converged journalism and quality: A case study of the Tampa Tribune news stories. Convergence: The International Journal of Research into New Media Technologies, 10(4), 73-91.

Huang, J. S., \& Heider, D. (2007). Media convergence: A case study of a cable news station. The International Journal on Media Management, 9(3), 105-115.

James, W. (1908). The meaning of the word 'Truth'. Mind, 17(3), 455-456.

Jenkins, H. (2006). Convergence culture: Where old and new media collide. New York and London: NYU press. 
Katz, R. L. (1974). Skills of an Effective Administrator. An HBR Classic. Harvard Business Review, 52(5), 90-102.

Knight, G. R. (2006). Philosophy and education: An introduction in Christian perspective (4th ed.). Berrien Springs, MI: Andrews University Press.

Kolb, D. A. (1976). Management and the learning process. California management review, 18(3), 21-31.

Kolb, D. A. (1984). Experiential learning: Experience as the source of learning and development. Englewood Cliffs, NJ: Prentice-Hall.

Kolb, D. A. (2015). Experiential learning: Experience as the source of learning and development (2nd ed.). Upper Saddle River, NJ: Pearson Education, Inc.

Kolb, A. Y., \& Kolb, D. A. (2017). The experiential educator: Principles and practices of experiential learning. ELTHE: A Journal for Engaged Educators, 1(1), 7-44.

Kolodzy, J. (2009). Convergence explained, playing catch-up with news consumers. In A. E. Grant \& J. S. Wilkinson (Eds.), Understanding media convergence: the state of the field (pp. 31-51). New York, NY: Oxford University Press.

Kotter, J. P. (1988). The leadership factor. New York, NY: Free Press.

Lather, P. (1993). Fertile obsession: Validity after poststructuralism. The sociological quarterly, 34(4), 673-693.

Lewin, K. (1942). Field theory and learning The forty-first yearbook of the National Society for the Study of Education: Part II, The psychology of learning. (pp. 215242). Chicago, IL: University of Chicago Press.

Lincoln, Y. S. (1995). Emerging criteria for quality in qualitative and interpretive research. Qualitative Inquiry, 1, 275-289.

Livingstone, D. W. (1999). Exploring the icebergs of adult learning: Findings of the first Canadian survey of informal learning practices. Toronto: Ontario Institute for Studies in Education of the University of Toronto. (ERIC Document Reproduction Service No. ED436651).

Livingstone, D. W., \& Raykov, M. (2016). The growing gap between post-secondary schooling and further education: Findings of 1998, 2004, 2010 and 2016 National surveys the employed canadian labour force. The Canadian Journal for the Study of Adult Education (Online), 28(2), 1-23.

Loverde, L. (2005). Learning organizations and quadruple loops of feedback. Ingenierías, 7(26), 29-36. 
Malcolm, J., Hodkinson, P., \& Colley, H. (2003). The interrelationships between informal and formal learning. Journal of workplace learning, 15(7/8), 313-318.

Marsick, V. J., Watkins, K. E., Callahan, M. W., \& Volpe, M. (2008). Informal and incidential learning in the workplace. In M. C. Smith \& N. DeFrates-Densch (Eds.), Handbook of research on adult learning and development (pp. 570-600). New York, NY: Routledge.

McClelland, D. C. (1973). Testing for competence rather than for intelligence. American psychologist, 28(1), 1-14.

Merriam, S. B., Caffarella, R. S., \& Baumgartner, L. (2007). Learning in adulthood: A comprehensive guide (3rd ed.). New York, NY: John Wiley.

Mezirow, J. (1981). A Critical Theory of Adult Learning and Education. Adult Education, 32(1), 3-24.

Mezirow, J. (1997). Transformative learning: Theory to practice. New directions for adult and continuing education, 1997(74), 5-12.

Mezirow, J. (2003). Transformative Learning as Discourse. Journal of Transformative Education, 1(1), 58-63.

Mirabile, R. J. (1997). Everything you wanted to know about competency modeling. Training \& Development, 51(8), 73-78.

Mishra, S. (2014). Media convergence: Indian journalists' perceptions of its challenges and implications. Convergence: The International Journal of Research into New Media Technologies, 20, 1-11.

Mitchell, A., Rosenstiel, T., Santhanam, L. H., \& Christian, L. (2012). The future of mobile news. The explosion in mobile audiences and the close look at what it means for news. Pew Research Center's Project for Excellence in Journalism, October 1, 2012, 1-71.

Naquin, S. S., \& Holton, E. F. (2006). Leadership and managerial competency models: A simplified process and resulting model. Advances in Developing Human Resources, 8(2), 144-165.

Perryman, N. (2008). Doctor who and the convergence of media: A case study in 'transmedia storytelling'. Convergence: The International Journal of Research into New Media Technologies, 14(1), 21-39.

Prahalad, C. K., \& Hamel, G. (1990). The core competence of the corporation. Harvard Business Review, 4(2), 95-107.

Quinn, S. (2005). Convergence's fundamental question. Journalism Studies, 6(1), 29-38. 
Richardson, L., \& St. Pierre, E. A. (2005). Writing: A Method of Inquiry. In N. K. Denzin \& Y. S. Lincoln (Eds.), The Sage handbook of qualitative research (pp. 959-978). Thousand Oaks, CA: Sage Publications Ltd.

Robbins, S. P., \& Judge, T. A. (2001). Organizational behavior (13th ed.). London: Pearson Prentice-Hall.

Saldaña, J. (2012). The coding manual for qualitative researchers. Thousand Oaks, CA: Sage Publications Inc.

Senge, P. (2006). The fifth discipline: The art \& practice of the learning organization. New York, NY: Doubleday.

Siemens, G. (2005). Connectivism: A learning theory for the digital age. International Journal of Instructional Technology and Distance Learning, 2(1), 3-10.

Simonin, B. L. (2017). N-loop learning: part I - of hedgehog, fox, dodo bird and sphinx. The Learning Organization, 24(3), 169-179.

Stake, R. E. (1995). The art of case study research: Sage Publications, Inc.

Stenport, A. W., Markstedt, E., \& Crain, M. (2014). Charting and challenging digital media convergence practice and rhetoric through longitudinal media population surveys. Convergence: The International Journal of Research into New Media Technologies, 20(2), 140-156.

Stone, M., \& Bierhoff, J. (2002). The state of multimedia newsrooms in Europe. Paper presented at the Presentation at the 'Media in Transition 2'conference, May.

Tanner, A., Forde, K. R., Besley, J. C., \& Weir, T. (2012). Broadcast journalism education and the capstone experience. Journalism \& Mass Communication Educator, 67(3), 219-233.

Thomas, G. (2011). A typology for the case study in social science following a review of definition, discourse, and structure. Qualitative Inquiry, 17(6), 511-521.

Tylor, J. (2015). An examination of how student journalists seek information and evaluate online sources during the newsgathering process. New Media \& Society, $17(8), 1277-1298$

Verweij, P. (2009). Making convergence work in the newsroom: A case study of convergence of print, radio, television and online newsrooms at the African media matrix in South Africa during the national arts festival. Convergence: The International Journal of Research into New Media Technologies, 15(1), 75-87.

Von Bertalanffy, L. (1969). General system theory: Foundations, development, applications. New York, NY: George Braziller, Inc. 
Von Glasersfeld, E. (1989). Constructivism in education. Oxford: Pergamon Press.

Vygotsky, L. S.(1978). Interaction between learning and development. Readings on the development of children, 23(3), 34-41.

Wenger, D. H., \& Owens, L. C. (2012). Help wanted 2010 an examination of new media skills required by top US news companies. Journalism \& Mass Communication Educator, 67(1), 9-25.

Westera, W. (2001). Competences in education: a confusion of tongues. Journal of Curriculum studies, 33(1), 75-88.

Yang, B. C., Wu, B. E., Shu, P. G., \& Yang, M. H. (2006). On establishing the core competency identifying model: A value-activity and process oriented approach. Industrial Management \& Data Systems, 106(1), 60-80.

Yin, L., \& Liu, X. (2014). A gesture of compliance: media convergence in China. Media, Culture \& Society, 36(5), 561-577.

Yin, R. K. (2003). Case study research: Design and methods. Thousand Oaks, CA: Sage Publications, Inc.

Yin, R. K. (2009). How to do better case studies. The SAGE handbook of applied social research methods, 2, 254-282. 
VITA 


\title{
CHRISTIANE E. THEISS
}

\section{KEY FACTS}

- 15 years of experience as Management and Corporate Consultant with an emphasis on Business and Organizational Development, Talent Acquisition and Management, Training, Change and Project Management

- In-depth Strategic Human Resources experience and knowledge with an emphasis on HR Processes, Resourcing, People Development, HR Marketing, Learning and Development, Ethics \& Compliance

- $\quad$ Personality Profile: Strategic, Achiever, Activator, Maximizer

\author{
EDUCATION \\ 2011 - 2019 PhD studies in Leadership, Andrews University, Berrien Springs, MI/U.S.A. \\ 1996 - 1999 Post-graduate studies in General Management, Bad Harzburg Akademie, Bad \\ Harzburg/Germany \\ 1986 - 1993 Master's Degree in Economic and Social Geography, Munich University of \\ Technology, Munich/Germany
}

\section{EMPLOYMENT HISTORY}

\begin{tabular}{|c|c|}
\hline 2018 - Present & $\begin{array}{l}\text { Social Department of the City of Zurich, Zurich/Switzerland } \\
\text { Head of Human Resources }\end{array}$ \\
\hline $2017-2018$ & $\begin{array}{l}\text { PDAG (Psychiatric Services Canton of Argovia) AG, Brugg/Switzerland } \\
\text { Head of People Development / Deputy Head of Human Resources }\end{array}$ \\
\hline $2016-2016$ & $\begin{array}{l}\text { Meyer Burger Technologies AG, Thun/Switzerland } \\
\text { Head Global HR Processes and Systems }\end{array}$ \\
\hline 2015 - Present & $\begin{array}{l}\text { MedVint - Medical Volunteers international, Greece/Turkey/Serbia/Bosnia } \\
\text { Co-Founder and Staffing Director }\end{array}$ \\
\hline $2012-2015$ & $\begin{array}{l}\text { AZ Management Services AG, Aarau/Switzerland } \\
\text { Head of Human Resources Management, AZ Medien Group }\end{array}$ \\
\hline $2007-2012$ & $\begin{array}{l}\text { Alstom Ltd., Baden/Switzerland \& Levallois-Perret/France } \\
\text { Director Projects Global HR Processes and Tools / Director Resource Planning } \\
\text { and Coordination / Global Project Manager e-Recruitment, Head Recruiting }\end{array}$ \\
\hline $2003-2007$ & $\begin{array}{l}\text { streamline-group AG, Zollikon/Switzerland } \\
\text { Member of the Board / CEO Streamline Management Selection AG / Partner / } \\
\text { Consultant }\end{array}$ \\
\hline $2002-2003$ & $\begin{array}{l}\text { drf consulting AG, Urdorf/Switzerland } \\
\text { Consultant Headhunting }\end{array}$ \\
\hline $2002-2002$ & $\begin{array}{l}\text { ish } \mathrm{GmbH} \& \mathrm{Co} . \mathrm{KG}, \text { Cologne \& Karlsruhe/Germany } \\
\text { Director Resourcing }\end{array}$ \\
\hline $1996-2002$ & $\begin{array}{l}\text { Crest Management Consultants GmbH Frankfurt, Eschborn/ Germany \& Highland, } \\
\text { Michigan/U.S.A. } \\
\text { Partner and Head of Profit Center / Senior Consultant }\end{array}$ \\
\hline $1995-1996$ & $\begin{array}{l}\text { Steinbach \& Partner Managementberatung GmbH, Bad Vilbel/Germany } \\
\text { Junior Consultant }\end{array}$ \\
\hline $1994-1995$ & $\begin{array}{l}\text { Kienbaum Personalberatung GmbH, Frankfurt/Germany } \\
\text { Researcher }\end{array}$ \\
\hline $1991-1994$ & $\begin{array}{l}\text { Gesellschaft für Markt- und Absatzforschung mbH, Ludwigsburg/Germany } \\
\text { Market and Retail Analyst }\end{array}$ \\
\hline
\end{tabular}


VOLUNTARY SERVICE

$\begin{array}{cl}2017-\text { Present } & \text { ASI Europe, President } \\ 2013-2017 & \text { ASI Europe, VP Marketing \& Membership Growth } \\ 2011-2013 & \text { ASI Europe, VP Finances \& Treasurer } \\ 2006-2015 & \text { ASI Switzerland, President } \\ 1991-1997 & \text { Deutscher Verein für Gesundheitspflege, Coordinator Regional Group Munich }\end{array}$

As a member of the academic community of Andrews University, I pledge that I have not received, used, or given any unauthorized assistance on this thesis.

Christiane E. Theiss 